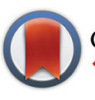

CrossMark

\&lick for updates

Cite this: Polym. Chem., 2015, 6 , 5143

Received 8th April 2015

Accepted 16th June 2015

DOI: $10.1039 /$ c5py00525f

www.rsc.org/polymers

\section{Surface-initiated controlled radical polymerizations from silica nanoparticles, gold nanocrystals, and bionanoparticles}

\author{
Lei Wu, ${ }^{a, b}$ Ulrich Glebe ${ }^{a}$ and Alexander Böker*a,c
}

In recent years, core/shell nanohybrids containing a nanoparticle core and a distinct surrounding shell of polymer brushes have received extensive attention in nanoelectronics, nanophotonics, catalysis, nanopatterning, drug delivery, biosensing, and many others. From the large variety of existing polymerization methods on the one hand and strategies for grafting onto nanoparticle surfaces on the other hand, the combination of grafting-from with controlled radical polymerization (CRP) techniques has turned out to be the best suited for synthesizing these well-defined core/shell nanohybrids and is known as surfaceinitiated CRP. Most common among these are surface-initiated atom transfer radical polymerization (ATRP), surface-initiated reversible addition-fragmentation chain transfer (RAFT) polymerization, and surface-initiated nitroxide-mediated polymerization (NMP). This review highlights the state of the art of growing polymers from nanoparticles using surface-initiated CRP techniques. We focus on mechanistic aspects, synthetic procedures, and the formation of complex architectures as well as novel properties. From the vast number of examples of nanoparticle/polymer hybrids formed by surface-initiated CRP techniques, we present nanohybrid formation from the particularly important and most studied silica nanoparticles, gold nanocrystals, and proteins which can be regarded as bionanoparticles.

\section{Introduction}

A wide range of nanoparticles, including silica nanoparticles ${ }^{1-10}$ gold nanocrystals, ${ }^{11-15}$ and bionanoparticles, ${ }^{16,17}$ have been extensively studied and investigated in recent years. However, restricted by their surface properties, versatile use of diverse nanoparticles for further processing and applications is challenging. For example, even slight changes of the external surrounding can lead to plasmonic coupling as well as irreversible aggregation of gold nanoparticles ${ }^{18,19}$ and instability of bionanoparticles. ${ }^{20,21}$ One approach to tackle these difficulties is to form hybrid nanostructures by covalently coating a polymer shell around the nanoparticle core. The resulting nanohybrids usually combine the fascinating electronic, optical, magnetic, photonic, and biological properties of the nanostructure core with the properties of the designed polymer shell, such as solubility, processability, chemical and

\footnotetext{
${ }^{a}$ Fraunhofer Institute for Applied Polymer Research IAP, Geiselbergstr. 69, 14476 Potsdam-Golm, Germany.E-mail: alexander.boeker@iap.fraunhofer.de ${ }^{b} D W I$ - Leibniz Institute for Interactive Materials e.V., Lehrstuhl für Makromolekulare Materialien und Oberflächen, RWTH Aachen University, Forckenbeckstr. 50, D-52056 Aachen, Germany

${ }^{c}$ Lehrstuhl für Polymermaterialien und Polymertechnologie, Universität Potsdam, D-14476 Potsdam, Germany
}

physical compatibility, stability or even responsiveness to external stimuli. ${ }^{2-24}$ Moreover, the properties of nanostructured materials can be specifically tuned for the desired application by the attachment of well-selected polymers. ${ }^{25-27}$

Polymer chains can be attached onto nanoparticle cores in different ways. The traditional approach is to synthesize nanoparticles and polymers individually and connect them subsequently. ${ }^{28-31}$ This approach is called the grafting-to method. Since both components are tailor-made prior to the desired covalent linkage, the structure and architecture can be specifically designed. However, due to steric hindrance on the nanoparticle surface, the grafting density of polymers is relatively low and sometimes not sufficient for further applications. ${ }^{32}$ The second classical method for hybrid synthesis is the in situ sol-gel process. ${ }^{33-36}$ The pre-formed polymer chains act as a stabilizer or template and sometimes even as a reducing agent during the nanohybrid synthesis. The two other straightforward and later on developed approaches for the attachment of polymer chains onto nanoparticle surfaces are grafting-through and grafting-from. These methods cover all strategies in which the polymer chains are growing directly from the surface of nanoparticles. For the grafting-through method, a polymerizable group i.e. a monomer ${ }^{37}$ or a macromonomer ${ }^{38}$ is anchored onto the surfaces of nanoparticles. Then, the polymerization is started in the solution that 
contains initiator, monomer and (macro)monomer-NP. Sooner or later, the pre-attached polymerizable moiety will be integrated into the growing polymer chains. ${ }^{39}$ The much more applied grafting-from method has become increasingly popular in recent years. Functional initiators are chemically linked onto the nanoparticle surface to initiate the polymerization directly, which is called surface-initiated polymerization. The achievable polymer grafting density is higher when using grafting-from than grafting-to, as the steric hindrance is much lower for a polymerization from a surface (as only the small initiator is grafted onto the nanoparticle surface prior to polymerization). Various functional initiators can be linked to the nanoparticle surfaces according to the type of polymerization used. ${ }^{40-51}$ From the multitude of available polymerization techniques, controlled radical polymerization (CRP) has been shown to be the most effective technique to graft polymer chains from a nanoparticle surface with respect to monomer versatility, variable functionalities, mild reaction conditions, chemical compatibility, uniform molecular weight, and advanced polymer architectures. This strategy is called surface-initiated CRP, which has been extensively studied and will be discussed in the following parts of this review. A high degree of control over the size, architecture, uniformity, and functionality of the polymer chains is essential for the hybrid materials to be applied in the vast majority of functional core/ shell nanostructure applications. ${ }^{52}$ Utilizing the CRP technique, well-defined polymers with distinct structure, architecture, molecular weight, and versatile functionalities can be obtained.

Controlled radical polymerization is well known as living free radical polymerization (LFRP $)^{53,54}$ while IUPAC recommends the terms reversible-deactivation radical polymerization (RDRP) or controlled reversible-deactivation radical (CRDR) polymerization. ${ }^{53,55}$ In recent years, the following three most common CRP methods have been extensively studied: atom transfer radical polymerization (ATRP), ${ }^{55-62}$ reversible addition-fragmentation chain transfer (RAFT) polymerization, ${ }^{63-67}$ and nitroxide-mediated polymerization (NMP). ${ }^{68-74}$ Before introducing surface-initiated CRP in section 2 , it should be pointed out that due to their respective characteristic polymerization mechanisms, ATRP, RAFT, and NMP have their own special unique areas concerning available monomers, functional initiators as well as polymer architectures, which leads to varying emphasis and considerations for the nanohybrid fabrication.

For a classical ATRP process, an alkyl halide initiator and a catalyst system (usually transition metal complexes, e.g. $\mathrm{Cu}^{\mathrm{I}}$ / ligand) are needed. The $\mathrm{Cu}^{\mathrm{I}} /$ ligand, in a lower oxidation state, activates the alkyl halide initiators through an inner-sphere electron transfer (ISET) process generating the radicals. During the propagation of the polymer chains, the active radicals can be reversibly deactivated back to dormant species by reaction with the formed $\mathrm{Cu}^{\mathrm{II}} /$ ligand in a higher oxidation state. By this fast activation-deactivation equilibrium, termination reactions as well as self-coupling or disproportionation of active radical species are diminished, and the (macro)radicals keep an apparent livingness for propagation, which is called the persistent radical effect. ${ }^{75-78}$ Thus, the living radicals grow with equal probability, and monomers are polymerized in a controlled way (Scheme 1a). The initiators, transition metal catalysts and ligands required for ATRP are usually commercially available. Most importantly, the ATRP technique is compatible with a wide range of monomers, including not only more activated monomers ${ }^{64}$ such as styrene (St), vinylpyridine (VP), (meth)acrylate, (meth)acrylamide, acrylonitrile (AN), and their derivatives, but also less activated monomers ${ }^{64}$ such as vinyl acetate (VAc), ${ }^{79} \mathrm{~N}$-vinylpyrrolidone (NVP), ${ }^{80}$ and $\mathrm{N}$-vinylcarbazole (NVC). ${ }^{81}$ Various reaction conditions are applicable, e.g.

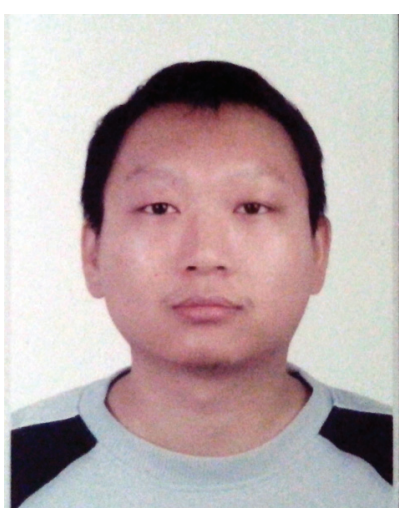

Lei Wu
Lei Wu joined the Graduate School of Chinese Academy of Sciences (GUCAS) and National Center for Nanoscience and Nanotechnology

(NCNST), Beijing, China, from 2008 to 2011 under the co-supervision of Prof. Zhiyong Tang and Prof. Rui Song. After obtaining his Master's degree, he moved to Prof. Dr Alexander Böker's group at the Leibniz Institute for Interactive Materials e.V. in Aachen, Germany in the beginning of 2012 for his doctoral studies. Lei Wu's current research interests are focused on the fabrication of polymer/nanoparticle hybrid structures via surface-initiated controlled radical polymerizations, responsive polymers, as well as self-assembly of nanoparticles at liquid/liquid interfaces.

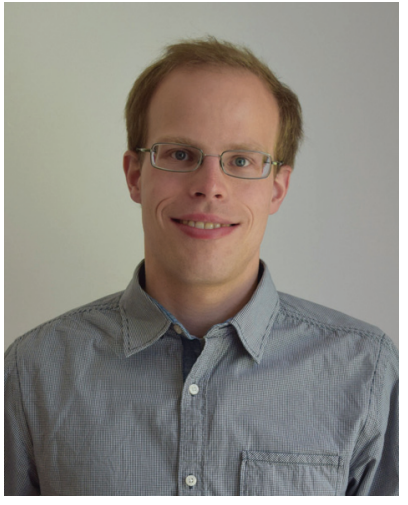

Ulrich Glebe
Ulrich Glebe studied Nanostructure and Molecular Sciences at the University of Kassel, Germany. He accomplished his doctoral thesis in the group of Prof. Dr Siemeling at the University of Kassel, from 2008 to 2012. In 2013, he joined the group of Prof. Dr Alexander Böker at the Leibniz Institute for Interactive Materials e.V. in Aachen, Germany as a postdoc. From April 2015 on, he has continued his research in the same group at the Fraunhofer Institute for Applied Polymer Research (IAP). His research interests are the synthesis and self-assembly of protein-polymer conjugates as well as enzyme catalysis. 
(a)
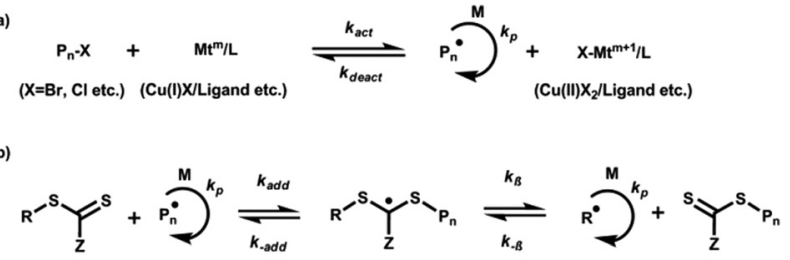

(c)

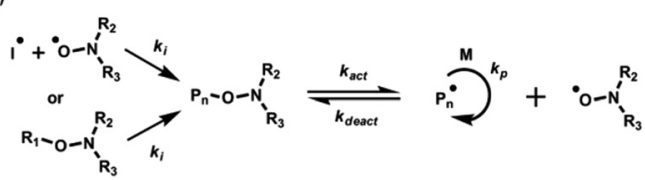

Scheme 1 (a) General equilibrium of the classical ATRP process. $M$ is the monomer and $k_{\mathrm{p}}$ is the propagation rate constant. The kinetic parameters $k_{\text {act }}$ and $k_{\text {deact }}$ represent the rate constants of activation and deactivation, respectively. $\mathrm{P}_{n}^{*}$ is the propagating radical. (b) Mechanism of RAFT equilibrium. $\mathrm{R}$ is the $\mathrm{R}$-group of the CTA or R-group-derived polymeric adduct. For the kinetic parameters, $k_{\text {add }}$ and $k_{-\beta}$ are the rate constants for the addition reaction of CTA (or macro-CTA) with the propagating (or initiator-derived) radicals, whereas $k_{\text {-add }}$ and $k_{\beta}$ are the fragmentation rate constants for the intermediate radicals. (c) Activation-deactivation equilibrium in NMP. The kinetic parameter $k_{\mathrm{i}}$ represents the rate constant for initiation. The upper initiating process is a bi-component system which is usually the case for conventional radical polymerization with nitroxides. The initiating process shown in the lower part is a mono-component system being present for alkoxyamines.

bulk or solution as homogeneous reaction systems and aqueous, superfluid $\mathrm{CO}_{2}$, ionic liquids etc. as emulsion or suspension polymerizations. ${ }^{55,59,82}$ However, complete removal of the toxic transition metal catalyst after polymerization is still challenging and critical for biological and electronic applications. Furthermore, for acidic monomers, ATRP is not as convenient as RAFT because acidic moieties interfere with the catalyst complex. Hence, a two-step process has to be

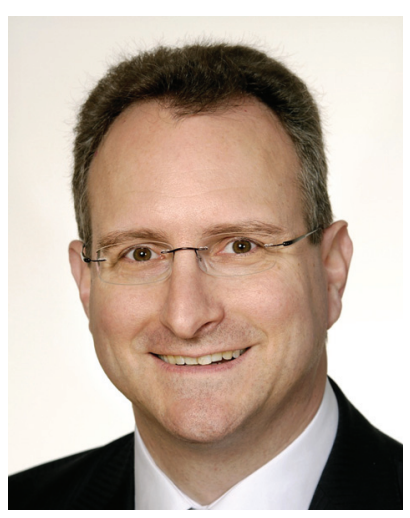

Alexander Böker
Alexander Böker is the director of the Fraunhofer Institute for Applied Polymer Research (IAP) and holds the Chair for Polymer Materials and Polymer Technology at the University of Potsdam, Germany. He received his $\mathrm{PhD}$ from Bayreuth University in 2002 working with Prof. G. Krausch and Prof. Axel H.E. Müller. From 2002 to 2004 he was a postdoctoral fellow with Thomas P. Russell at the University of Massachusetts, Amherst. Alexander Böker has published more than 100 papers in peer-reviewed journals. His main research interests include guided self-assembly of block copolymer systems, hierarchical (bio)nanoparticle assemblies and the control of self-assembly processes via external fields. employed, e.g. ATRP of protected monomers followed by deprotection by hydrolysis. ${ }^{83-85}$

RAFT polymerization is similar to conventional radical polymerization, only differing in the addition of a RAFT agent, also called a chain transfer agent (CTA), which is usually a thiolcarbonylthiol derivative with a stabilizing Z-group and a re-initiating R-group. ${ }^{63,86-88}$ The CTA reacts reversibly with propagating polymer radicals to form dormant polymeric chains. The continuous reversible deactivation process mediated by rapid exchange between the (macro)radicals and the RAFT agent renders the polymerization living (Scheme 1b). ${ }^{64,66,89-91}$ The RAFT technique is especially attractive as it is compatible with almost all common vinyl monomers from conventional radical polymerization, has a high tolerance towards functional groups, and can be performed under mild reaction conditions. Furthermore, as RAFT polymerization is free from possibly toxic metal catalysts, it is better suited for biological and medical applications than ATRP. Additionally, chain-end transformation after RAFT polymerization is comparably simple, which qualifies this technique for further functionalization. $^{92,93}$ However, the commercial availability of RAFT agents is limited, so that a complex synthesis of these agents is sometimes required. ${ }^{88}$ Moreover, RAFT polymerization is still challenging with basic monomers and those with primary amino groups. $^{62}$

In NMP, the controlled radical process is based on the equilibrium between growing active (macro)radicals and dormant species formed by the coupling of growing (macro)radicals with nitroxide radicals (Scheme 1c). This coupling is reversible with the equilibrium on the side of the radical adduct, which limits irreversible radical chain termination thus making the polymerization living and controllable. Originally, this equilibrium was obtained by adding (2,2,6,6-tetramethylpiperidin-1yl)oxidanyl (TEMPO) or derivatives to conventional radical polymerization. ${ }^{6-71}$ This initiating system is a bi-component system, which involves initiators for conventional radical polymerization and nitroxides (upper drawing in Scheme 1c). This process is unstable and the initiation efficiency is not reproducible, because of the cage effect and the induced fragmentation of primary radicals. ${ }^{74}$ To circumvent this problem, a unimolecular initiation system based on alkoxyamines $\mathrm{R}_{1} \mathrm{ONR}_{2} \mathrm{R}_{3}$ was developed, which is the dominating NMP initiating strategy at present. ${ }^{6-71}$ Under certain conditions, the alkoxyamine can undergo homolysis via dissociation of the $\mathrm{C}-\mathrm{O}$ bond, generating an alkyl radical for initiation and a stable nitroxide. Compared to the bi-component system, the generated alkyl radical and nitroxide remain equimolar, which leads to a better control of the molecular weight, chain distribution, and polymerization process (lower drawing in Scheme 1c). ${ }^{68-71}$ The NMP process based on alkoxyamines is much more straightforward compared to RAFT and ATRP, because it is a unimolecular system. ${ }^{72-74}$ The NMP technique has been successfully applied for the polymerization of many different monomers, especially St, (meth)acrylate and their derivatives, even though some disadvantages remain limiting the universal use of this technique. ${ }^{74}$ Usually, higher polymerization 
temperatures are needed for the homolysis of alkoxyamines and a well-controlled reversible activation-deactivation equilibrium. ${ }^{74}$ In addition, the commercial availability of alkoxyamines is quite limited. ${ }^{74}$

According to the above description of CRP, surface-initiated CRP covers surface-initiated ATRP, surface-initiated RAFT polymerization, and surface-initiated NMP. Each technique has been extensively investigated for the fabrication of polymer nanoparticle core/shell hybrids using various functional monomers. Each polymerization method has its advantages and disadvantages. However, if one method cannot be applied, most likely one of the two others can be applied. Fig. 1 shows all monomers that are included in the examples within this review. The abbreviations given in Fig. 1 are used for the monomers in all following sections. The outline of this review is the following: after presenting the fundamental concept and mechanism of surface-initiated CRP, the main part applies this knowledge to the various nanoparticles. Due to the vastness of the area of different nanoparticles, we limited the scope to the most commonly used ones. The inorganic nanoparticles that have been omnipresent in the last few years are most importantly silica nanoparticles and gold nanocrystals. Nature provides many different kinds of bionanoparticles. Out of these, one class of biological species can be functionalized with polymers in a quite similar fashion to classic inorganic nanoparticles, and they are proteins. As the strategies and methods for the formation of hybrid materials are similar, proteins are included in this review as a kind of bionanoparticle. The section about surface-initiated CRP from silica nanoparticles is divided into four parts. The first three subsections describe the techniques for growing polymers from silica nanoparticles using surface-initiated ATRP, surfaceinitiated RAFT polymerization, and surface-initiated NMP, respectively. The fourth part will specifically introduce interesting Y-shaped asymmetric initiators for sequential surfaceinitiated CRP to fabricate bi-functional polymer grafted silica nanoparticles. We focus on the synthetic protocols for the creation of polymer grafted nanoparticles, along with a brief view on the properties and applications of hybrid materials. The following sections will deal with gold nanocrystals and bionanoparticles, respectively. Here, we give a brief overview of the polymerizations from these nanostructures before concluding with some general remarks on the development of surfaceinitiated CRP.

\section{Surface-initiated CRP mechanisms}

Surface-initiated ATRP has been extensively explored to grow polymer chains from nanoparticle surfaces with various grafting densities. First, alkyl halide initiators are fixed onto the nanoparticle surface. Then, in the presence of a transition metal catalyst, usually a $\mathrm{Cu}^{\mathrm{I}} /$ ligand system, the attached initiators are activated forming the living radicals. Governed by the activation-deactivation equilibrium which is similar to the classical ATRP process in bulk or solution, monomers are polymerized in a controlled way from the surfaces of nanoparticles (Scheme 2a). The grafting density of the immobilized initiator is usually higher than the density of anchored CTAs and attached alkoxyamines, owing to the smaller steric hindrance of ATRP initiators during the attachment in comparison with RAFT agents and alkoxyamines. ${ }^{41,42,44,94-100}$ Further ATRP variants, especially reverse ATRP, Activator Generated by Electron Transfer (AGET) ATRP, Activator ReGenerated by Electron Transfer (ARGET) ATRP, and electrochemically mediated ATRP (e-ATRP), have also been successfully utilized to grow polymers from the surfaces of hydroxyapatite, ${ }^{101}$ silicon, ${ }^{102,103}$ gold, ${ }^{104}$ quantum dots ${ }^{105}$ chitosan, ${ }^{106}$ silica nanoparticles, ${ }^{107-109}$ cellulose ${ }^{110}$ iron oxide, ${ }^{111}$ and carbon nanotubes. ${ }^{112}$ In this review, we mainly focus on the fundamental surface-initiated ATRP from nanoparticles.

In a typical surface-initiated RAFT process, RAFT agents are immobilized onto the nanoparticle surfaces and re-initiated from the substrate following the classical RAFT mechanism. As a RAFT agent contains two functional parts, its immobilization can be divided into two categories: (i) R-group approach in which the leaving and re-initiating R-group is attached onto the nanoparticles and (ii) Z-group approach, where the stabilizing Z-group is anchored onto the nanoparticles. However, both strategies have their advantages and limitations. In the R-group approach, the nanoparticles are part of the R-group. The living polymeric radicals form and grow from the nanoparticle surfaces leading to high molecular weight and dense grafting (Scheme 2b). ${ }^{44,96,113,114}$ However, for very high grafting density, the molecular distribution will be broadened through bimolecular termination, which arises from the so-called migration effect by a reaction-diffusion mechanism. ${ }^{43}$ A very effective surface migration of the grafted radicals can occur via successive degenerative (exchange) chain transfer. Hence, two originally well-separated active radicals on the surface can migrate towards each other, increasing the rate of termination (Fig. 2b). ${ }^{43}$ In the Z-group approach, the nanoparticles are part of the leaving Z-group. Living radicals are released from the surfaces, propagate in the solution, and diffuse back onto the surfaces (Scheme 2c). Intrinsically, this mechanism is more similar to grafting-to. Because of steric hindrance, the grafting density is usually lower when compared to the R-group approach. ${ }^{115-123}$ Nevertheless, because of the intrinsic similarity to the grafting-to mechanism, the Z-group approach produces better controlled grafted polymer chains with a narrow molecular weight distribution.

As mentioned above, alkoxyamines have the general molecular structure $\mathrm{RONR}_{1} \mathrm{R}_{2}$. In a surface-initiated NMP process, the alkoxyamines are covalently linked onto the surfaces of nanoparticles via the R-group. Initiation from the anchored alkoxyamines proceeds via thermal decomposition of the $\mathrm{NP} /$ alkyl part and the $\mathrm{ONR}_{1} \mathrm{R}_{2}$ group. Subsequently, the (macro)radicals directly propagate from the surfaces (Scheme 2d). Similar to NMP in bulk or solution, the equilibrium between active growing (macro)radicals and nitroxide-capped dormant species renders the polymerization living. 
Styrene and derivatives

E

styrene

(St)<smiles>C=Cc1ccc(CCl)cc1</smiles>

4-vinylbenzyl chloride (VBC)

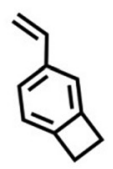

4-vinylbenzocyclobutene (VBCB)<smiles>C=Cc1ccncc1</smiles>

(4VP)

Vinylpyridines<smiles>C=Cc1ccccn1</smiles>

2-vinylpyridine (2VP)

Acrylic acid and esters
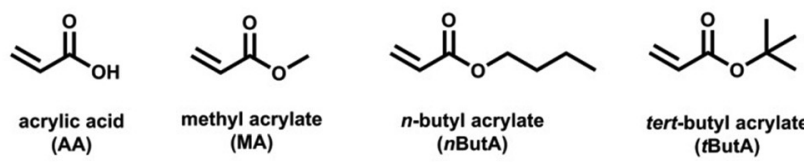

tert-butyl acrylate (tButA)<smiles>C=Cc1ccc(O)cc1</smiles>

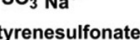
(NaStS) (nButA)<smiles>C=CC(=O)OCCOC(=O)C(C)Br</smiles>

2-(2-bromopropionyloxy)ethyl acrylate (BPEA)<smiles>C=CC(=O)OCC1C=CC2=CC=C3C=CC=C4C=CC1=C2C43</smiles>

pyren-1-ylmethyl acrylate (PyAc)<smiles>C=CC(=O)OCCNc1ccc([N+](=O)[O-])c2nonc12</smiles>

4-(2-acryloyloxyethylamino)-7-nitro-

2,1,3-benzoxadiazole

(NBDAE)

Methacrylic acid and esters

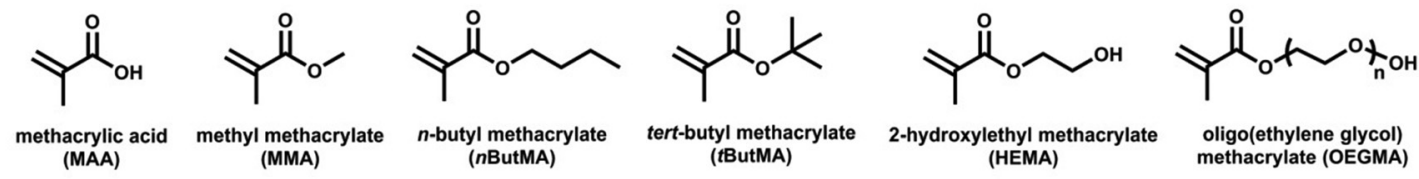<smiles>C=C(C)C(=O)OCC(O)CO</smiles>

glycerol monomethacrylate (GMA)

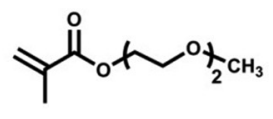

methoxy di(ethylene glycol) methacrylate (DEGMMA)<smiles>C=C(C)C(=O)OCCOCCOC</smiles>

methoxy tri(ethylene glycol)
methacrylate (TEGMMA)<smiles>C=C(C)C(=O)OCc1ccccc1</smiles>

benzyl methacrylate (BnMA)<smiles>C=C(C)C(=O)OCCOCC</smiles>

methoxy oligo(ethylene glycol) methacrylate (OEGMMA) methoxy poly(ethylene glycol) methacrylate (PEGMMA)<smiles>C=C(C)C(=O)OCCSSc1ccccn1</smiles>

pyridyldisulfide ethylmethacrylate (PDSM)

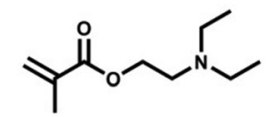
2-(diethylamino)ethyl methacrylate
(DEAEMA)

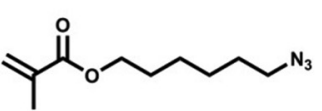

6-azidohexyl methacrylate (AHMA)

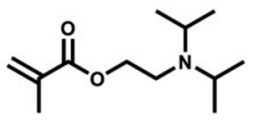

2-(diisopropylamino)ethyl

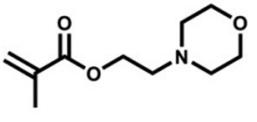

2-(N-morpholino)-ethyl methacrylate (MEMA)

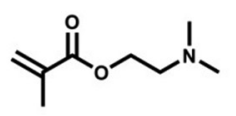

$N, N$-dimethylaminoethyl methacrylate (DMAEMA)

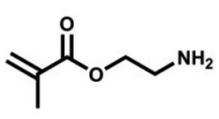

-aminoethyl methacrylate (AEMA)

Fig. 1 Structure, full name, and abbreviation of all the functional monomers described for surface-initiated CRP in this review.<smiles>C=C(C)C(=O)OCCC[Si](OC)(OC)OC</smiles>

methacryloxypropyltrimethoxysilane (MPTS)

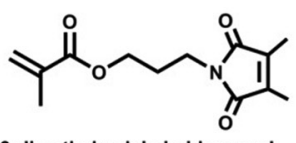

2,3-dimethylmaleic imidopropyl methacrylate (DMIPM) 
<smiles>C=C(C)C(=O)OCCC[Se]O</smiles>

potassium 3-sulfopropyl methacrylate (KSPMA)

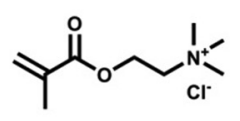

2-(methacryloyloxy)-ethyl-trimethylammonium chloride (METAC)

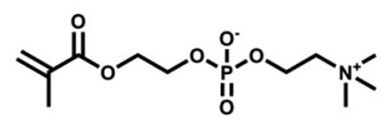

2-(methacryloyloxy)-ethyl phosphorylcholine (MPC)

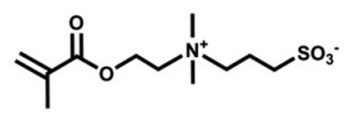

[2-(methacryloyloxy)ethyl]dimethyl(3-sulfopropyl)ammonium hydroxide (DMAPS)

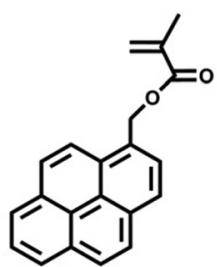

(1-pyrene)methyl-2-methyl-2-propenoate (PyMMP)

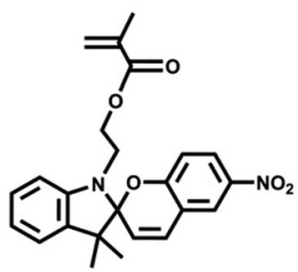

1'-(2-methacryloxyethyl)-3',3'-dimethyl-6nitrospiro-(2H-1-benzopyran-2,2'-indoline) (SPMA)

Acrylamide, N-substituted and N,N-disubstituted (meth)acrylamides<smiles>C=CC(N)=O</smiles><smiles>C=CC(=O)N(C)C</smiles>

acrylamide (AM)
$N, N$-dimethylacrylamide (DMAA)<smiles>C=CC(=O)NC(C)C</smiles>

$N$-isopropyl acrylamide (NIPAM)

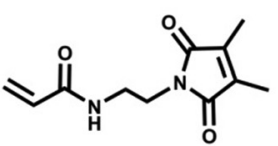
2-(dimethyl maleinimido)- $N$-ethyl-acrylamide
(DMIAAm) $\begin{gathered}\text { 2-hydroxypropyl methacrylamide } \\ \text { (HPMA) }\end{gathered}$

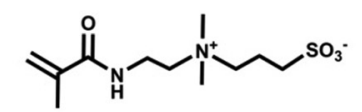

[2-(methacryloylamino)ethyl]dimethyl(3-sulfopropyl) ammonium hydroxide (SBAM)<smiles>C=C(C)C(=O)NCCC[N+](C)(C)CC(=O)O</smiles>

carboxybetaine methacrylate (CBMA1)<smiles>C=C(C)C(=O)NCCC[N+](C)(C)CCCCCC(=O)O</smiles>

carboxybetaine methacrylate (CBMA5)

Diene, diacrylamide and dimethacrylates
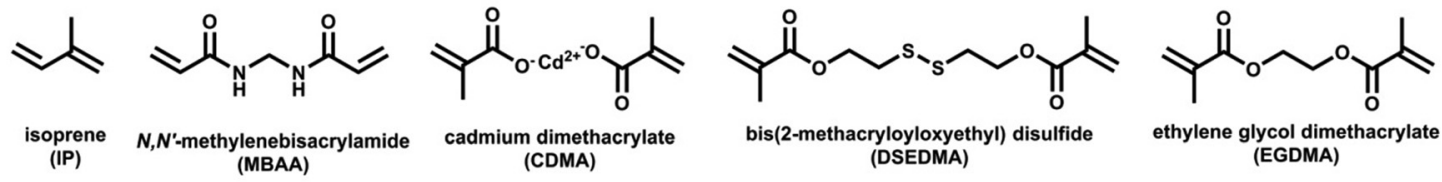

Other monomers

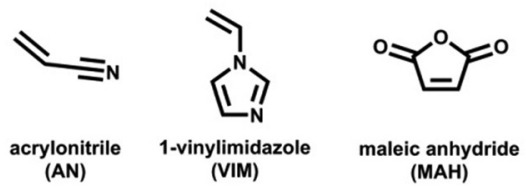

Fig. 1 (Contd).

\section{Silica nanoparticles}

Silica nanoparticles have been extensively studied and applied in various areas such as colloid chemistry, catalysis, nanopatterning, photonics, drug delivery, and biosensing because of their high rigidity, thermal stability as well as physical and chemical resistance. ${ }^{1-10}$ Usually, silica nanoparticles can be synthesized by the Stöber method ${ }^{124}$ and the inverse microemulsion technique. ${ }^{125}$ Recently, a novel approach has been reported for the synthesis of silica nanospheres with diameters less than $20 \mathrm{~nm}$ using a basic amino acid (e.g. lysine) as the catalyst. $^{126-129}$ The highly active nanoparticle surface which is covered with silanol $(\mathrm{Si}-\mathrm{OH})$ groups enables the combination of silica nanoparticles with many organic materials, especially polymers to fabricate silica polymer nanocomposites. ${ }^{130}$ These hybrid materials combine the advantages of silica nanoparticles (rigidity, stability) and organic polymers (flexibility, processability, functionality) to enlarge the potential applications of silica nanoparticles. ${ }^{131}$ Various routines can be applied to fabricate silica polymer nanocomposites, including mixing for blends, the sol-gel process which is also known as a template method, and surface modification to yield core/ shell particles. ${ }^{131}$ The surface modification with polymers can be achieved by grafting-to, grafting-through or grafting-from, each having the specific advantages and disadvantages already discussed above. In the case of grafting-from, the attachment of functional initiators is crucial for surface polymerization. Owing to the high accessibility and reactivity of the surface 
(a) Surface-Initiated ATRP

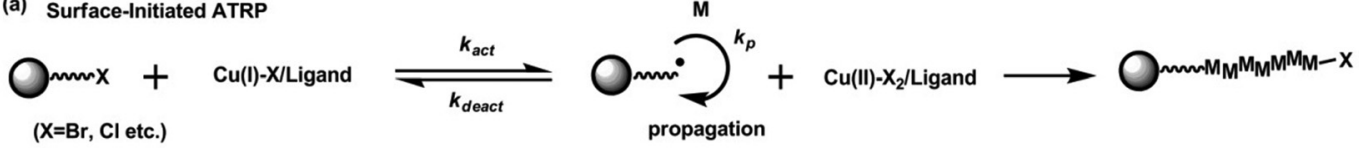

(b) Surface-Initiated RAFT

R-group approach

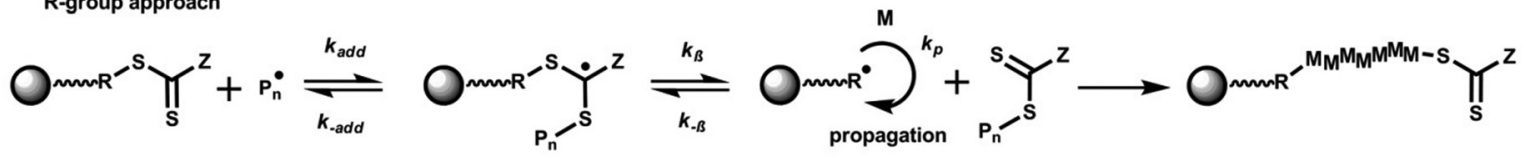

(c) Surface-Initiated RAFT

Z-group approach
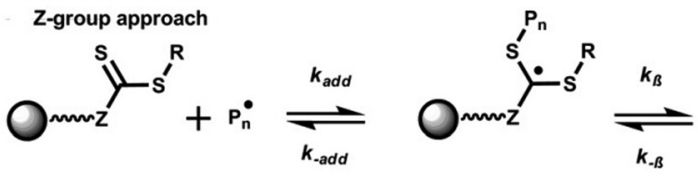<smiles>O=CC(=S)SP</smiles><smiles>[R]CN(C)SC(=S)OCCOc1cccc([R])c1</smiles>

(d) Surface-Initiated NMP

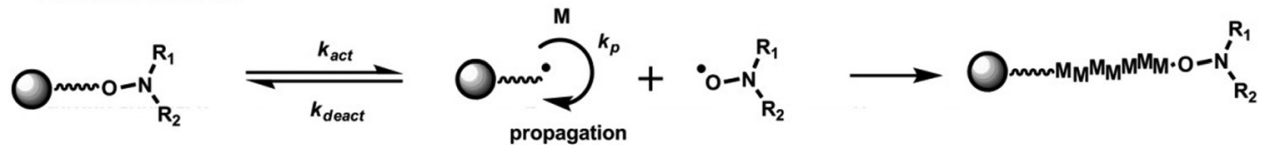

Scheme 2 General mechanisms of surface-initiated ATRP (a), surface-initiated RAFT polymerization with R-group approach (b) and Z-group approach (c), as well as surface-initiated NMP (d). Gray spheres represent nanoparticles, M denotes the monomers, and $k_{\mathrm{p}}$ is the propagation rate constant. In (a) and (d), the kinetic parameters $k_{\text {act }}$ and $k_{\text {deact }}$ represent the rate constants of activation and deactivation, respectively, in surfaceinitiated ATRP and NMP. In (b) and (c), R- represents the R-group or R-group-derived polymeric adduct, while Z- is the stabilizing group in the CTA for RAFT polymerization. $k_{\text {add }}$ and $k_{-\beta}$ are the rate constants for the addition reaction of CTA (or macro-CTA) with the propagating (or initiatorderived) radicals, whereas $k_{- \text {add }}$ and $k_{\beta}$ are the fragmentation rate constants for the intermediate radicals.

(a) ATRP or NMP

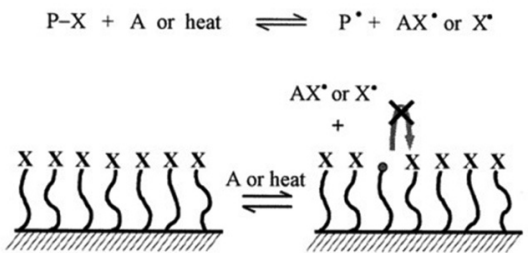

(b) RAFT

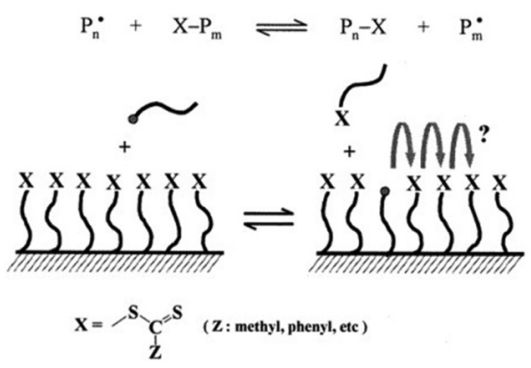

Fig. 2 Comparison of the key processes of (a) surface-initiated ATRP or surface-initiated NMP and (b) surface-initiated RAFT polymerization with the R-group approach. In (b), the effective surface migration of grafted radicals occurs via successive degenerative (exchange) chain transfer. Reprinted with permission from Y. Tsujii et al., Macromolecules, 2001 , 34, 8872-8878. Copyright 2001 American Chemical Society. ${ }^{43}$ silanol groups, ATRP initiators, RAFT agents, nitroxides, alkoxyamines, free radical initiators, ${ }^{48,132}$ ring-opening polymerization (ROP) initiators, ${ }^{49,133}$ living anionic initiators ${ }^{50,134}$ and ruthenium carbenes for ring-opening metathesis polymerization (ROMP) ${ }^{51,135,136}$ can be anchored onto silica nanoparticles. For surface-initiated CRP techniques, ATRP initiators, RAFT agents, and alkoxyamines can be covalently bound to the silica nanoparticle surface mainly utilizing three different strategies. First, a functional silane, which contains an initiator on one side and a silane group on the other side, can be attached onto the nanoparticle surface via direct condensation. The second possibility is by coupling the initiators via a linker to silica nanoparticle surfaces. Another approach is the in situ synthesis of initiators directly on the silica nanoparticle surface. Tables 1-4 provide a summary of functional initiators used for surface-initiated CRP from silica nanoparticles. These four tables specify the nature of the anchoring group, the chemical structure of the functional initiator, the polymerization technique, and the monomers used for the polymerization. In the following sections, we give details of surface-initiated ATRP, surface-initiated RAFT, and surfaceinitiated NMP from silica nanoparticles. In the last part of this section, Y-shaped initiators for sequential surface-initiated CRP are described. 
Table 1 Functional initiators and monomers used for surface-initiated ATRP from silica nanoparticles ${ }^{a, b}$

Entry Initiator linkage

ATRP initiator functionalized silane attached onto silica nanoparticle surfaces

1<smiles>C[Si](C)(CCc1ccc(CCl)cc1)OC[I-]O</smiles>

2<smiles>CC(Br)C(=O)OCCC[Si](C)(C)OCC[IH]O</smiles>

3

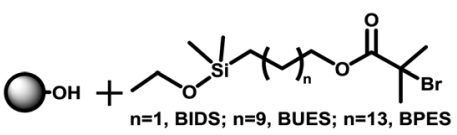

4<smiles>CO[Si](OC)(OC)c1ccc(CCl)cc1</smiles>

5<smiles>CO[Si](CCc1ccc(CCl)cc1)(OC)OC</smiles>

6<smiles>CCO[Si](CCCOC(=O)C(C)(C)Br)(OCCCCCCO)OCC[I-]O</smiles>

7

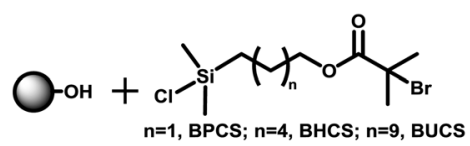

8

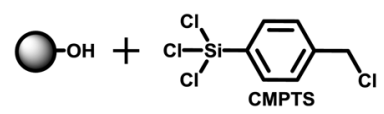

9

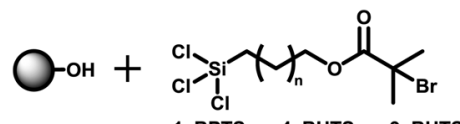

$n=1$, BPTS; $n=4$, BHTS; n=9, BUTS

10<smiles>CC(CCC(Cl)(Cl)Cl)OC(=O)C(C)Cl</smiles>

ATRP initiator coupled via a linker to silica nanoparticle

11

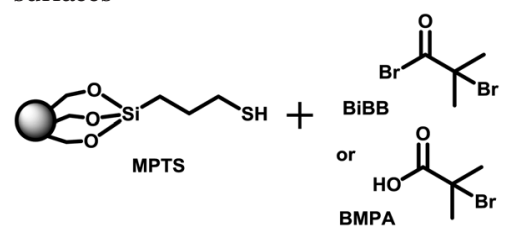

12

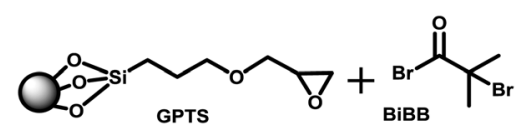

Monomer(s)

$\mathrm{St}^{40}$

$\mathrm{St},{ }^{137} \mathrm{MMA}^{137}$ BIDS: St ${ }^{41,137,138}$ MMA,${ }^{137,139,140}$ OEGMMA, ${ }^{141}$ MEMA,${ }^{141}$ HEMA, ${ }^{141}$
GMA,${ }^{141}$ DMAEMA,${ }^{142}$ DEAEMA,${ }^{142}$ NaStS,${ }^{142}$ NaVB,${ }^{142}$ tButA,${ }^{138}$ $\mathrm{MA}^{138}{ }^{138} \mathrm{BnMA}^{140}$

BUES: $\mathrm{St}^{41}$ BPES: $\mathrm{St}^{41}$ NIPAM $^{143}$

NIPAM,${ }^{144}$ MMA,${ }^{145}$ BnMA,${ }^{145}$ nButMA,${ }^{145}$ ButMA,${ }^{145}$ EGDMA,${ }^{145}$ $\mathrm{VBC}^{145}$ VIM $^{145}$

BPE: MMA $,{ }^{95} \mathrm{St}^{138} t \mathrm{ButA}^{138}{ }^{138} \mathrm{MA},{ }^{138}$ SPMA,${ }^{146}$ DMAEMA $^{146}$

BHE: MMA ${ }^{147}$

BPCS: St, ${ }^{148,149} n$ ButA, ${ }^{148}$ MMA, ${ }^{148}{ }^{4 V P},{ }^{100}$ PEGMMA,${ }^{150}$ TEGMMA,${ }^{150}$ DEGMMA, ${ }^{150} \mathrm{NaStS}^{151}$ DMAEMA, ${ }^{25,149} \mathrm{AN}^{149}$

BHCS: $n$ ButA,${ }^{94} \mathrm{MMA}^{152} \mathrm{St}^{152}$

BUCS: DEGMMA, ${ }^{153}$ TEGMMA, ${ }^{150,153-155}$ PEGMMA,${ }^{150}{ }^{15 u t M A}{ }^{155}$ $4 \mathrm{VP},{ }^{100} \mathrm{SPMA},{ }^{156} \mathrm{St}^{157} \mathrm{AM}^{157}$

BPTS: METAC $^{26}$

BHTS: BPEA, ${ }^{158} t$ ButA $^{158}$

BUTS: SPMA, ${ }^{159,160}$ MMA $^{159,160}$

SPMA,${ }^{159}$ MMA $^{159}$

$\mathrm{St}^{161}$

St, ${ }^{162} \mathrm{MMA}^{162}$ 
Table 1 (Contd.)

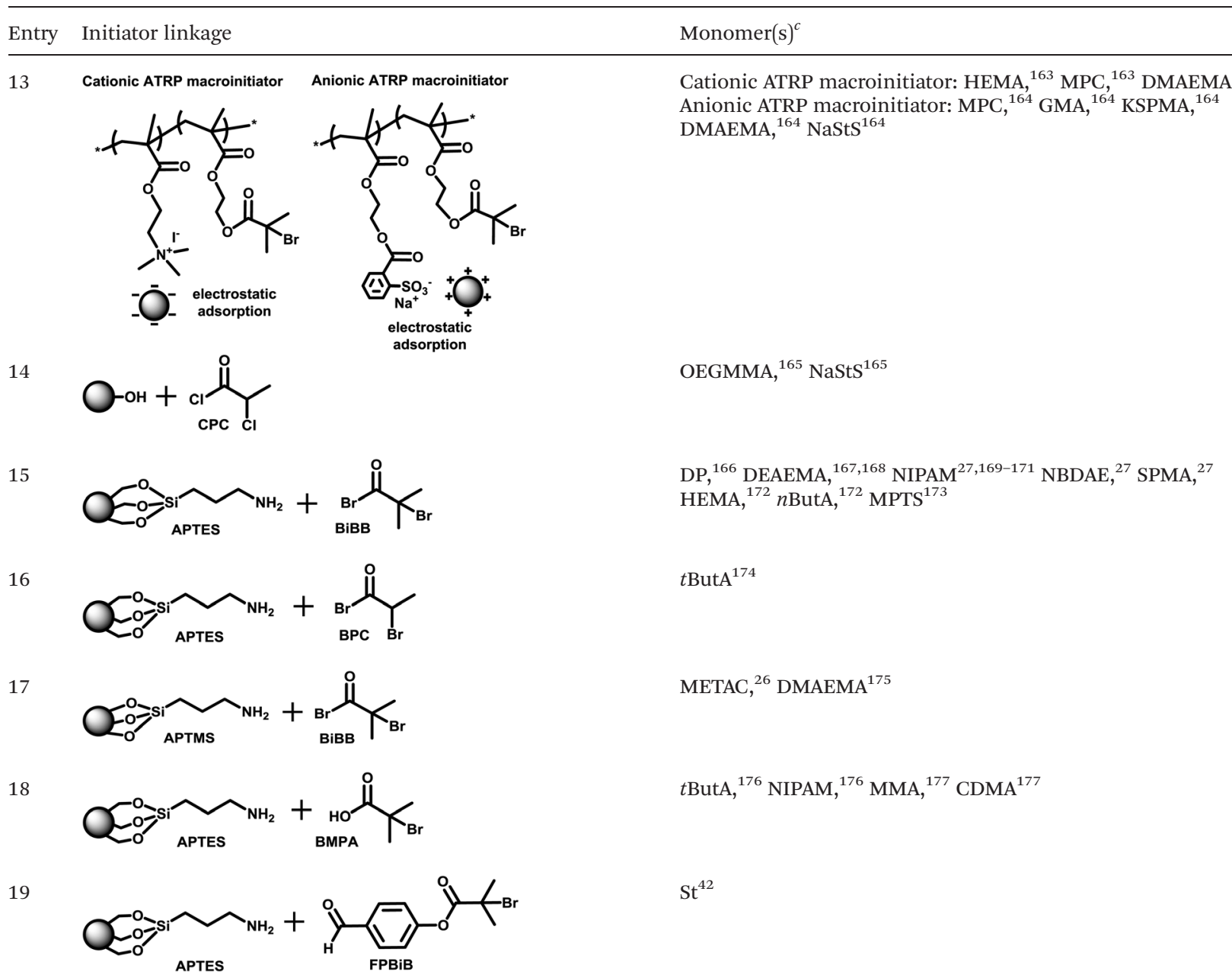

${ }^{a}$ Abbreviations: CDES, (2-(4-chloromethylphenyl)ethyl) dimethylethoxysilane; BPDS, (3-(2-bromopropionyl)oxypropyl) dimethylethoxysilane; BIDS, (3-(2-bromoisobutyryl)oxypropyl)dimethylethoxysilane; BUES, (11-(2-bromoisobutyryl)oxyundecyl)dimethylethoxysilane; BPES, (15-(2bromoisobutyryl)oxypentadecyl)dimethylethoxysilane; CMPS, (( $p$-chloromethyl)phenyl)trimethoxysilane; CMPES, (( $p$-chloromethyl)phenylethyl)trimethoxysilane; BPE, (3-(2-bromo-2-methyl)propionyloxypropyl)triethoxysilane; BHE, (6-(2-bromo-2-methyl)propionyloxyhexyl)triethoxysilane; BPCS, (3-(2-bromo-2-methyl)propionyloxy)propyl dimethylchlorosilane; BHCS, (6-(2-bromo-2-methyl)propionyloxy)hexyl dimethylchlorosilane; BUCS, (11-(2-bromo-2-methyl)propionyloxy)undecyl dimethylchlorosilane; CMPTS, 4-(chloromethyl)phenyl trichlorosilane; BPTS, (3-(2-bromo-2methyl)propionyloxy)propyl trichlorosilane; BHTS, (6-(2-bromo-2-methyl)propionyloxy)hexyl trichlorosilane; BUTS, (11-(2-bromo-2-methyl)propionyloxy)undecyl trichlorosilane; CUTS, 11-(2-chloropropionyloxy)undecyl trichlorosilane; MPTS, 3-mercaptopropyl triethoxysilane; BiBB, 2-bromoisobutyryl bromide; BMPA, 2-bromo-2-methylpropionic acid; GPTS, (3-glycidoxypropyl)trimethoxysilane; CPC, 2-chloropropionyl chloride; APTES, (3-aminopropyl)triethoxysilane; BPC, 2-bromopropionyl bromide; APTMS, (3-aminopropyl)trimethoxysilane; FPBiB, 4 -formylphenyl 2-bromoisobutyrylate. ${ }^{b}$ Gray spheres represent silica nanoparticles. ${ }^{c}$ For full names and structures of the monomers, refer to Fig. 1.

\subsection{Surface-initiated ATRP from silica nanoparticles}

Table 1 gives an overview of functional initiators and corresponding monomers used for surface-initiated ATRP from silica nanoparticles. The main text refers to the entries in the table.

Surface-initiated ATRP from silica nanoparticles was systematically reported for the first time by Patten and coworkers. $^{40,137}$ They synthesized several ATRP initiator functionalized silanes, namely CDES, BPDS, and BIDS, respectively (Table 1, entries 1-3). The functional silane has an alkyl halide on one side for ATRP initiation and a silane group on the other side for attachment onto silica nanoparticle surfaces via direct condensation. After the preparation of the initiatormodified nanoparticles, i.e. macroinitiators, well-defined polymer nanoparticle hybrids were obtained by surfaceinitiated ATRP. Densely grafted polystyrene (PSt) or poly (methyl methacrylate) (PMMA) formed visible outer layers which were directly observed by transmission electron microscopy (TEM), as illustrated in Fig. 3. For polymerizations of St and MMA, the authors comparatively studied the criteria for a controlled/living radical polymerization and indicated that introducing either a sacrificial free initiator or a deactiva- 
Table 2 Functional RAFT agents and monomers used for surface-initiated RAFT polymerizations from silica nanoparticles ${ }^{a, b}$

\begin{tabular}{ll} 
Entry & RAFT agent linkage \\
\hline & R-group approach \\
& RAFT agent functionalized silane attached onto silica nanoparticle \\
surfaces
\end{tabular}

1<smiles>CO[Si](C)(C)CCCOC(=O)C(SC(=S)c1ccccc1)[N+](=O)[O-]</smiles>

2<smiles>CCO[Si](CC(C)(C)OC(=O)C(SC(=S)SC)c1ccccc1)(OCC)OCCPO</smiles>

3<smiles>CCSC(=S)SCc1ccc(S(OC)(OC)OC)cc1</smiles>

4<smiles>CC(C)(C)CSC(=S)SC(C)(C)C(=O)OCCSCC[Si](C)(C)O[Si](C)(C)O[Si](C)(C)CCO</smiles>

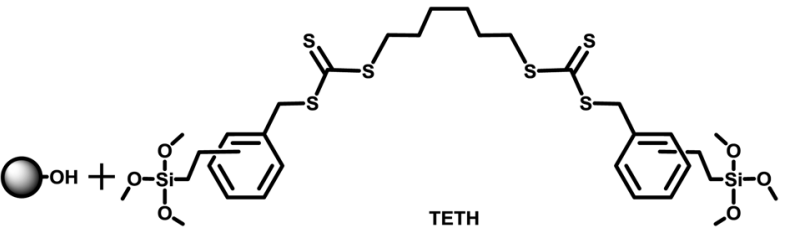
RAFT agent coupled onto silica nanoparticle surfaces via a linker

6
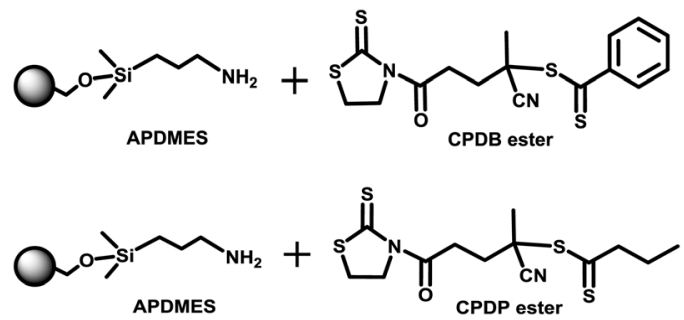

8

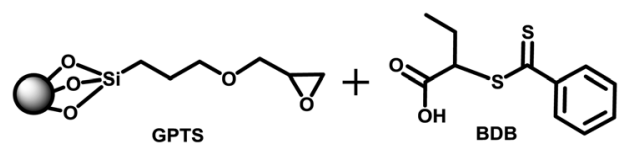

9

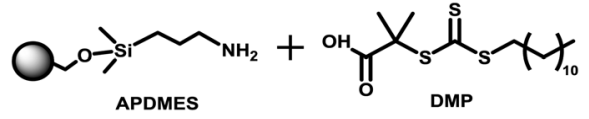

10

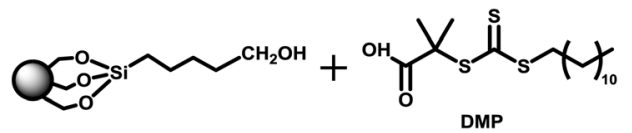

11

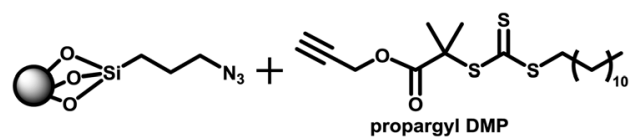

Monomer(s) ${ }^{c}$

$\mathrm{St}^{113} n \mathrm{ButA}^{113}$

St, ${ }^{44}$ MMA,${ }^{44}$ NIPAM, ${ }^{44}$ nButA, ${ }^{44}$ VBC,${ }^{200,201}$ PyAc $^{201}$

$\mathrm{AA}^{202}$

NIPAM $^{203}$

$\mathrm{MA}^{204}$

St, ${ }^{96}$ MMA,${ }^{96,205}$ MAA,,${ }^{97}$ AHMA,${ }^{205} t$ ButMA,${ }^{206}$ DMIPM,,${ }^{206}$ HPMA,${ }^{206} t$ ButMA,${ }^{97,207} \mathrm{St}^{, 208}{ }^{20} \mathrm{MMA}^{208}$

DEAEMA,${ }^{209}$ PDSM $^{209}$

$\mathrm{St}^{210}$

$\mathrm{MA}^{211}$

$\mathrm{St}^{212}$ NIPAM, ${ }^{213} \mathrm{AA}^{214}$

$\mathrm{St},{ }^{45} \mathrm{MA}^{45}$ 
Table 2 (Contd.)

Entry RAFT agent linkage

Z-group approach

RAFT agent functionalized silane attached onto silica nanoparticle surfaces

14

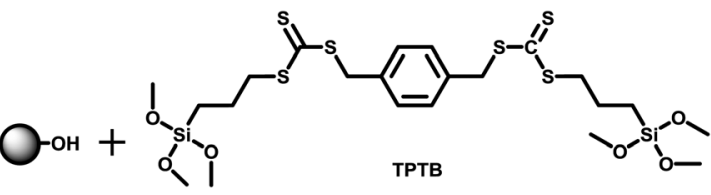

$\mathrm{MA}^{204}$

15<smiles>CO[Si](CCCSC(=S)SCc1ccccc1)(OC)OC</smiles>

16<smiles>COC(=O)C(SC(=S)SCCC[Si](OC)(OC)OC[I-]O)c1ccccc1</smiles>

RAFT agent coupled onto silica nanoparticle surfaces via a linker

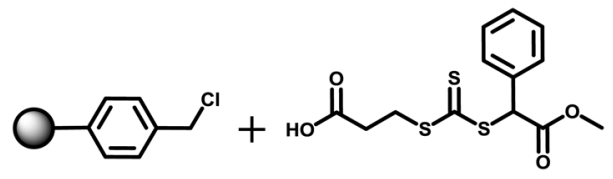

18<smiles>CCCCCCCCCCCCC(=O)O</smiles>

$\mathrm{MA},{ }^{115,116} \mathrm{MMA}^{115} n$ ButA, ${ }^{115} \mathrm{St}^{115}$

$\mathrm{MA}^{116}$

${ }^{a}$ Abbreviations: DBDMS, (3-(2-dithiobenzoatepropionyl)propyl)dimethylmethoxysilane; EHT, 6-(triethoxysilyl)hexyl 2-(((methylthio)carbonothioyl)thio)-2-phenylacetate; MBET, (4-(trimethoxysilyl)benzyl)ethylcarbonotrithioate; DMP-HBPS, 2-(dodecylthiocarbonothioylthio)-2methylpropionic acid-hyperbranched polysiloxysilane; TETH, 1,6-bis(o,p-2'-trimethoxysilylethylbenzyltrithiocarbonyl)hexane; APDMES, 3-aminopropyl dimethylethoxysilane; CPDB ester, 4-cyanopentanoic acid dithiobenzoate mercaptothiazoline ester; CPDP ester, 4-cyano-4-(propylsulfanylthiocarbonyl)sulfanylpentanoic acid mercaptothiazoline ester; BDB, 2-butyric acid dithiobenzoate; DMP, 2-(dodecylthiocarbonothioylthio)-2-methylpropionic acid; BCBD, benzyl 9H-carbazole-9-carbodithioate; BDTB, benzyl dithiobenzoate; TPTB, 1,4-bis(3'-trimethoxysilylpropyltrithiocarbonylmethyl)benzene; BTPT, $S$-benzyl-S'-trimethoxysilylpropyltrithiocarbonate; $\quad$ MPTT, $S$-phenyl (methoxycarbonylmethyl)-S'-trimethoxysilylpropyltrithiocarbonate; MPPA, 3-(methoxycarbonylphenylmethylsulfanylthiocarbonylsulfanyl) propionic acid; BSPA, 3-(benzylsulfanylthiocarbonylsulfanyl) propionic acid. ${ }^{b}$ Gray spheres represent silica nanoparticles. ${ }^{c}$ For full names and structures of the monomers, refer to Fig. 1.

tor copper(II) complex can induce the surface-initiated polymerization in a more controlled manner. ${ }^{137}$ The presence of a sacrificial initiator quickly accumulates an appropriate amount of $\mathrm{Cu}^{\mathrm{II}}$ via the termination of polymer radicals at the early stage of polymerization. The $\mathrm{Cu}^{\mathrm{II}}$ species ensures a fast deactivation process and suppresses termination reactions by radical coupling, thus controlling the polymerization by the persistent radical effect. ${ }^{95,137,147,178,179}$ Additionally, free polymers produced by the sacrificial free initiator form an entangled network structure which prevents nanoparticle diffusion, diminishes interparticle coupling, and avoids gelation or aggregation. ${ }^{95,137,147,178,179}$ Up to now, utilizing surfaceinitiated ATRP, various synthetic polymers such as PSt, ${ }^{41,138,148,161,162}$ PMMA, ${ }^{139,147,148,162,177}$ poly(n-butyl acrylate) 
Table 3 Functional alkoxyamines applied for surface-initiated NMP from silica nanoparticles ${ }^{a}$

Entry Linkage or formation of alkoxyamines $\quad$ Monomer(s) ${ }^{b}$

Alkoxyamine silanes anchored onto silica nanoparticle surfaces by condensation

1<smiles>CC(C)(CCl)CCOCC(ON1C(C)(C)CCCC1(C)C)c1ccccc1</smiles>

2<smiles>CC(ON(C(c1ccccc1)C(C)C)C(C)(C)C)c1ccc(COCCCCC[Si](Cl)(Cl)Cl)cc1</smiles>

3<smiles>CCO[Si](CC(C)(C)CC(=O)OCC(ON(C(C(C)(C)C)C(C)(C)C)C(C)(C)C)c1ccccc1)(OCC)OCC</smiles>

4<smiles>CCOP(=O)(OCC)C(N(C)C(C)(C)C)C(C)(C)C</smiles>

5<smiles>CCOP(=O)(OCC)C(C)N(OC(C)C(=O)NCCC[Si](OC)(OC)OC)C(C)(C)C</smiles>

6<smiles>CCOP(=O)(OCC)C(N(OC(CC(C)(C)C(=O)O)C(=O)OCCC[Si](OC)(OC)OC)C(C)(C)C)C(C)(C)C</smiles>

7<smiles>CCCCOC(=O)CC(C)(C)C(=O)NCCC[Si](C)(C)OCC[Te]O[O-]</smiles>

$\mathrm{St}^{46}$

$\mathrm{St},{ }^{233} \mathrm{MAH},{ }^{233} \mathrm{VBCB}^{233}$ $n$ ButA, ${ }^{99,238} \mathrm{St}^{238}$

CBMA- $1,{ }^{47}$ CBMA- $5{ }^{47}$ $n$ ButA $^{239,240}$

$\mathrm{St}^{241}$ 
Table 3 (Contd.)

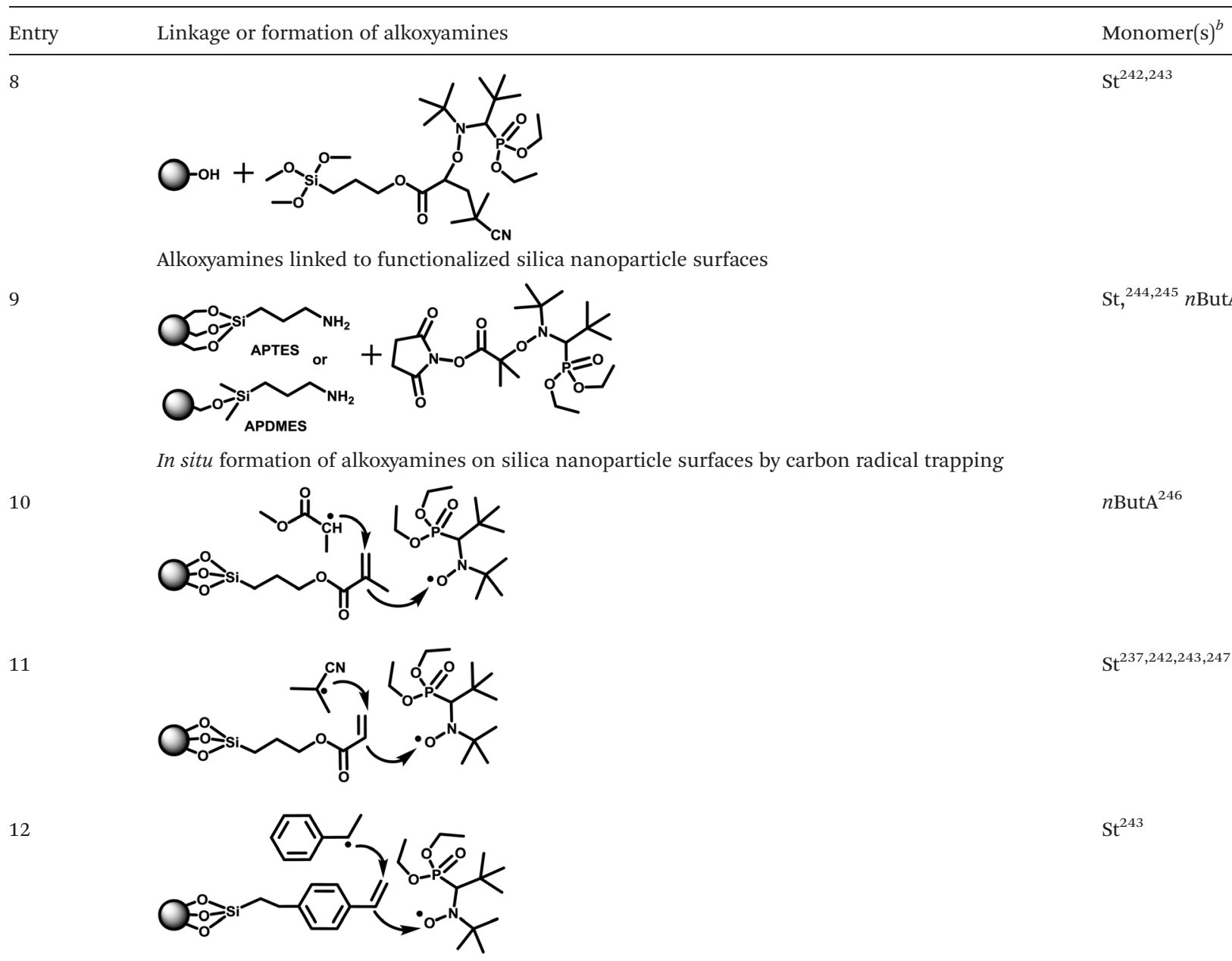

${ }^{a}$ Gray spheres represent silica nanoparticles. ${ }^{b}$ For full names and structures of the monomers, refer to Fig. 1.

(PnButA), ${ }^{94,148}$ poly(tert-butyl acrylate) (PtButA), ${ }^{174}$ poly(methoxyoligo(ethylene glycol)methacrylate) (POEGMMA), ${ }^{141,165}$ poly(2-(N-morpholino)-ethyl methacrylate) (PMEMA), ${ }^{141}$ poly(2hydroxylethyl methacrylate) (PHEMA), ${ }^{141,163}$ poly(glycerol monomethacrylate) (PGMA) ${ }^{141}$ poly $(N, N$-dimethylaminoethylmethacrylate) (PDMAEMA), ${ }^{142,163,164}$ poly(2-(diethylamino)ethyl methacrylate) (PDEAEMA) ${ }^{142}$ as well as polyelectrolytes $^{142,151,163-165}$ have been grafted from silica nanoparticles (Table 1). Due to the living character of CRP techniques, it is possible to continue the polymerization with a second monomer after the consumption of the first monomer, which leads to block copolymer-grafted silica nanoparticles. ${ }^{138,148}$

Compared to the Stöber method, reverse microemulsion techniques and amino acid catalysis are two attractive ways of synthesizing monodispersed silica nanoparticles with diameters less than $55 \mathrm{~nm} .{ }^{125-128}$ However, such small silica nanoparticles tend to irreversibly form aggregates, because of their high surface to volume ratio. To overcome this disadvantage, grafting a polymer outer layer is effective to afford good dis- persibility of the silica nanoparticles to adopt them for further applications. Ohno and coworkers used the reverse microemulsion technique and lysine catalysis to produce monodispersed silica nanoparticles with average diameters of 55 and $15 \mathrm{~nm}$, respectively. ${ }^{95}$ Subsequently, these nanoparticles were surface-modified with the ATRP initiator functionalized silane BPE (Table 1, entry 6). Upon the addition of a sacrificial free initiator, the polymerization of MMA proceeded in a living manner from the initiator functionalized silica nanoparticles. ${ }^{95}$ Due to the excellent solubility of PMMA in many organic solvents, the PMMA grafted silica hybrid nanoparticles can be dispersed very well in $\mathrm{N}, \mathrm{N}$-dimethylformamide (DMF), acetone, tetrahydrofuran (THF), and toluene. The authors suspended the $55 \mathrm{~nm}$ core silica nanoparticles grafted with PMMA $\left(M_{\mathrm{n}}=122000 \mathrm{~g} \mathrm{~mol}^{-1}\right.$ and PDI $=1.19$ ) in a mixture of chlorobenzene/1,2-dichloroethane and let it stand at room temperature. Several minutes after the onset of the experiment, tiny iridescent flecks were observed showing the self-assembly of the nanoparticles forming a colloidal crystal (Fig. 4a and b). Confocal laser 
Table 4 Functional Y-shaped asymmetric initiators used for sequential surface-initiated living polymerizations from silica

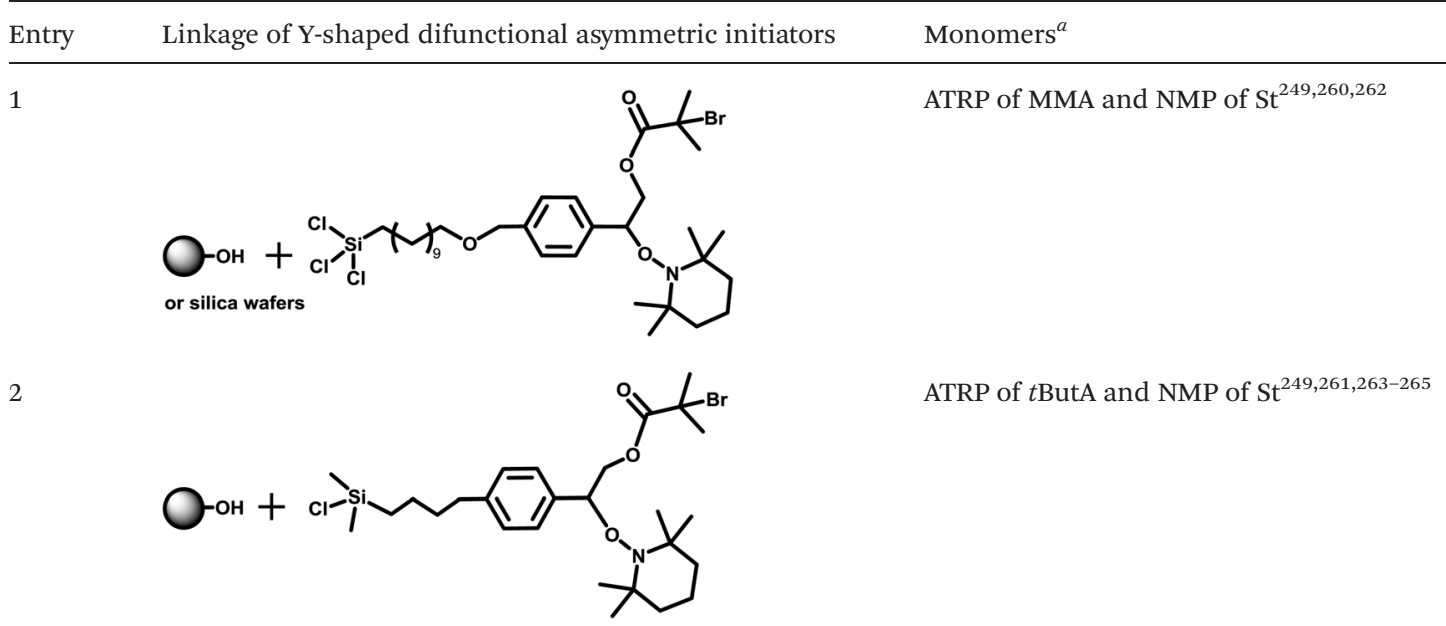

3<smiles>CCO[Si](CCCc1ccc(C(COC(=O)C(C)(C)Br)ON2C(C)(C)CCCC2(C)C)cc1)(OCC)OC[Te]O</smiles>

4<smiles>CC1(C)CCCC(C)(C)N1OC(COC(=O)c1ccc(CCl)cc1)c1ccc(CCC[Si](Cl)(Cl)Cl)cc1</smiles>

5<smiles>CCO[Si](CCCc1ccc(C(CO)ON2C(C)(C)CCCC2(C)C)cc1)(OCC)OCC</smiles>

6

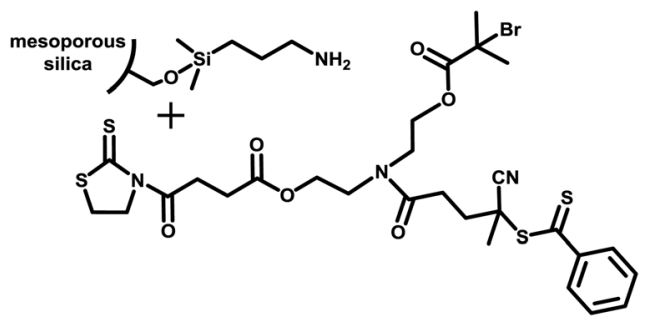

ATRP of $t$ ButA and NMP of $\mathrm{St}^{249,255,256,266,267}$

Living cationic ROP of 2-phenyl-2-oxazoline (PhOXA) and NMP of $\mathrm{St}^{257}$

ROP of $\varepsilon$-caprolactone (CL) and NMP of $\mathrm{St}^{258}$

RAFT polymerization of HPMA and ATRP of DEAEMA ${ }^{259}$

${ }^{a}$ For full names and structures of the monomers, refer to Fig. 1.

scanning microscopy (CLSM) visualized the crystal structure (Fig. 4c)..$^{95}$

Silica nanoparticles coated with polymer brushes which are responsive to external stimuli like $\mathrm{pH}$, temperature, or light are potential building blocks for smart nanodevices. One exemplarily studied $\mathrm{pH}$-responsive polymer is poly(4-vinylpyridine) ( $\mathrm{P} 4 \mathrm{VP})$ with a $\mathrm{p} K_{\mathrm{a}}$ value approximately in the range of
4-5. ${ }^{180,181}$ Classical ATRP of 4VP in solution was first described by the group of Matyjaszewski. ${ }^{182,183}$ Jiang and coworkers grafted dense P4VP brushes from BPCS (Table 1, entry 7) or CMPTS (Table 1, entry 8) immobilized silica nanoparticles by surface-initiated ATRP with a polymer content as large as $80 \%{ }^{100}$ Due to the high polymer content, the authors pointed out a potential application of the P4VP grafted silica nano- 
(A)
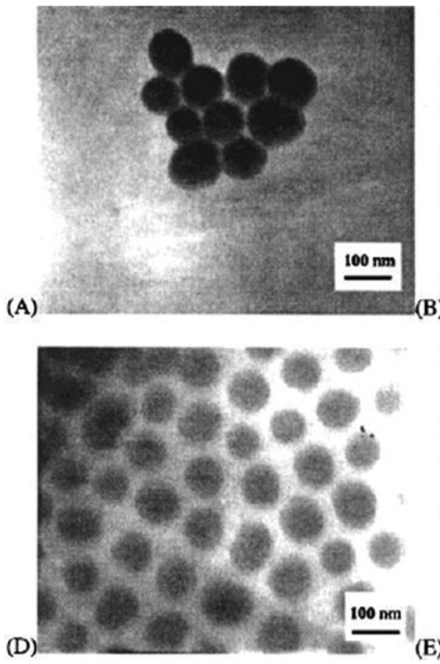
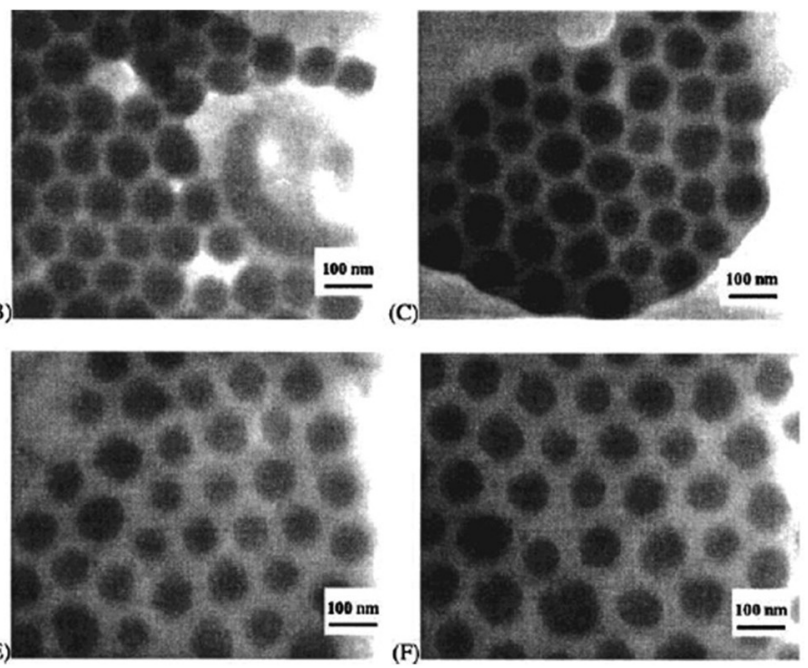

Fig. 3 TEM images for different monomer conversions for the surface-initiated ATRP of St from the surface of $75 \mathrm{~nm}$ BPDS-functionalized silica nanoparticles. The percentage of the monomer conversion is (A) 3.7, (B) 7.9, (C) 11.6, (D) 16.7, (E) 21.0, and (F) 24.6. Correspondingly, the numberaverage molecular weight $\left(M_{n}\right)$ of grafted PSt is $3.6,6.2,8.9,12.0,14.3$, and $15.4 \mathrm{~kg} \mathrm{~mol}^{-1}$, respectively. The images of the PSt silica nanohybrids show micrometer-sized polymer film domains containing a monolayer of silica nanoparticles. The silica nanoparticles are arranged within the PSt film in a hexagonal array, and the spacing between the nanoparticles increases with increasing molecular weight of the grafted polymer. Reprinted with permission from T. von Werne et al., J. Am. Chem. Soc., 2001, 123, 7497-7505. Copyright 2001 American Chemical Society. ${ }^{137}$
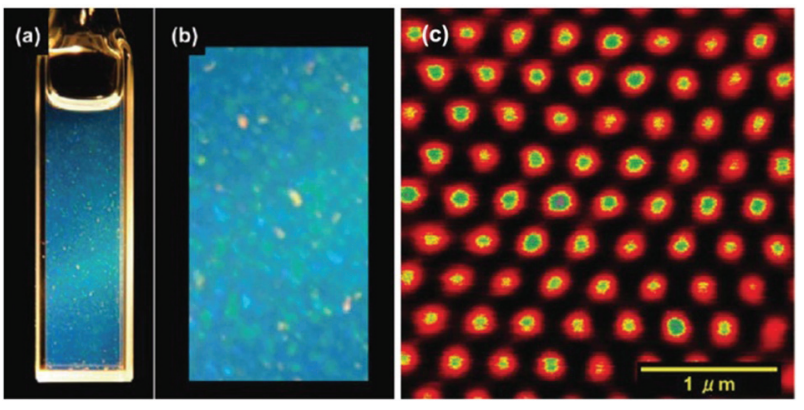

Fig. 4 (a) and (b) Photographs of a suspension of PMMA grafted silica nanoparticles in a solvent mixture of chlorobenzene/1,2-dichloroethane $(66 / 34 \mathrm{v} / \mathrm{v})$ illuminated from behind with white light. The $M_{\mathrm{n}}$ of the grafted PMMA is $122000 \mathrm{~g} \mathrm{~mol}^{-1}$ and the average diameter of the silica nanoparticle core is $55 \mathrm{~nm}$. (c) Confocal laser scanning microscopic image of the colloidal crystals obtained from the PMMA grafted silica nanoparticles. The mean nearest-neighbor interparticle distance is $350 \mathrm{~nm}$. Reprinted with permission from K. Ohno et al., Macromolecules, 2010, 43, 8805-8812. Copyright 2010 American Chemical Society. ${ }^{95}$

particles as a crosslinker in proton exchange membranes to improve the membrane performance. ${ }^{100}$ In addition, other kinds of pH-responsive polymers such as poly(2-(diisopropylamino)ethylmethacrylate) (PDP) ${ }^{166}$ and PDEAEMA ${ }^{167}$ were successfully grown from silica nanoparticles by surface-initiated ATRP (Table 1, entry 15). Moreover, smart surfaces were constructed by coating PDP- or PDEAMEA-grafted silica nanoparticles on substrates such as glass slides, silica wafers, and mica. ${ }^{166,167}$
In addition to pH-responsive silica nanohybrids, thermoresponsive polymer-grafted silica nanoparticles were successfully synthesized and investigated. The covalent attachment of thermoresponsive polymer chains to solid substrates such as silica nanoparticles is an effective way of tailoring the surface properties. Poly( $N$-isopropyl acrylamide) (PNIPAM) is one of the classical and most intensively studied thermoresponsive water soluble polymers. It has a lower critical solution temperature (LCST) of $32{ }^{\circ} \mathrm{C}$. Below the LCST, the PNIPAM chains are hydrated by intermolecular hydrogen bonding and become reversibly hydrophobic above the LCST by intramolecular hydrogen bonding. ${ }^{184-186}$ Classical ATRP of NIPAM has been successfully achieved in DMF/water $50 / 50(\mathrm{v} / \mathrm{v}),{ }^{187}$ various alcohols like 2-propanol (i-PrOH) and tert-butyl alcohol $(t-\mathrm{BuOH})^{188,189}$ as well as pure water ${ }^{190}$ at low temperature. To transfer the polymerization to grafting from silica nanoparticles turned out to be challenging. Wang et al. reported on thermoresponsive silica nanoparticle/PNIPAM hybrid materials by aqueous surface-initiated ATRP at room temperature (Table 1, entry 15). ${ }^{169}$ Instead of using initiator functionalized silanes, the authors directly coupled BiBB to amine modified silica nanoparticles. As the polymerization solvent was water, a high concentration of polymeric radicals and unavoidable chain transfer or termination occurred. ${ }^{53}$ Besides, $\mathrm{CuX} /$ bipyridine is not considered to be a suitable catalytic system for the ATRP of acrylamide monomers. ${ }^{53,54}$ Thus, the thickness of the PNIPAM shell could not be well controlled. ${ }^{169}$ To improve this, Liu and coworkers synthesized narrowly distributed thermoresponsive PNIPAM brushes by surfaceinitiated ATRP from BiBB functionalized silica nanoparticles using 2-propanol and $\mathrm{CuCl} /$ tris(2-(dimethylamino)ethyl)amine 
( $\mathrm{Me}_{6}$ TREN) as the solvent and the catalyst system, respectively (Table 1, entry 15). ${ }^{170}$ The PNIPAM brushes were densely grafted from the silica nanoparticles in a controlled manner (Fig. 5a). Laser light scattering (LLS) showed a two-stage decrease of the intensity-average hydrodynamic radius $<R_{\mathrm{h}}>$ and average radius of gyration $\left\langle R_{\mathrm{g}}>\right.$ of the PNIPAM grafted silica nanoparticles upon heating (Fig. 5b). ${ }^{170}$ The first transition occurred in a temperature range of $20-30{ }^{\circ} \mathrm{C}$ which can be ascribed to the $n$-cluster-induced collapse of the inner zone of PNIPAM brushes. This $n$-cluster concept was developed by de Gennes. ${ }^{191}$ According to the concept, the inner zone of polymer brushes can exhibit attractive $n$-body $(n>2)$ interactions, while the two-body interactions are still repulsive. The attractive $n$-body interactions can induce the collapse of the inner polymer brushes. ${ }^{170,191,192}$ The collapse of the outer zone of the PNIPAM brushes showed a second phase transition above $30{ }^{\circ} \mathrm{C}$. This phase transition behavior of PNIPAM brushes demonstrated the thermoresponsiveness of PNIPAM chains on the nanoparticle surface. ${ }^{170}$ Consequently, the PNIPAM grafted surfaces displayed thermoresponsive wettability changes. This thermally modulated wettability property enabled temperature-dependent interactions with bioactive compounds. For example, PNIPAM modified silica beads proved to be an effective packing material for high-performance liquid chromatography (HPLC), which was shown by the successful separation of three aromatic compounds (toluene, diphenyl ketone, biphenyl) using water as the mobile phase. ${ }^{171}$ The group of Nagase grafted PNIPAM chains on monolithic silica rod columns. The obtained efficient chromatography materials can separate hydrophobic steroids in a short time and with high resolution. ${ }^{144}$ Further examples of the synthesis of thermoresponsive water soluble polymer brushes are listed in Table 1 (entries 3, 7,

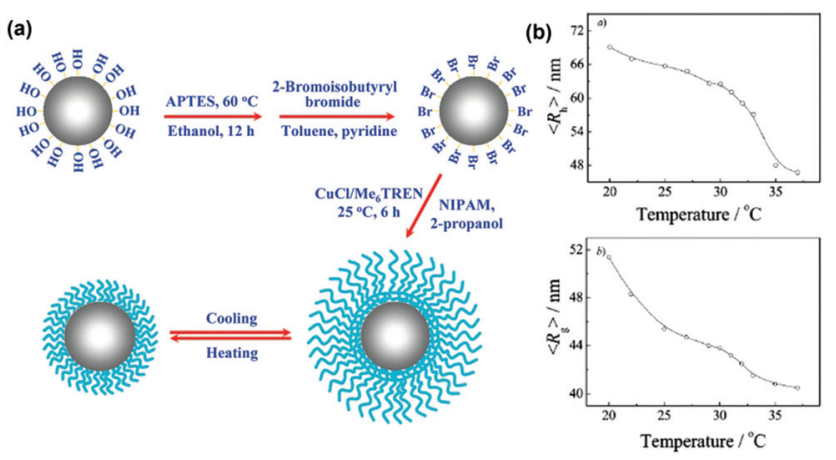

Fig. 5 (a) Schematic illustration of the synthesis of hybrid silica nanoparticles coated with thermoresponsive PNIPAM brushes via surfaceinitiated ATRP. The densely grafted PNIPAM brushes exhibit reversible thermoresponsive swelling/collapse phase transitions. (b) Temperature dependence of a) intensity-average hydrodynamic radius, $\left\langle R_{\mathrm{h}}\right\rangle$, and b) average radius of gyration, $\left\langle R_{\mathrm{g}}\right\rangle$, of hybrid silica nanoparticles coated with PNIPAM brushes in aqueous solution. The concentration of nanoparticles is $5 \mu \mathrm{g} \mathrm{ml}^{-1}$. Reprinted with permission from $\mathrm{T}$. Wu et al., Chem. Mater., 2008, 20, 101-109. Copyright 2008 American Chemical Society. ${ }^{170}$
13, and 17), namely the formation of poly(methoxypoly(ethylene glycol)methacrylate) (PPEGMMA), ${ }^{150}$ poly(methoxydi(ethylene glycol)methacrylate) (PDEGMMA), ${ }^{150,153}$ poly(methoxytri (ethylene glycol)methacrylate) (PTEGMMA), ${ }^{150,153,154}$ PMEMA, ${ }^{141}$ and thermoresponsive ionic liquid (IL) soluble poly(benzyl methacrylate) (PBnMA) ${ }^{140}$ as well as thermo- and pH-dual responsive PDMAEMA ${ }^{25,142,164,175}$ from silica nanoparticles by surface-initiated ATRP.

Light responsiveness can be introduced by photochromic compounds. These compounds can reversibly modulate the molecular properties through remote irradiation with a specific wavelength and are therefore highly attractive for numerous material systems. Such photochromic moieties can be incorporated into polymer matrices to change the polymer structure, conformation, and solvation by a remote lighttrigger. The property changes of the material arise from the altered interactions of the different forms of the photochromic groups with the polymer main chain, solvent molecules, or the side groups of the other monomer. Utilizing this strategy, photoresponsive systems tailored for specific applications were designed. During the past few years, spiropyran (SP) has emerged to be very promising for the construction of photoactive nanomaterials. ${ }^{193,194}$ UV irradiation induces the ring opening isomerization from neutral and colorless SP to zwitterionic blue/purple and fluorescent merocyanine (MC). ${ }^{193,194}$ SP is optically transparent in the visible (Vis) region without strong emission, while MC absorbs strongly at $\lambda_{\max }=$ 550-600 nm with an intense emission band approximately centered at $650 \mathrm{~nm} \cdot{ }^{193,194}$ Bell et al. copolymerized SPMA, an SP containing monomer (Fig. 1), with MMA from silica nanoparticles via surface-initiated ATRP (Table 1, entries 9 and 10). ${ }^{159,160}$ The authors utilized UV/Vis spectroscopy to analyze the kinetics of the isomerization of SP to MC and the following bleaching process. ${ }^{159}$ The kinetics of the bleaching process fits a superposition of two first-order rate reactions indicating two distinct MC species, free and H-stacked MC. ${ }^{159}$ Comparing the monomers and polymers, H-stacked MC solely exists in polymer brushes, because only this environment provides significant steric crowding which allows and facilitates the reorganization of free MC. ${ }^{159}$ The H-type noncovalent $\pi-\pi$ interactions of MCs provide a useful tool for supramolecular engineering to fabricate polymeric nanocapsules. ${ }^{146}$ DMAEMA and SPMA were randomly copolymerized from BPE fixed silica nanoparticle surfaces via Cu-mediated ATRP. Within the crowded environment of polymer brushes, after UV irradiation, the MC isomers crosslinked the copolymer shell by the H-type MC-MC stacks and robust pH-responsive vesicles were formed after hydrofluoric acid (HF) etching the inorganic silica cores (Fig. 6a). ${ }^{146}$ The obtained nanovesicles showed pH-responsive properties (Fig. 6b). Vis irradiation can dissociate the H-stacks and disrupt the nanovesicles straightforwardly, which is environmentally friendly (Fig. 6b).

SP can also be utilized in fluorescence resonance energy transfer (FRET) systems. In a FRET process, energy is transferred from a donor to an acceptor fluorophore. ${ }^{195}$ The donor is initially in its electronic excited state and can transfer 

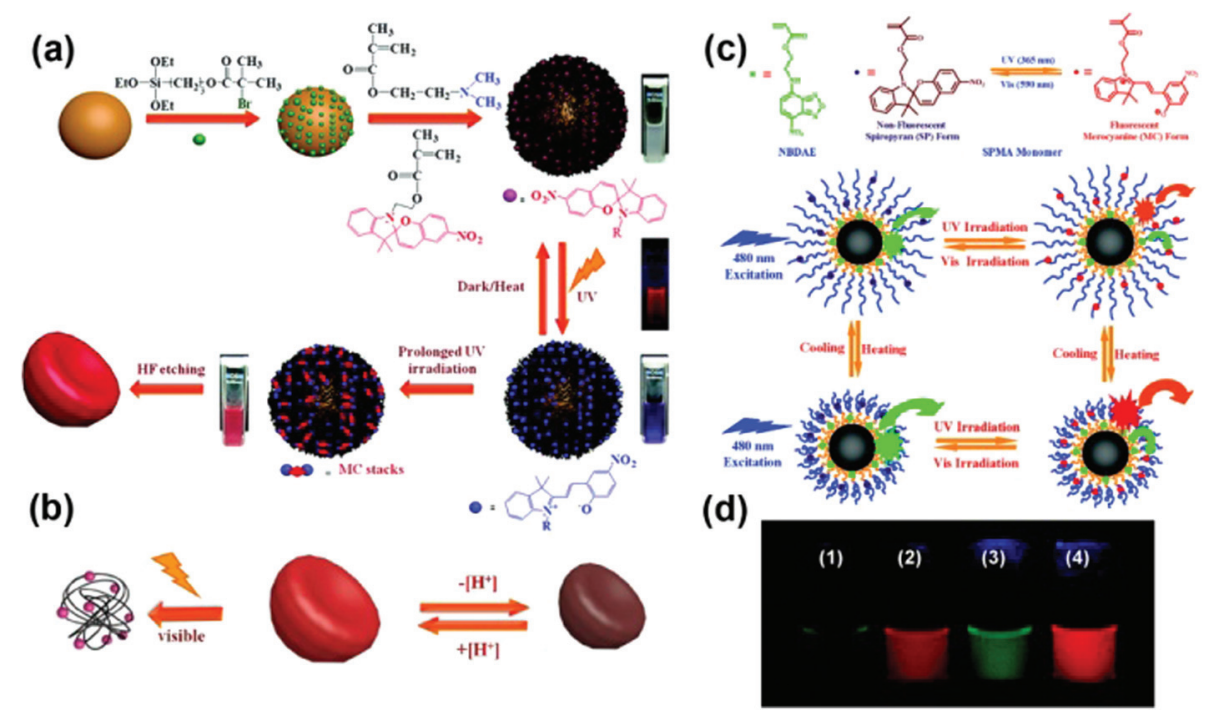

Fig. 6 (a) Synthetic procedure for fabricating polymer-based nanocapsules. First, BPE was immobilized onto the surface of silica nanoparticles (green dots in the first step), and next the photosensitive SPMA was randomly copolymerized with DMAEMA via surface-initiated ATRP (the second step). After prolonged UV irradiation $(\lambda=365 \mathrm{~nm})$ to induce the SP to MC isomerization of the chromophore units and promote the formation of intraparticle $\mathrm{H}$-type $\mathrm{MC}-\mathrm{MC}$ stacks within the polymeric layer, HF etching leads to robust nanocapsules. (b) The pH-responsive nanocapsules can be disrupted in the protonated state induced by visible light. Reprinted with permission from D. S. Achilleos et al., J. Am. Chem. Soc., 2012, 134, 5726-5729. Copyright 2012 American Chemical Society. ${ }^{146}$ (c) Schematic illustration of the reversible modulation of a multicolor fluorescent system based on hybrid silica nanoparticles coated with thermoresponsive P(NIPAM-co-NBDAE)- $b$-P(NIPAM-co-SPMA) brushes. The inner and outer layers are selectively labeled with FRET donor (NBDAE) and photoswitchable acceptor (SPMA) moieties, respectively. The FRET process can be switched on or off via UV or Vis irradiation. The FRET efficiency can be tuned via thermo-induced collapse/swelling of the responsive polymer brushes. (d) Photographs recorded during $365 \mathrm{~nm}$ UV illumination under varying conditions: (1) $20{ }^{\circ} \mathrm{C}$, upon Vis irradiation, (2) $20^{\circ} \mathrm{C}$, upon UV irradiation, (3) $35^{\circ} \mathrm{C}$, upon Vis irradiation, and (4) $35^{\circ} \mathrm{C}$, upon UV irradiation. The duration of UV or Vis irradiation is 4 min in all cases. Reprinted with permission from T. Wu et al., Chem. Mater., 2009, 21, 3788-3798. Copyright 2009 American Chemical Society. ${ }^{27}$

energy to the acceptor based on a nonradioactive dipoledipole coupling mechanism. The energy transfer efficiency is inversely proportional to the sixth power of the donor-to-acceptor distance, which makes FRET sensitive to small changes in distance. The colorless SP can undergo isomerization to the fluorescent MC upon UV irradiation. Nanoparticles suitable for a photoswitchable FRET process were fabricated by incorporating the SP system together with another fluorophore into the polymer shell around the nanoparticles. Liu et al. synthesized P(NIPAM-co-NBDAE) and P(NIPAM-co-SPMA) blocks sequentially from silica nanoparticles by surface-initiated ATRP (Fig. 6c). ${ }^{27}$ They prepared a nanosensor on the basis of photoswitchable FRET. When excited at $480 \mathrm{~nm}$, fluorescence emission of NBDAE centered at $530 \mathrm{~nm}$ was observed, which generally matches the absorbance band of the excited SPMA (MC form). Thus, NBDAE is the FRET donor and SPMA is the photoswitchable acceptor. UV irradiation switches on the FRET process by inducing the isomerization from the nonphotoactive SP to the FRET acceptor MC, while Vis irradiation switches off the FRET by inducing the reverse isomerization. Temperature induced swelling/collapse of the PNIPAM chains adjusts the distance between the donor and acceptor units, thus tuning the FRET efficiency. These processes are shown in Fig. 6c. The P(NIPAM-co-NBDAE)- $b$-P(NIPAM-co-SPMA) grafted silica nanoparticles can act as a thermosensitive UV dependent ratiometric fluorescent meter (Fig. 6d). ${ }^{27}$
Combining surface-initiated ATRP with other techniques, more advanced polymer architectures such as hyperbranched, ${ }^{158}$ comb-coil, ${ }^{172}$ mixed brushes, ${ }^{42}$ and Janus ${ }^{143,157,176}$ have been fabricated on the surfaces of silica nanoparticles. Hyperbranched polymers play an increasingly important role in interface and surface sciences, due to their highly compact and globular shape as well as monodispersity of the polymers. Mori et al. synthesized an initiator-monomer, BPEA (compare Fig. 1), which contains an alkyl bromide group for initiation in addition to the polymerizable acrylic group. ${ }^{158}$ The initiator unit BHTS was fixed on silica nanoparticles to subsequently synthesize hyperbranched polymer brushes via surface-initiated ATRP of BPEA, which was called self-condensing vinyl polymerization (SCVP) by the authors (Fig. 7a). ${ }^{158}$ In a similar attempt, the authors obtained hyperbranched poly-(acrylic acid) (PAA) grafted silica hybrid nanoparticles, by copolymerizing BPEA with $t$ ButA and subsequently hydrolyzing the tert-butyl groups into carboxylic groups. ${ }^{158}$ Zhao et al. reported the first synthesis of comb-coil polymer brushes on a silica nanoparticle surface. ${ }^{172}$ This involved two steps. First, PHEMA brushes were grown from silica nanoparticles by surface-initiated ATRP. Then, polylactide (PLA) and PnButA were synthesized simultaneously from the backbone and the terminal bromide of the PHEMA chains, respectively, by two different mechanisms (the scheme is illustrated in Fig. 7b). ${ }^{172}$ The hydroxyl groups on the PHEMA pendant chains are initiators for ROP to form the comb PLA, 
(a)

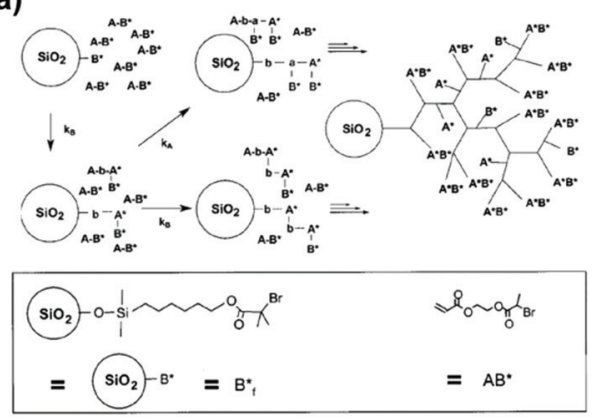

(b)

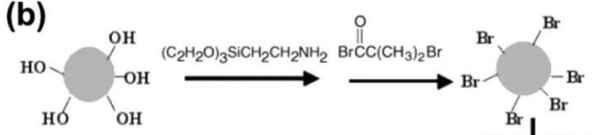

(c)

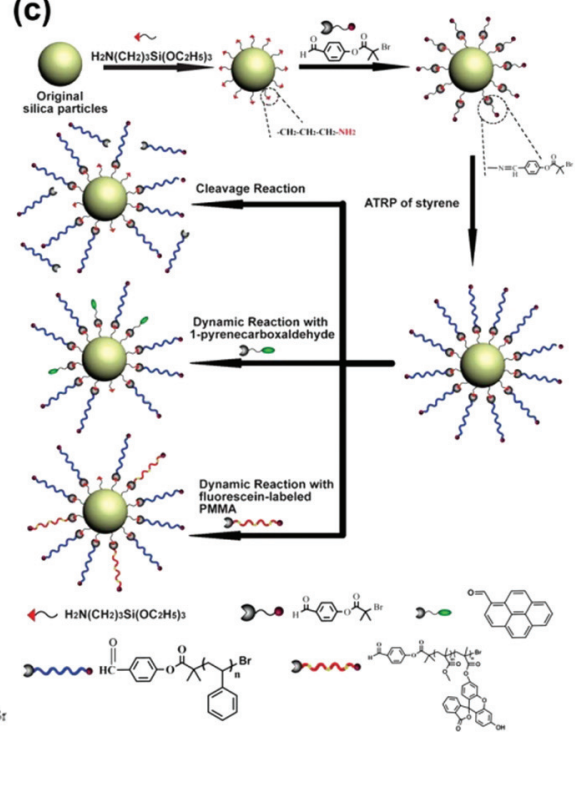

Fig. 7 (a) SCVP of BPEA from functionalized silica nanoparticles. Capital letters indicate vinyl groups $(A)$ and active centers $\left(A^{*}, B^{*}\right)$ while lowercase letters stand for reacted ones (a, b). Reprinted with permission from H. Mori et al., Langmuir, 2002, 18, 3682-3693. Copyright 2002 American Chemical Society. ${ }^{158}$ (b) Schematic representation for the preparation of comb-coil polymer brushes on the surface of silica nanoparticles. Reprinted with permission from H. Zhao et al., Macromolecules, 2005, 38, 10619-10622. Copyright 2005 American Chemical Society. ${ }^{172}$ (c) Schematic representation for the preparation of cleavable PSt brushes on silica nanoparticles, and dynamic exchange reactions between PSt brushes and 1-pyrenecarboxaldehyde as well as PSt and aldehyde-terminated fluorescein-labeled PMMA. Reproduced from ref. 42.

while the alkyl bromide groups at the end of the PHEMA chains are used as initiators for AGET ATRP of PnButA. ${ }^{172}$

The concept of so-called dynamic covalent chemistry was also applied for nanoparticle functionalization. Chemical reactions that are carried out reversibly under conditions of equilibrium control are considered in the context of dynamic covalent chemistry. ${ }^{196}$ This dynamic process allows the exchange of molecular components at equilibrium achieving a thermodynamically stable system. ${ }^{197,198}$ For example, imine bonds can be dynamically formed from the condensation of amines and aldehydes. ${ }^{197}$ The dynamic imine bond was employed to attach an ATRP initiator onto nanoparticles by the reaction of FPBiB with amine modified silica nanoparticles (Table 1, entry 19). ${ }^{42}$ Subsequently, PSt brushes were prepared by surface-initiated ATRP. Meanwhile, the authors synthesized aldehyde-terminated fluorescein labeled PMMA by ATRP of MMA and fluorescein methacrylate (FMA), using FPBiB as the initiator. Afterwards, they used the dynamic exchange reaction between the PSt coated silica nanoparticles and the aldehydeterminated fluorescein labeled PMMA straightforwardly to fabricate the mixed brushes of PSt/PMMA on the silica nanoparticle surface (Fig. 7c). ${ }^{42}$ The ${ }^{1} \mathrm{H}$-NMR spectrum of the cleaved PSt/PMMA mixed brushes showed the signals of the phenyl groups on the PSt chains and of the methyl protons on the PMMA chains.

Janus particles are special nanoparticles with differently functionalized halves having varying properties. Janus silica nanoparticles can be obtained by grafting two distinct polymer brushes on the opposite sides. Several methods exist to prepare these Janus nanoparticles, namely toposelective modification by wax colloidosomes, ${ }^{176}$ in situ biphasic grafting, ${ }^{157}$ or utilizing single crystal templates. ${ }^{143}$ A wide range of particles with different sizes and compositions can be used as emulsifiers to form Pickering emulsions. The assembly of nanoparticles at the Pickering emulsion interface allows an asymmetric modification, as the two sides of the particles are separated by the stabilized oil/water interface and protected in the two phases. However, the particles rotate at the interface, and it is unclear how this rotation affects the asymmetric modification. To tackle this problem, a solidification method of the nanoparticles was utilized by Granick. ${ }^{199}$ The silica nanoparticles are embedded in a frozen wax/water Pickering emulsion interface, where the rotation is restricted. ${ }^{199}$ Using the wax/water interface as a template mask, Stamm et al. modified the free side of the silica nanoparticles with ATRP initiators. After detachment, PNIPAM or PtButA was grown from this modified side via surface-initiated ATRP. ${ }^{176}$ A second polymer, P2VP, was immobilized onto the other side using grafting-to. The synthetic procedure is illustrated in Fig. $8 \mathrm{a} .{ }^{176}$ The group of Yang presented the formation of Janus nanoparticles by simultaneously grafting different polymers in the two Pickering emulsion phases via surface-initiated ATRP (Fig. 8b). ${ }^{157}$ They first used CMPTS (Table 1, entry 8) anchored silica nanoparticles as emulsifiers to stabilize water-in-oil (w/o) 


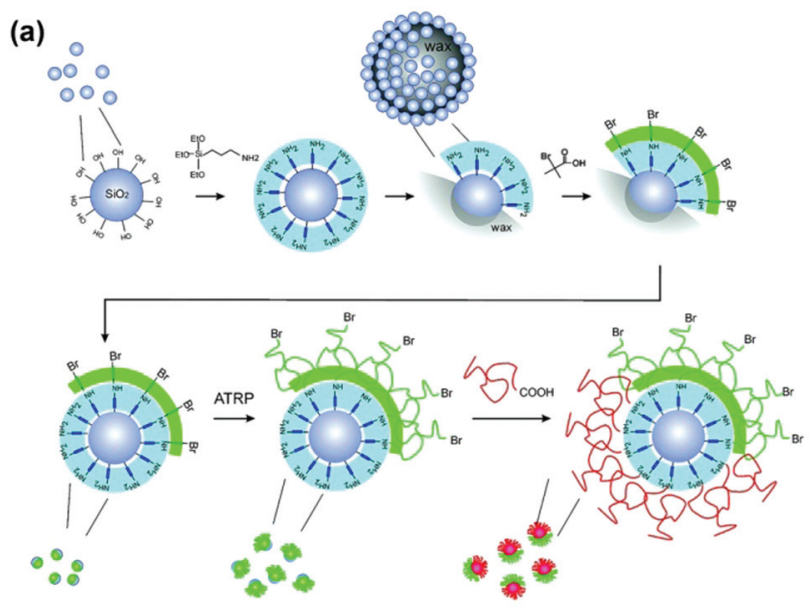

(b)

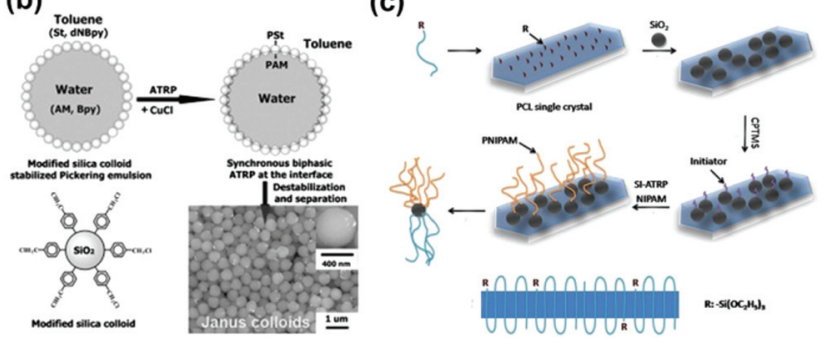

Fig. 8 Fabrication of Janus nanoparticles via toposelective modification using different templates. (a) Scheme of the synthesis of bicomponent Janus particles by grafting-from and grafting-to approaches, using wax colloidosomes as a template. Reprinted with permission from S. Berger et al., Macromolecules, 2008, 41, 9669-9676. Copyright 2008 American Chemical Society. ${ }^{176}$ (b) Schematic illustration of the synthesis of Janus colloids by biphasic surface-initiated ATRP at a w/o Pickering emulsion droplet interface and TEM image of the obtained Janus colloids. Reprinted with permission from B. Liu et al., Angew. Chem., Int. Ed., 2008, 47, 3973-3975. Copyright 2008, Wiley-VCH. ${ }^{157}$ (c) Synthesis procedure to obtain Janus silica nanoparticles using PCL single crystals as a template. The bottom shows the side-view of a PCL $\left(M_{n}\right.$ approximately $7000 \mathrm{~g} \mathrm{~mol}^{-1}$ ) single crystal illustrating the chain folding. Reprinted with permission from T. Zhou et al., Macromolecules, 2012, 45, 8780-8789. Copyright 2012 American Chemical Society. ${ }^{143}$

Pickering emulsions. The two sides of the nanoparticles were separated by the water-oil interface, and the residual $-\mathrm{CH}_{2} \mathrm{Cl}$ group from the CMPTS was used for ATRP initiation. The dispersed water phase contained the monomer AM and the water soluble ligand 2,2'-bipyridine (Bpy), while the continuous oil phase consisted of toluene as a solvent, St as a monomer, and the oil-soluble ligand 4,4'-di-5-nonyl-2,2'-bipyridine (dNBpy). After adding $\mathrm{CuCl}$, polyacrylamide (PAM) and PSt were synchronously grown from the two sides of silica nanoparticles by surface-initiated ATRP in the water and oil phases, respectively. The hydrophilic/lipophilic interactions between the ATRP system and the original silica nanoparticles restrict the rotation and facilitate further formation of Janus colloids (Fig. 8b). Instead of the liquid/liquid interface, a poly( $\varepsilon$-caprolactone) (PCL) single crystal was utilized as a flat hard template mask to synthesize amphiphilic Janus silica nanoparticles. ${ }^{143}$
Alkoxysilane-terminated hydrophobic PCL can form single crystals by folding the polymer chains back and forth. By careful control of the crystallization conditions and chain structure, the alkoxysilane ends can be accumulated on the crystal surface to be able to immobilize $50 \mathrm{~nm}$ silica nanoparticles via chemisorption on these functional groups. After this immobilization, the free side of the silica nanoparticles was functionalized with CMPS (Table 1, entry 4), and surfaceinitiated ATRP of NIPAM was conducted to graft PNIPAM brushes. After dissolving the PCL single crystals in acetone, free Janus nanoparticles decorated with PNIPAM and PCL on the two sides were obtained (Fig. 8c). ${ }^{143}$

\subsection{Surface-initiated RAFT from silica nanoparticles}

In the same way as in section 3.1, Table 2 gives an analogous overview of the RAFT agents and monomers employed for surface-initiated RAFT polymerizations from silica nanoparticles.

As discussed in the surface-initiated CRP mechanisms part, surface-initiated RAFT polymerization can be categorized into R-group and Z-group approaches, according to the anchored part of the RAFT agent onto the nanoparticle surface. To the best of our knowledge, the R-group approach was explored for the first time by Fukuda's group. ${ }^{43}$ Unlike the common R-group approach, they grafted oligomeric PSt chains from silica particles by surface-initiated ATRP, and converted the terminal halides to dithiobenzoyl groups by reaction with 1-phenylethyl dithiobenzoate (Fig. 9a). Surface-initiated RAFT polymerization was further carried out to polymerize St from the RAFT agent terminated oligomeric PSt grafted silica nanoparticles. The differences between the kinetics of RAFT polymerizations with and without a free RAFT agent were compared. Thereof, the authors concluded on the importance of adding a free RAFT agent to control the surfaceinitiated RAFT polymerization. By adding a free RAFT agent, the concentrations of dormant and active chains on the surface can be effectively maintained by exchange reactions between surface radicals and free radicals. This renders the graft polymerization controllable even to high conversions. ${ }^{43}$ Moreover, the free polymers increase the viscosity of the solution, thus preventing interparticle coupling, gelation and aggregation. ${ }^{44}$ Following this strategy, the addition of a free RAFT agent was widely applied for surface-initiated RAFT polymerizations. ${ }^{44,114,200-202,206}$ Another issue was noticed in the fundamental article by Fukuda. Gel permeation chromatography (GPC) spectra of the grafted polymers showed a shoulder which was assigned to dead chains from the recombination of polymer radicals (solid curves in Fig. 9b). In contrast, no shoulder appeared in the GPC spectra of free polymers (dash curves in Fig. 9b). This means that recombination reactions occurred much more frequently on the surface than in solution. ${ }^{43}$ This specific enhanced recombination is derived from a so-called migration effect, which has already been mentioned in section 2 and is attributed to a reaction-diffusion mechanism process. ${ }^{43}$ A very effective surface migration of grafted 
(a)
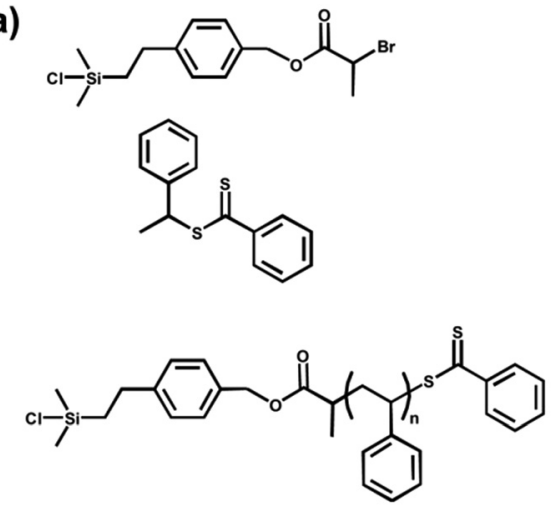

(b)

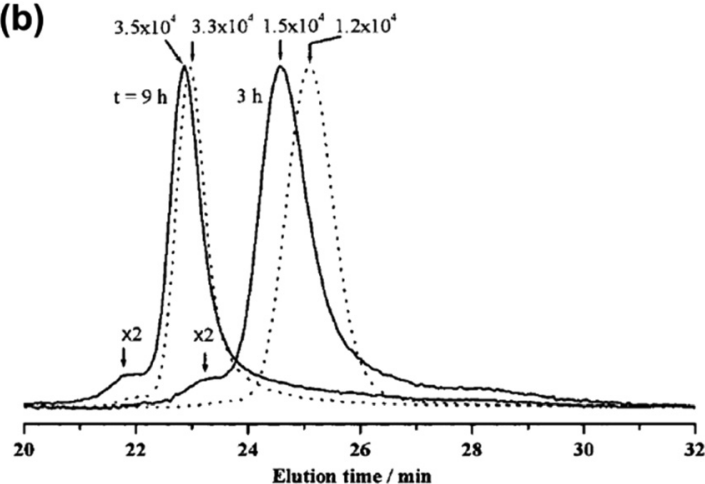

Fig. 9 (a) The structures of the functional initiator for surface-initiated ATRP, the RAFT agent 1-phenylethyl dithiobenzoate, and oligomeric PSt RAFT agent utilized in the group of Fukuda. (b) GPC spectra of grafted (solid curve) and free (broken curve) polymers after $3 \mathrm{~h}$ and $9 \mathrm{~h}$ of surface-initiated RAFT polymerization of St at $110{ }^{\circ} \mathrm{C}$. The difference in number-average molecular weight $\left(M_{n}\right)$ between the grafted and free polymers is nearly equal to the $M_{\mathrm{n}}=3400 \mathrm{~g} \mathrm{~mol}^{-1}$ of the precursory oligomeric PSt. Reprinted with permission from Y. Tsujii et al., Macromolecules, 2001, 34, 8872-8878. Copyright 2001 American Chemical Society. ${ }^{43}$

radicals can occur via successive degenerative (exchange) chain transfer, especially for dense surface grafting (Fig. 2). The effective migration can narrow the molecular weight distribution of the polymer chains. Oppositely, this migration broadens the chain length distribution by bimolecular termination, especially when the density is too large and the migration speed boosts.

To avoid the ATRP of oligomeric polymer chains and subsequently convert the end groups to RAFT agents, other strategies were developed to attach RAFT agents onto nanoparticle surfaces. Benicewicz et al. reported the synthesis of a RAFT agent functionalized silane, DBDMS, containing both a dimethylmethoxysilane head group and a dithioester RAFT agent (Table 2, entry 1). ${ }^{113}$ This RAFT agent functionalized silane can be directly anchored onto silica nanoparticles by condensation of the methoxysilane group, thus introducing the dithioester R-group onto the silica nanoparticle surface. ${ }^{113}$ The authors polymerized two different monomers, St and $n$ ButA, with varying surface densities, and compared these processes with model free RAFT polymerizations. For the surface- initiated RAFT polymerization, they observed retardation which arose from the surface migration effect because of concentrated localized RAFT agent on the particle surfaces. ${ }^{43,113}$ Additionally, PSt was successfully chain extended from the $\mathrm{P} n$ ButA-grafted-SiO ${ }_{2}$ nanoparticles, demonstrating the livingness and high re-initiating efficiency of macro-RAFT agents on the surface. ${ }^{113}$ Using this concept, other RAFT agent functionalized silanes have been synthesized and used for surfaceinitiated RAFT polymerizations via the R-group approach (Table 2, entries 2-5). For example, Ohno et al. synthesized a RAFT agent functionalized silane, EHT (Table 2, entry 2), and attached it onto silica nanoparticles. ${ }^{44}$ The surface-initiated RAFT polymerizations of St, MMA, NIPAM and $n$ ButA were conducted in a living manner in the presence of free RAFT agents. ${ }^{44}$ Due to their high uniformity, these hybrid nanoparticles can be three-dimensionally ordered and formed colloidal crystals. ${ }^{44,95}$

RAFT polymerization is able to polymerize a wide range of vinyl monomers with a high tolerance towards functional groups, which other CRP techniques, especially ATRP, cannot accomplish. For instance, side reactions occur during the ATRP of VBC, because of the dissociation of the $\mathrm{C}-\mathrm{Cl}$ bond in the monomer. Furthermore, monomers containing carboxyl groups such as AA are not compatible with ATRP, and their polymerizations by ATRP need pre-protection of the functional groups. ${ }^{83-85}$ Instead, RAFT polymerization is the ideal radical process for these monomers. VBC was effectively polymerized using the RAFT technique, not only in solution with comonomers, ${ }^{121,217-220}$ but also from EHT fixed silica nanoparticles (Table 2, entry 2) ${ }^{200}$ VBC can thermally auto-initiate the surface-initiated RAFT polymerization without any extra initiator (Fig. 10a, synthetic route i).$^{201}$ Incorporating the fluorescent comonomer PyAc, $\mathrm{P}(\mathrm{VBC}-\mathrm{co}$-PyAc) grafted silica nanoparticles were synthesized, as shown in Fig. 10a (synthetic route ii). ${ }^{201}$ Moreover, VBC has great potential for introducing various functionalities in a post-modification step. By quaternizing the VBC with triethylamine (TEA), the P(VBC-co-PyAc) chains became hydrophilic and water soluble fluorescent silica nanohybrids were yielded (Fig. 10a, synthetic route iii, and 10b). ${ }^{201}$ The quaternized P(VBC-co-PyAc)- $g$-silica nanoparticles were dispersed very well in aqueous solution and showed fluorescence under $365 \mathrm{~nm}$ UV irradiation (Fig. 10b). These hybrid materials were tested for biological applications in cancer treatment. The hydrophilic fluorescent particles proved to be stable in biological media and uptaken into the endosomes of human colon cancer cells, which was applied for in vitro cellimaging. ${ }^{201} \mathrm{Xu}$ et al. prepared well-defined PAA brushes from silica nanoparticles via surface-initiated RAFT polymerization. ${ }^{202}$ A RAFT agent functionalized silane, MBET (Table 2, entry 3), was designed and anchored onto silica nanoparticles by its R-group. The authors studied the structure and responsiveness of the PAA grafted silica nanoparticles thoroughly by TEM, dynamic light scattering (DLS), GPC, thermogravimetric analysis (TGA), and conductometric titration. The large amount of carboxyl groups provided abundant coupling sites for streptavidin (SA) immobilization via NHS/EDC chemistry. 
(a)

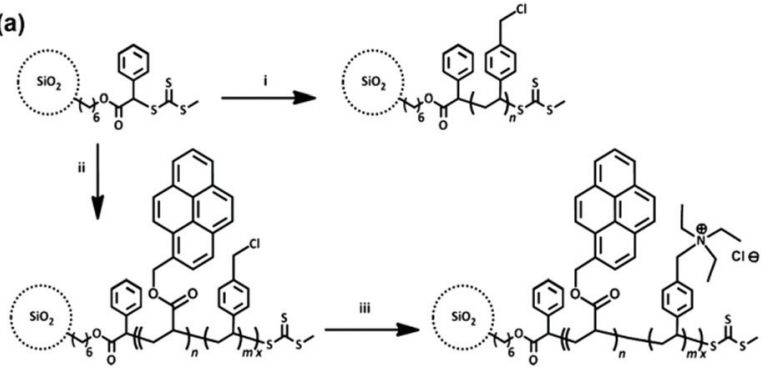

(i) VBC, DMF, PABTC, $110^{\circ} \mathrm{C}$; (ii) VBC, PyAc, DMF, PABTC, $110^{\circ} \mathrm{C}$; (iii) THF, $\mathrm{H}_{2} \mathrm{O}, \mathrm{TEA}, 30^{\circ} \mathrm{C}$.

(b)

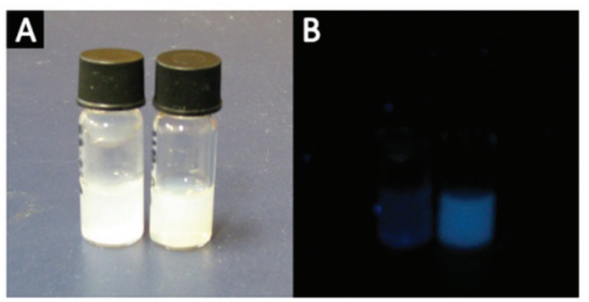

Fig. 10 (a) Fabrication of hydrophilic fluorescent silica nanohybrids: (i) surface-initiated RAFT polymerization of VBC from EHT fixed silica nanoparticles via thermal auto-initiation, (ii) surface-initiated RAFT copolymerization of VBC and PyAc from EHT fixed silica nanoparticles, and (iii) post-modification of the core-shell nanoparticles by quaternizing the VBC block with TEA. PABTC is a free RAFT agent, namely 2-(butylthiocarbonothioylthio)propionic acid. (b) Optical images of TEAquaternized PVBC-silica and P(VBC-co-PyAc)-silica nanoparticles: (A) under visible light and (B) under $365 \mathrm{~nm}$ UV irradiation. Reprinted with permission from J. Moraes et al., Chem. Mater., 2013, 25, 3522-3527. Copyright 2013 American Chemical Society. ${ }^{201}$

These SA coupled nanoparticles have a wide range of biological applications such as biotin recognition.

As described in the last two paragraphs, RAFT agent functionalized silanes can be effectively attached onto silica nanoparticles to subsequently initiate RAFT polymerizations from the surface. However, the synthesis and purification of such functional silanes involve multiple steps. Intermediate compounds are usually purified via column chromatography, but the adsorption of silane groups on the silica gel leads to low overall yields. ${ }^{96,113}$ Therefore, Benicewicz et al. developed another versatile route for RAFT agent immobilization onto silica nanoparticle surfaces. First, they functionalized silica nanoparticle surfaces by coating with a monolayer of aminosilane. Then, an activated RAFT agent, a CPDB ester, which is easier to synthesize and purify compared to RAFT agent functionalized silanes, was linked to the amino groups on the surface (Table 2, entry 6). ${ }^{96}$ The kinetics of surface-initiated RAFT polymerizations of MMA and St via the R-group approach, performed with or without a free RAFT agent, were studied and compared. Following this RAFT agent coupling method, various monomers e.g. AHMA, ${ }^{205} \mathrm{MAA}^{97}$ $t$ ButMA, ${ }^{97,207} \mathrm{St}^{210}$ and $\mathrm{MA}^{211}$ were polymerized from silica nanoparticle surfaces (Table 2, entries 6-10). Moreover, the Benicewicz group synthesized bimodal polymer brushes from CPDB anchored silica nanoparticles by a step-by-step tech-

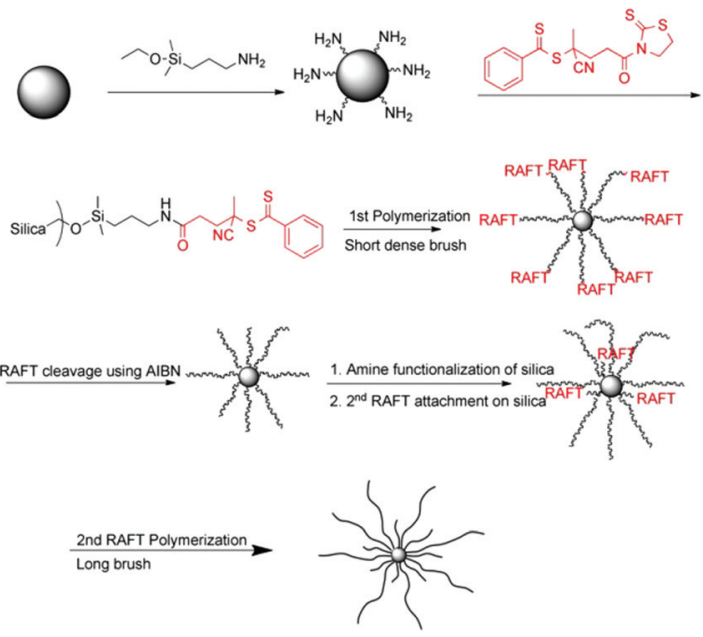

Fig. 11 Schematic illustration of the synthesis of bimodal brush grafted nanoparticles using step-by-step surface-initiated RAFT polymerization. Reprinted with permission from A. Rungta et al., Macromolecules, 2012, 45, 9303-9311. Copyright 2012 American Chemical Society. ${ }^{208}$

nique. ${ }^{208} \mathrm{~A}$ bimodal polymer brush is defined as a homopolymer brush with two distinct lengths of monodispersed chains tethered to a surface. ${ }^{208}$ They initially prepared a first dense polymer brush by surface-initiated RAFT polymerization and cleaved the CTAs in the chain ends. Then, a second RAFT agent was attached onto the silica nanoparticles, and longer chains with less grafting density were polymerized (Fig. 11). ${ }^{208}$ The large population of short chains screened the interparticle attractions, while the small number of long chains enhanced the excluded volume repulsions. The bimodal brush grafted silica nanoparticles showed superior dispersion within a homopolymer matrix, compared with monomodal polymer grafted nanoparticles. ${ }^{208}$ Using this strategy, polymer chains of different lengths can be grown from silica nanoparticles.

The grafting of homopolymers from silica nanoparticles described so far can be extended to the synthesis of block and crosslinkable copolymer chains. In this way, new properties can be added to the hybrid materials and advanced structures formed. For example, silica nanoparticles are well suited as sacrificial templates to fabricate nanocapsules as the silica core can be etched away with HF. Recently, Huang et al. fabricated narrowly distributed hollow polymeric nanocapsules utilizing surface-initiated RAFT block copolymerization from CPDB anchored silica nanoparticles using a similar approach to that already presented in the previous paragraph. ${ }^{206}$ They first grew poly(tert-butyl methacrylate) (PtButMA) from the silica nanoparticle surface, incorporating about $11.5 \%$ of a comonomer, DMIPM. The dimethylmaleimide group in this comonomer can be crosslinked forming dimers under UV illumination. The first PtButMA block was chain extended with a second block, poly(2-hydroxypropyl methacrylamide) (PHPMA), to obtain a water soluble polymeric shell (Fig. 12a). Crosslinking the DMIPM in the inner shell and etching the silica core with HF yielded polymeric nanocapsules. ${ }^{206}$ The 
(a)

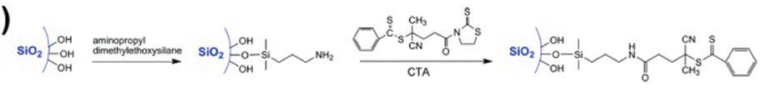

(b)
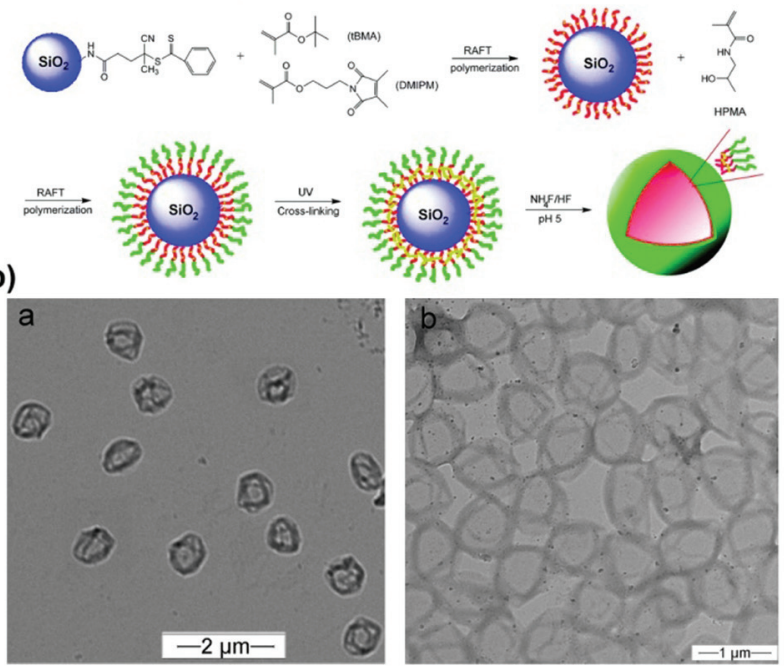

(c)
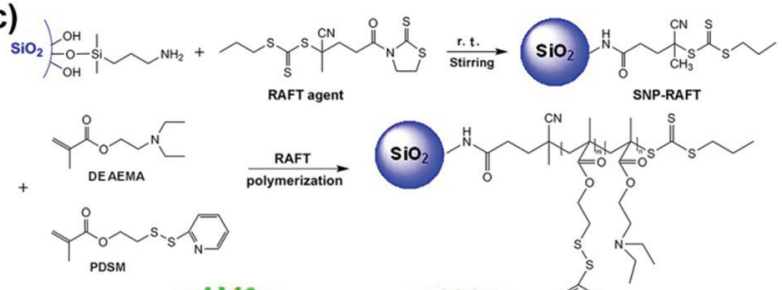

RAFT agent
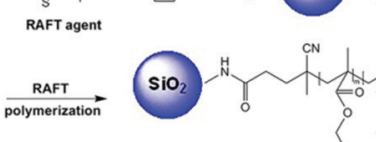

SNP-RAFT

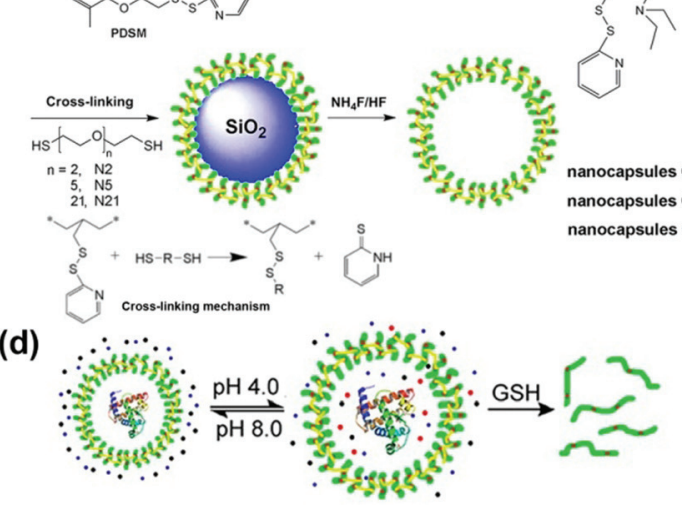

Fig. 12 (a) Schematic illustration of the synthesis of photo-crosslinked nanocapsules. (b) TEM images of $450 \mathrm{~nm}$ (left) and $900 \mathrm{~nm}$ (right) $\mathrm{P}$ (tButMA-co-DMIPM)-b-PHPMA hollow nanocapsules from different silica nanoparticle templates. Reprinted with permission from X. Huang et al., Macromolecules, 2011, 44, 8351-8360. Copyright 2011 American Chemical Society. ${ }^{206}$ (c) General procedure for the synthesis of polymeric nanocapsules with crosslinkers of different lengths. (d) The permeability of the nanocapsule membrane can be tuned by changing the $\mathrm{pH}$. Moreover, the nanocapsules can be biologically degraded using glutathione (GSH) as a reducing agent to cleave the disulfide bonds. Reprinted with permission from X. Huang et al., ACS Nano, 2012, 6, 9718-9726. Copyright 2012 American Chemical Society. ${ }^{209}$

thickness of the nanocapsule wall can be varied by controlling the molecular weight of the grafted polymer. The size of the nanocapsules can also be regulated by using silica nanoparticle templates of different sizes (Fig. 12b). In a similar approach, the authors synthesized a kind of intelligent and biodegradable nanocapsule. ${ }^{209}$ The shell consists of the copolymer P(DEAEMA-co-PDSM). The pH-responsive PDEAEMA is used as a membrane-generating component. The pyridyldisulfide moieties in the PDSM block can be exchanged by reacting with a thiol compound. Correspondingly, these moieties can be crosslinked by reacting with a dithiol crosslinker, forming a robust shell (Fig. 12c). The permeability of the nanocapsule membrane can be tuned by changing the $\mathrm{pH}$ or using crosslinkers of different lengths. ${ }^{209}$ The formed nanocapsules can be biologically degraded, using glutathione (GSH) as a reducing agent to cleave the disulfide bonds (Fig. 12d). ${ }^{209}$ The shells of these formed polymeric nanocapsules can be easily designed during the polymerization process and have a uniform single layer or a multilayer with flexible structures plus an easily tunable permeability, the latter depending on the synthesized polymer blocks. Hence, this approach shows advantages over bilayer membranes formed in polymersomes.

RAFT polymerization from silica nanoparticles has been often combined with click chemistry, especially Huisgen's $\mathrm{Cu}^{\mathrm{I}}$ catalyzed azide-alkyne cycloaddition (CuAAC). Click chemistry has been widely studied and applied in surface functionalization, functional polymer synthesis, supramolecular chemistry, self-assembly, and biology during the last few years underlining its importance in polymer and polymer/nanoparticle hybrid synthesis. ${ }^{221-229}$ Brittain et al. reported the preparation of DMP anchored silica nanoparticles by click coupling alkyne terminated DMP with azide modified silica nanoparticles (Table 2, entry 11). ${ }^{45}$ The grafting density of RAFT agents on the silica nanoparticle surface is 1.2-1.3 RAFT agents per $\mathrm{nm}^{2}$ which is higher than achievable with the other described attaching approaches ${ }^{44,96,97,205,207,208}$ demonstrating the high efficiency of click chemistry.

RAFT agents can be in situ synthesized on the silica nanoparticle surface. Compared to the other two presented approaches for the RAFT agent immobilization, this in situ synthesis has overwhelming advantages in view of its versatility, simplicity, and avoidance of complex purifications, e.g. gel chromatography. In one example, a mixture of $\mathrm{CS}_{2}$ with carbazole c14,215 or phenyl magnesium bromide bas $^{216}$ was added dropwise to chloromethylphenyl functionalized silica nanoparticles, leading to the in situ formation of RAFT agent supported silica nanoparticles (Table 2, entries 12 and 13). Zhu et al. used this approach to synthesize the RAFT agent BCBD directly on silica nanoparticle surfaces (Table 2, entry 12 and Fig. 13a). ${ }^{114}$ Then, they grafted P4VP by surface-initiated RAFT polymerization from the BCBD anchored silica nanoparticles (Fig. 13a). P4VP has been extensively studied because of its capability of coordinating metal ions at the pyridine nitrogen atoms. ${ }^{230-232} \mathrm{Au}^{3+}$ was coordinated to the P4VP chains in aqueous solution and reduced by sodium borohydride $\left(\mathrm{NaBH}_{4}\right)$ or trisodium citrate. In this way, gold nanoparticles with an average diameter of 2.5 or $15 \mathrm{~nm}$, respectively, were formed and embedded in the P4VP brush shell. ${ }^{114}$ The $15 \mathrm{~nm}$ gold nanoparticles supported by P4VP grafted silica showed a very high surface-enhanced Raman scattering (SERS) effect (Fig. 13b). ${ }^{114}$ 
(a)

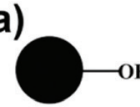

(Bare Silica)
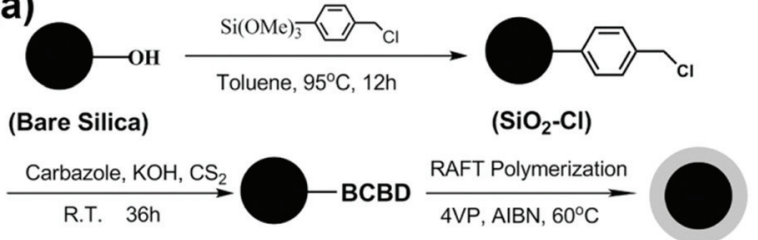

$\left(\mathrm{SiO}_{2}-\mathrm{BCBD}\right)$

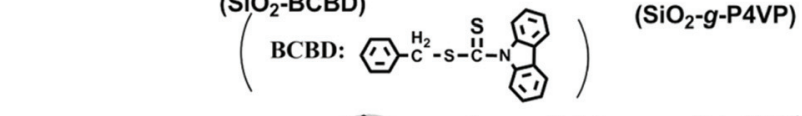

$\left(\mathrm{SiO}_{2}-\mathrm{g}\right.$-P4VP)

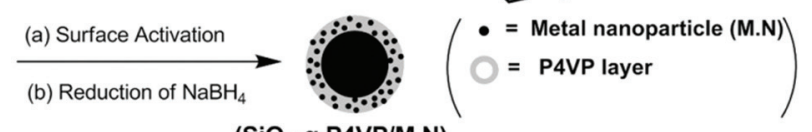

(b)

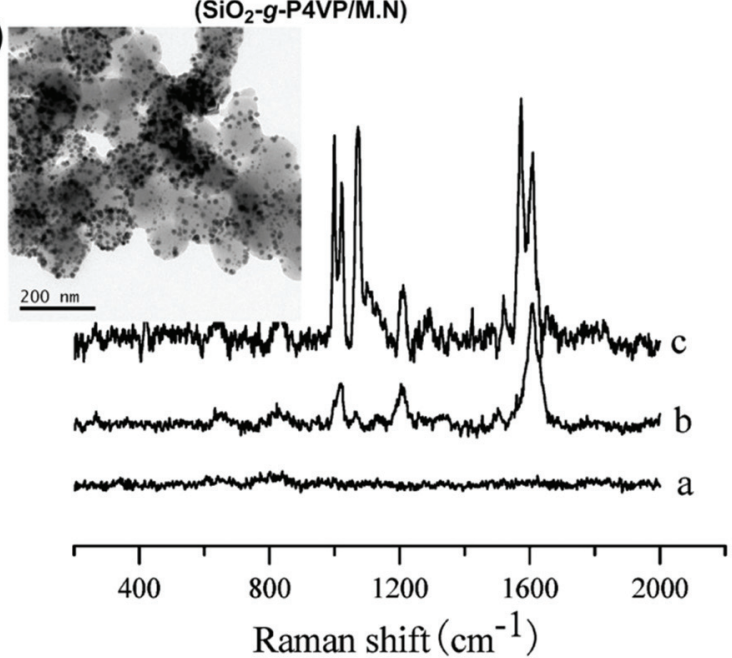

Fig. 13 (a) Schematic illustration for the preparation of core-shell $\mathrm{SiO}_{2}-g$-P4VP nanoparticles with metal nanoparticles embedded in the shell layer. (b) SERS spectra of a, $\mathrm{SiO}_{2}-g$-P4VP nanoparticles; b, $\mathrm{SiO}_{2}-g$ $\mathrm{P} 4 \mathrm{VP} / \mathrm{Au}$ nanoparticles with an average Au diameter of $15 \mathrm{~nm}$; and $\mathrm{c}$, $\mathrm{SiO}_{2}-\mathrm{g}-\mathrm{P} 4 \mathrm{VP} / \mathrm{Au}$ nanoparticles with an average $\mathrm{Au}$ diameter of $15 \mathrm{~nm}$ and adsorbed thiophenol. Inset: TEM image of the $\mathrm{SiO}_{2}-g-\mathrm{P} 4 \mathrm{VP} / \mathrm{Au}$ nanoparticles with an average Au diameter of $15 \mathrm{~nm}$ reduced by trisodium citrate aqueous solution. Reprinted with permission from J. Liu et al., Langmuir, 2010, 26, 14806-14813. Copyright 2010 American Chemical Society. ${ }^{114}$

Perrier and coworkers systematically reported the surfaceinitiated RAFT polymerization from silica particles using the Z-group approach (Table 2, entries 15-18). ${ }^{115-117}$ They functionalized silica particles with CMPS and covalently bound MPPA to the pendant chloride via its Z-group. A series of well-defined homopolymers were then successfully grafted onto the surfaces of MPPA anchored silica particles. ${ }^{115,116}$ It has already been discussed in section 2 that the particles are part of the leaving Z-group in the surface-initiated RAFT polymerization via Z-group approach. As living radicals propagate in the solution, this mechanism is intrinsically more similar to graftingto. Additionally, the authors found that introducing free CTA during polymerization significantly improved the control on molecular weight as well as distribution, and enhanced the grafting efficiency of polymers by improving the control over polymerization in solution and favoring the addition-fragmen- tation onto solid surfaces. ${ }^{43,115,116}$ They also observed that the molecular weight of free and grafted polymers differed much more upon increasing conversion. ${ }^{116}$ This can be explained by a more pronounced shielding effect caused by the longer grafted polymer chains as conversion increases. This effect slows down the polymerization rate surrounding the surface by hindering the diffusion of monomers and active polymer chain radicals, and diminishes the degenerative transfer process onto the polymer dormant chains on the surface. ${ }^{115,116}$ To improve this, one solution is by using a less active free RAFT agent. The propagation of free chains in solution is slow enough to favor addition-fragmentation onto solid surfaces and to adjust comparable polymerization rates in solution and on the surface, thus obtaining well-defined free and grafted polymers. ${ }^{116}$ The highly efficient diblock copolymerization from silica supported macro-CTAs showed strong evidence of living polymeric chains. ${ }^{115}$ The group of Perrier further studied the effect of CTA loading, the type of anchored CTA and free CTA as well as solvent on the polymerization kinetics, molecular weight, and molecular weight distribution of the grafted and free polymers. ${ }^{117}$

\subsection{Surface-initiated NMP from silica nanoparticles}

Table 3 gives a detailed overview of alkoxyamines that were linked to silica nanoparticles using different strategies to initiate the NMP of the listed monomers.

To the best of our knowledge, surface-initiated NMP from solid surfaces such as silica wafers and silica gel particles was reported by Russell and Hawker for the first time. ${ }^{46}$ Two different active alkoxyamines (Table 3 , entry 1 ), named alkoxyamine silanes, were synthesized by sodium hydride $(\mathrm{NaH})$ condensation or Jacobsen catalysis followed by hydrosilylation. The surface-initiated NMP of St showed living character on adding free alkoxyamines to the solution. ${ }^{46}$ The alkoxyamine silanes can also be synthesized by free radical coupling the nitroxides with bromide terminated silanes, making use of the same copper catalyst known from the ATRP system (Table 3, entries $3-5) .{ }^{47,99,234-237,248}$ The surface-initiated NMP from silica nanoparticles has been investigated by several groups not only to graft homopolymers, ${ }^{99,233-237}$ but also a zwitterionic homopolymer ${ }^{47}$ or even copolymers. ${ }^{233,238} \mathrm{P}(\mathrm{St}-c o$-VBCB $)$ and $\mathrm{P}(\mathrm{St}-\mathrm{co}-\mathrm{MAH})$ were surface polymerized from silica nanoparticles followed by crosslinking of the benzocyclobutene and the maleic anhydride by thermal intermolecular coupling or diamine reaction, respectively, to produce robust shells. ${ }^{233}$ Subsequent etching of the silica cores resulted in uniform nanocapsules. ${ }^{233}$ Usually, the grafting density of alkoxyamines is lower than those of initiators used for surface-initiated ATRP, and these differences are related to the steric hindrance caused by the respective structures. ${ }^{98,99}$ In alkoxyamines, two tertiary butyl groups adjacent to the nitroxide group lead to a significantly higher steric hindrance than the bromine atom in ATRP initiators, thus restricting the diffusion of free alkoxyamines to the surface. ${ }^{98}$ Equally, the low initiation efficiency of alkoxyamines for surface-initiated NMP can also be attributed to the high steric hindrance on the surface. ${ }^{99}$ 
Another alternative approach for NMP from silica nanoparticles is to attach activated alkoxyamines to functionalized silica nanoparticles followed by surface-initiated NMP. For example, aminopropylsilane was covalently linked onto silica nanoparticles followed by the grafting of $N$-hydroxysuccinimide (NHS) activated alkoxyamines to the amino functionalized surfaces (Table 3, entry 9). Subsequently, well defined PSt- $g$-silica nanoparticles were obtained by surface-initiated NMP. ${ }^{244}$ In a simple one step procedure, Charleux and coworkers introduced amine modified silica, NHS activated alkoxyamine and the monomer in one pot allowing grafting and chain growth simultaneously at the polymerization temperature of e.g. $120^{\circ} \mathrm{C}$ for St. A high grafting density of up to 0.9 polymer chains per $\mathrm{nm}^{2}$ with high molecular weight polymer chains could be reached. ${ }^{245}$

Moreover, alkoxyamines can be formed in situ on the nanoparticle surface. This route consists of two steps. First, an alkene functionality is covalently linked to silica nanoparticles, e.g. through MPTS condensation. Then, alkoxyamines are formed in situ on the surface by trapping free alkoxyamines ${ }^{246}$ or free initiator radicals/nitroxides (Table 3, entries 10-12). ${ }^{242,247}$ Similarly to this in situ trapping method, an even simpler way exists to obtain surface alkoxyamine initiators in one step. All components are mixed together simultaneously to let the condensation of the functional silane and the trapping reaction of the $\mathrm{C}=\mathrm{C}$ double bond with an alkoxyamine $\mathrm{e}^{243}$ or nitroxide/initiator ${ }^{237,242,243}$ proceed together at the same time.

\subsection{Y-shaped asymmetric initiators for sequential surface- initiated CRP from silica nanoparticles}

Nanoparticles with binary mixed brushes represent a new class of environmentally responsive nanostructured materials. ${ }^{249}$ Two distinct homopolymers are grafted onto the surface which usually provides novel properties to the material due to responsiveness to multi-external stimuli. Generally, different combinations of surface-initiated ATRP, surface-initiated reverse ATRP, surface-initiated RAFT polymerization, surface-initiated NMP, and surface conventional free radical polymerization can be utilized in a grafting-from procedure to fabricate mixed brushes from a surface. ${ }^{102,208,250-254}$ However, this approach has intrinsic disadvantages. Since different species of initiators have to be attached to the substrate simultaneously or sequentially, uncontrollable preferential binding of one species, inhomogeneous distribution of the grafting initiators, and disordered phase separation in whatever scale cannot be avoided. Hence, the homogeneity of grafted polymers is reduced and further applications are limited. To tackle this drawback, novel asymmetric difunctional Y-shaped initiators were designed. ${ }^{255-259}$ The Y-shaped initiator contains two functional initiator units to sequentially initiate surface polymerization together with a functional end group for the attachment to a surface. ${ }^{260}$ The attached Y-shaped initiators self-assemble to a monolayer which affords two different initiating sites alternatively aligned. This ensures good mixing of the different grafted polymers at a molecular level. ${ }^{261}$ There are only several examples of the utilization of Y-shaped initiators for surfaceinitiated CRP from silica nanoparticles in recent years. This approach has been likewise used for the desired binary functionalization of silica wafers and mesoporous silica which will also be included in this subsection. Table 4 shows the structures of the Y-shaped initiators together with the monomers used for the respective CRP technique.

Zhao and coworkers developed the concept of asymmetric difunctional Y-shaped initiators and grafted binary mixed brushes initiated from silica wafers. ${ }^{260}$ The initiator used (Table 4, entry 1 ) contains an ethyl $\alpha$-bromoisobutyrate (EBiB) group to initiate an ATRP of MMA and an alkoxyamine group to start an NMP of St. The initiator was immobilized onto a silica wafer by its functional trichlorosilane group. The ATRP and NMP reactions cannot be performed simultaneously. Moreover, it is important to consider the sequence of the two polymerizations. The activation of ATRP initiators is a bimolecular mechanism, while in NMP, alkoxyamines undergo a unimolecular process initiated by thermal decomposition. ${ }^{57-59,72,74}$ The first grown polymer has less steric hindrance on a unimolecular reaction system favoring to prior perform ATRP. Furthermore, the reaction conditions for ATRP are relatively mild compared to those usually required for NMP. Alkoxyamine groups are stable under the usually used ATRP conditions. ${ }^{253}$ Additionally, the $\mathrm{C}-\mathrm{Br}$ bond in ATRP initiators is weak and can act as a chain transfer agent in the NMP process. ${ }^{260}$ According to all the above considerations, ATRP was performed first, followed by dehalogenation to remove the bromide groups on the polymer chain ends as well as unreacted ATRP initiators, followed by the NMP process. The authors successfully grafted PMMA by surface-initiated ATRP and PSt by surface-initiated NMP from the described asymmetric difunctional initiator. They further studied the effect of polymer chain length of the grafted mixed PMMA/PSt brushes on the responsiveness to different solvents. ${ }^{260,262}$

The same group used similar asymmetric Y-shaped initiators (Table 4, entries 2 and 3) to fabricate mixed polymer brushes from silica nanoparticles. Amphiphilic mixed PAA/PSt grafted nanoparticles were synthesized by sequential surfaceinitiated ATRP of $t$ ButA and NMP of St, followed by hydrolysis of $t$ ButA to AA (Fig. 14a). ${ }^{261} \mathrm{~A}$ free sacrificial initiator was added to well control the polymerization of $t$ ButA with living character under the chosen reaction conditions. This was proven by the almost overlapping GPC spectra of cleaved and free PtButA which have a narrow molecular weight distribution. ${ }^{261}$ Interestingly, the molecular weight of the polymer mixture cleaved from PtButA/PSt- $g$-silica nanoparticles is higher than that of either free PtButA or PSt, but lower than that of the sum of free PtButA and PSt. This clearly shows that the cleaved polymers are a mixture of PtButA, PSt, and PtButA-PSt diblock copolymers initiated from the same Y-initiator. $^{261}$ This finding illustrates the advantage of Y-shaped initiators over a mixture of two separate initiators. From a certain amount of Y-initiators, both polymerizations have been initiated from the same initiator and hence the different grafted polymers are well-mixed on the surface of the 
(a)
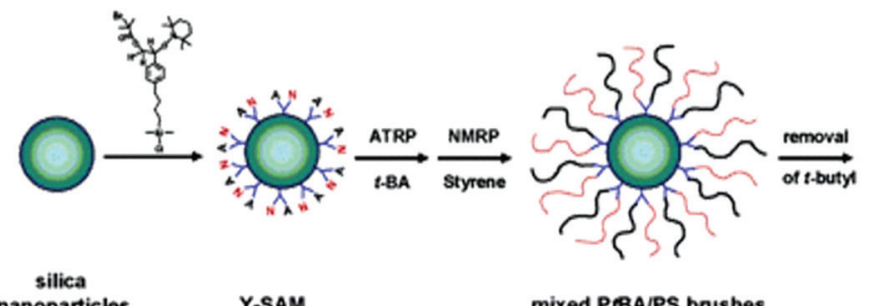

nanoparticles

Y-SAM

mixed PRAMP brushes

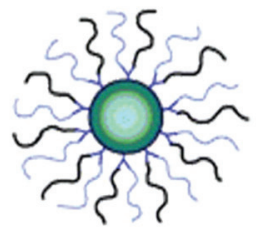

(b)

(c)
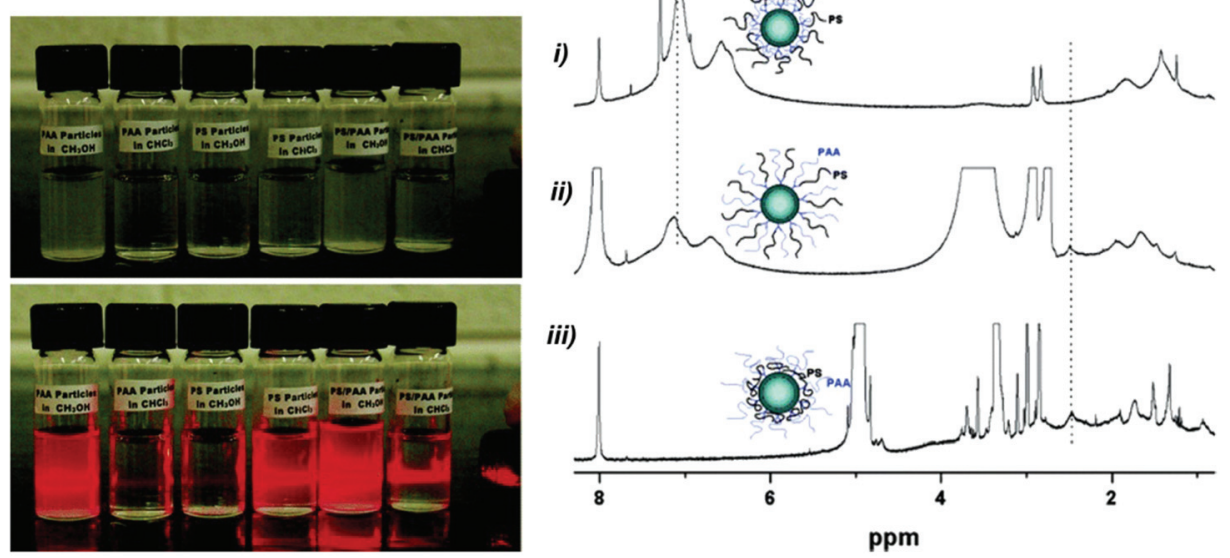

Fig. 14 (a) Synthesis of amphiphilic mixed PAA/PSt brushes on silica nanoparticles. (b) Tyndall light scattering experiments of functionalized nanoparticles in daylight (top) and under laser radiation (bottom): suspensions of PAA-silica nanoparticles are stable in $\mathrm{CH}_{3} \mathrm{OH}$ but not in $\mathrm{CHCl}_{3}$ (left two columns); PSt-silica nanoparticles are not stable in $\mathrm{CH}_{3} \mathrm{OH}$ but stable in $\mathrm{CHCl}_{3}$ (middle two columns); mixed PAA/PSt-silica nanoparticles are stable in both $\mathrm{CH}_{3} \mathrm{OH}$ and $\mathrm{CHCl}_{3}$ (right two columns). (c) ${ }^{1} \mathrm{H}-\mathrm{NMR}$ spectra of PAA/PSt-silica nanoparticles dispersed in i) $\mathrm{CDCl}_{3}$, ii) $D M F-\mathrm{d}_{7}$, and iii) $\mathrm{CD}_{3} \mathrm{OD}$; the scheme shows the reorganization of the PAA/PSt mixed brushes when exposed to different solvents. Reprinted with permission from D. Li et al., J. Am. Chem. Soc., 2005, 127, 6248-6256. Copyright 2005 American Chemical Society. ${ }^{261}$

nanoparticles. Moreover, after hydrolyzing the ester group in the cleaved Y-initiators, homo PSt chains were extracted from the polymer mixture. The GPC analysis showed that the molecular weight of grafted PSt is essentially equal to that of free PSt. This confirms the livingness of the surface-initiated NMP and the controllability that was achieved by adding free alkoxyamines. The obtained nanohybrids could be dispersed well in many solvents which exclusively dissolve PSt or PAA initially, demonstrating the reorganization of attached polymer chains in response to external stimuli (Fig. 14b and c). ${ }^{261}$ Moreover, with casting and annealing, microphase separations of the mixed PtButA/PSt brushes on the nanoparticle surface were observed such as laterally rippled structures, ${ }^{255,263-266}$ micellar structures, ${ }^{255,264,265}$ and truncated wedge-shaped structures. $^{256,267}$ The phase separation behavior is dominated by many factors, e.g. solvent selectivity, ${ }^{264}$ molecular weight, ${ }^{263,264}$ polymer chain disparity, ${ }^{255,265}$ chain grafting density, ${ }^{255,266}$ and silica nanoparticle size which affects the surface curvature. ${ }^{267}$

Several further examples of the use of Y-shaped initiators demonstrate the applicability of the approach also to other combinations of polymerization techniques like ROP with $\mathrm{NMP}^{257,258}$ or ATRP with RAFT. ${ }^{259}$ The combination of ROP and NMP even allows performing the two polymerizations simultaneously. Brittain et al. synthesized a Y-shaped initiator containing an alkoxyamine group to initiate NMP and a benzyl chloride group for ROP (Table 4, entry 4). ${ }^{257}$ NMP of St proceeds via a free radical addition mechanism, while ROP of PhOXA undergoes a cationic ring-opening mechanism. ${ }^{268,269}$ These two processes proceed independently without intervening each other. The Y-shaped initiator was attached to a silica wafer surface, and binary mixed homopolymer brushes of PSt and poly(2-phenyl-2-oxazoline) (PPhOXA) were synthesized simultaneously. Another Y-shaped initiator having a hydroxyl group for surface-initiated ROP and an alkoxyamine for surface-initiated NMP was utilized to functionalize silica nanoparticles, and PCL/PSt mixed brushes were fabricated at the same time (Table 4, entry 5). ${ }^{258}$ Mesoporous silica nanoparticles (MSN) have attracted much attention in life sciences. The large number of pores in the structures and dual-functional surfaces (exterior and interior) provide a potential platform for drug loading and release, especially when the mesoporous nanoparticles contain precisely attached polymers. The attachment of two or multiple polymers to the exterior and interior surfaces not only provide an enhanced stability when exposed to a biological environment, but also render the surface responsive to external stimuli, hence creating smart nanodevices. Huang et al. reported a novel Y-shaped initiator (Table 4, entry 6) to functionalize the exterior surface of mesoporous silica with bi-functional polymers via 


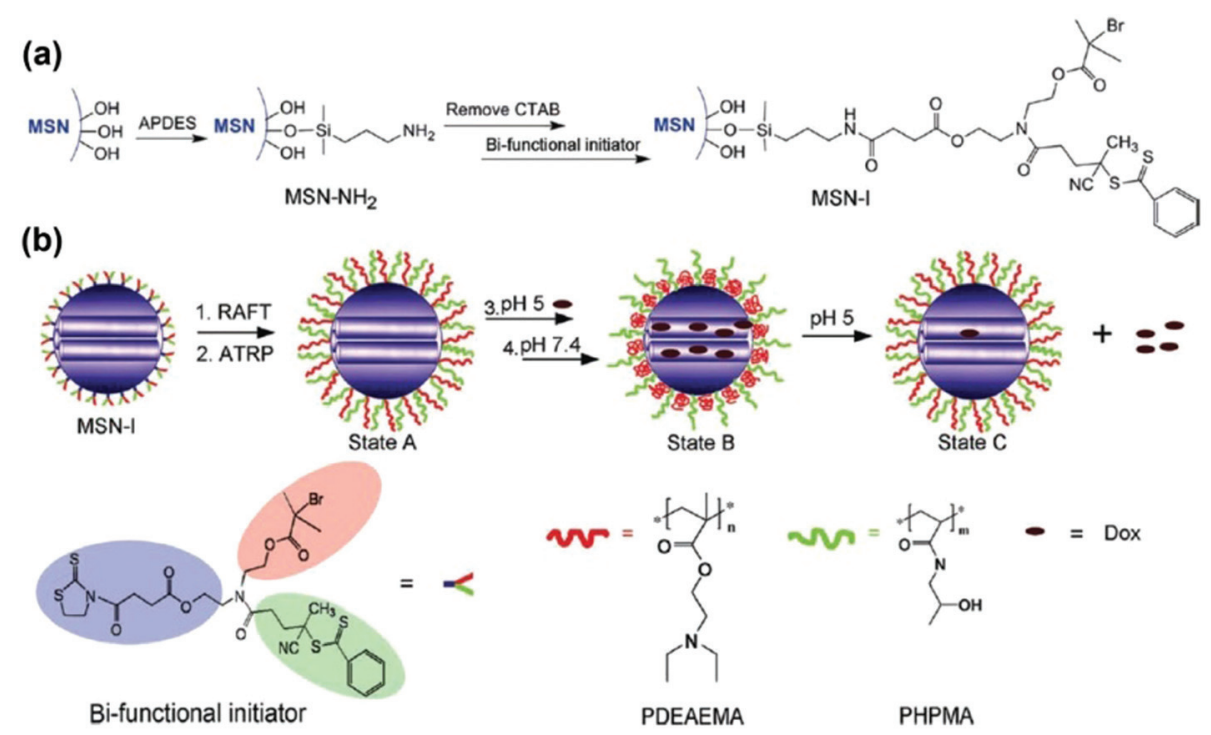

Fig. 15 (a) Linkage of a bi-functional asymmetric initiator to mesoporous silica nanoparticles and the general procedure to functionalize MSN independently with PHPMA and PDEAEMA. (b) Illustration of the use of these nanocarriers for the uptake and release of doxorubicin (Dox). Reprinted with permission from X. Huang et al., Small, 2012, 8, 3579-3583. Copyright 2012 Wiley-VCH. ${ }^{259}$

sequential surface-initiated RAFT and ATRP to fabricate smart drug carriers. ${ }^{259}$ The Y-shaped initiator consists of a CPDB end group for surface-initiated RAFT polymerization of HPMA and an EBiB functionality for surface-initiated ATRP of DEAEMA (Fig. 15a). Since the radicals generated during ATRP would also initiate a RAFT process by chain transfer, RAFT should be initiated prior to ATRP and deactivated by radical coupling. ${ }^{259}$ The interior mesopores act as channels to store the target substance, while the grafted water soluble PHPMA chains on the exterior surface stabilize the nanostructures. The $\mathrm{pH}$-dependent gatekeeper for the drug loading and release are the PDEAEMA chains on the exterior surface. In acidic solution, the PDEAMEA is positively charged, becomes hydrophilic, and opens the mesoporous silica core. Oppositely, in basic solution, the neutralized PDEAEMA chains turn hydrophobic and shrink on the surface closing the pores. The general process of the drug uptake and release is illustrated in Fig. 15b.

\section{Gold nanocrystals}

During the last few decades, gold nanocrystals, especially gold nanoparticles and gold nanorods, have attracted intense interest in diverse fields such as nanoelectronics, nanophotonics, nanosensors, catalysis, and biomedicine, because of their unique optical, electrical, catalytic, and chemical properties. ${ }^{11-15}$ Many methods have been reported on the synthesis of gold nanocrystals with different diameters, shapes, and surface properties. ${ }^{270-279}$ Generally, gold nanocrystals can be easily obtained with high reproducibility. However, although a mono- or multilayer of small molecular ligands like citrate, cetyltrimethylammonium bromide (CTAB), or amino acids are adsorbed on the nanocrystal surface, gold nanocrystals often cannot maintain their original colloidal stability and optical properties accompanied by irreversible aggregation in a wide range of solvents, temperature, $\mathrm{pH}$ or ionic strength. Hence, surface functionalization of gold nanocrystals is crucial for further applications. Gold nanocrystal surfaces have been modified with many kinds of inorganic/organic compounds such as metallic shells, ${ }^{279}$ silica coatings, ${ }^{280-282}$ gelatins, ${ }^{283}$ supramolecular hosts, ${ }^{284-288}$ DNAs, ${ }^{289-291}$ proteins, ${ }^{292,293}$ polypeptides,${ }^{294}$ dendrimers, ${ }^{295-297}$ liquid crystals, ${ }^{298-303}$ resins,${ }^{304}$ and especially polymers. ${ }^{35,305,306}$

Since the discovery in 1718 that starch could stabilize water soluble gold particles, it has been well known that polymers can stabilize gold nanocrystal dispersions. ${ }^{307,308}$ After recent developments in polymer science, there has been a thriving research area about polymer surface-modified gold nanocrystals, mainly gold/polymer core/shell nanocomposites. Compared to other kinds of attached ligands, polymers have many overwhelming advantages arising from their original chemical and structural properties. Polymer chains provide a certain steric shielding which helps to produce gold nanocrystals with high stability in solution. ${ }^{309-313}$ When the outer polymer shell is crosslinked, the stability of the nanocrystals is typically even more enhanced, especially at elevated temperatures. ${ }^{22,314,315}$ Besides providing stability, the bound polymer chains can act as functional scaffolds to self-assemble the gold nanocrystals into superstructures, e.g. ordered arrays at water/liquid or liquid/liquid interfaces, ${ }^{35,316,317}$ plasmonic strings, ${ }^{30,304,306,318}$ and plasmonic vesicles. ${ }^{319-321}$ When responsive or amphiphilic polymers are attached onto gold nanocrystals, the resultant composites show stimulus properties in response to changes of $\mathrm{pH},{ }^{322,323}$ ionic strength, ${ }^{35}$ temperature, ${ }^{23,36,312,313,322,324-326}$ 
or solvent..$^{316,327,328}$ Interestingly, a protective polymer layer with tunable permeability can also trap and release target molecules, which was applied for selective catalysis ${ }^{329,330}$ and showed a reversible SERS effect. ${ }^{331}$

Many approaches have been studied to fabricate gold/ polymer core/shell nanocomposites which can be roughly categorized as grafting-to, the in situ sol-gel process, graftingthrough, and grafting-from. As discussed in the Introduction, surface-initiated polymerization, as a grafting-from method, has several significant advantages over other surface functionalization techniques. Compared to grafting-to and in situ sol-gel process, the grafting density is considerably higher which is important for the stability and further applications of gold nanocrystals. Contrary to grafting-through, polymer chains can be obtained with a narrow molecular weight distri- bution, versatile functionalities, and various complex architectures. Many studies have been carried out on growth of polymers from gold nanocrystals by ROMP, ${ }^{332,333}$ living cationic polymerization, ${ }^{334}$ and CRP techniques. Herein, we give several examples of surface-initiated ATRP and surfaceinitiated RAFT polymerization from gold nanocrystals. Table 5 shows the structures of several functional ATRP initiators and one RAFT agent together with the monomers used for the respective surface-initiated CRP technique.

To the best of our knowledge, surface-initiated ATRP from gold nanoparticles was first studied by Hallensleben and coworkers. ${ }^{309}$ They anchored DTBU (Table 5, entry 1 ) onto dodecanethiol stabilized gold nanoparticles by ligand exchange. Subsequently, PnButA was successfully grown on the gold nanoparticle surface under traditional ATRP conditions. Walt

Table 5 Functional ATRP initiators and RAFT agent employed for surface-initiated CRP from gold nanocrystals ${ }^{a, b}$

\begin{tabular}{|c|c|c|c|}
\hline Entry & Linkage of ATRP initiators or RAFT agents & Attachment method & Monomer $(\mathrm{s})^{c}$ \\
\hline 1 & & Ligand exchange & $n$ ButA, ${ }^{309}$ MMA $^{317,335,336}$ MBAA, ${ }^{23,337}$ \\
\hline 2 & & Coupling & $\begin{array}{l}\text { NIPAM, }{ }^{23,337-339} 4 \mathrm{VP}^{323,340},^{341} \text { DMAEMA }^{341} \\
\text { DEAEMA, } \\
\text { PEGMMA, }^{341} \mathrm{tButA}^{335},{ }^{23} \\
\text { MMA }^{311}\end{array}$ \\
\hline 3 & & Condensation & $\mathrm{MMA}^{342}$ \\
\hline 4 & & $\begin{array}{l}\text { Sodium borohydrate }\left(\mathrm{NaBH}_{4}\right) \\
\text { reduction with DTBU }\end{array}$ & $n$ ButA $^{22}$ EGDMA $^{22}$ DSEDMA, ${ }^{22}$ MMA $^{310}$ \\
\hline 5 & & Ligand exchange & $\begin{array}{l}\text { DMAEMA, }{ }^{341} \text { DEAEMA, }{ }^{316,341} \text { PEGMMA, } \\
\text { MMA }^{316,319,343} 4 \mathrm{VP},{ }^{319,343}\end{array}$ \\
\hline 6 & & Coupling & OEGMMA,${ }^{24}$ DEGMMA $^{24}$ \\
\hline 7 & & Ligand exchange & HEMA $^{344}{ }^{\text {OEGMMA }}{ }^{344}$ \\
\hline 8 & & Coupling & NIPAM $^{345}$ \\
\hline
\end{tabular}

${ }^{a}$ Abbreviations: DTBU, 11,11'-dithiobis[1-(2-bromo-2-methylpropionyloxy)undecane]; DTBE, 2,2'-dithio-bis[1-(2-bromo-2-methylpropionyloxy)ethane]; ssDNA, single-stranded DNA; MUD, 11-mercaptoundecanol; BSA, bovine serum albumin; HAuCl ${ }_{4}$, chloroauric acid. ${ }^{b} \mathrm{Gray}$ spheres represent silica nanoparticles, and red spheres gold nanocrystals. ${ }^{c}$ For full names and structures of the monomers, refer to Fig. 1. 
et al. reported the surface-initiated ATRP of MMA from gold nanoparticles at room temperature. ${ }^{311}$ The gold nanoparticles were synthesized with MUD as the ligand and subsequent esterification with $\mathrm{BiBB}$ attached the ATRP initiator to the surface (Table 5, entry 2). ${ }^{311}$ Moreover, in another example, the authors pre-formed a crosslinked silica primer layer on the gold nanoparticle surface by adsorbing a monolayer of 3-mercaptopropyltrimethoxysilane (MPTES) followed by the hydrolysis with hydrochloric acid $(\mathrm{HCl})$. The silica layer not only protected the gold core, but also enabled the further condensation of CMPES which initiated ATRP of MMA at elevated temperatures (Table 5, entry 3). ${ }^{342}$ Matyjaszewski's group utilized a one-pot surface-initiated ATRP to fabricate a crosslinked polymer shell and linear tethered polymer brushes from gold nanoparticles (Table 5 , entry 4). ${ }^{22}$ To accomplish this requirement, a two-step monomer addition was adopted (Fig. 16a). First, a crosslinker, EGDMA or DSEDMA, was added with a small amount of the vinyl monomer $n$ ButA. Because of different monomer reactivities, the crosslinkable monomer was consumed faster and preferentially polymerized into the inner layer. The subsequent addition of further $n$ ButA formed

(a)

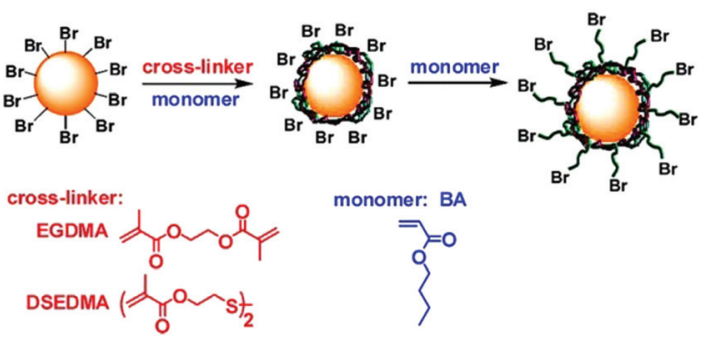

(b)
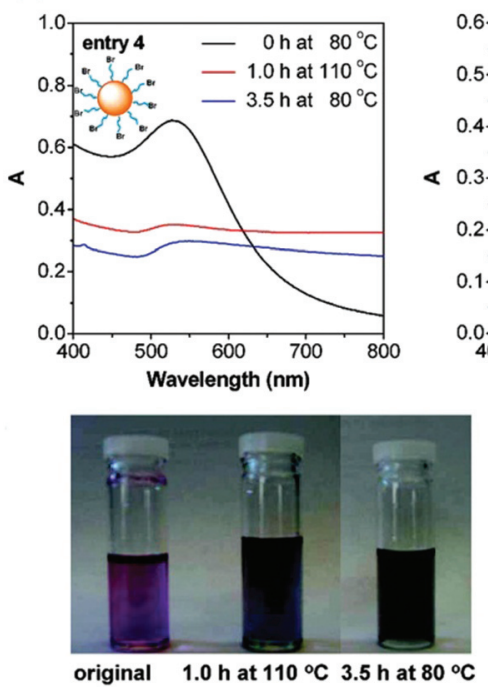
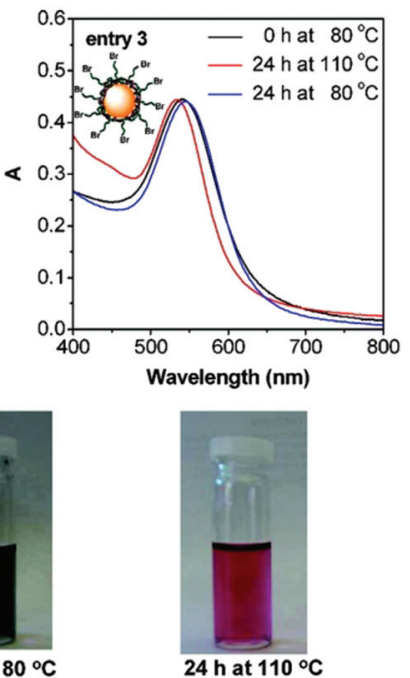

Fig. 16 (a) One-pot synthesis of robust core/shell gold nanoparticles stabilized by a crosslinked inner shell and well-defined tethered polymer brushes. (b) UV-Vis spectra and appearances of (left) Au-NPs modified with linear PBA brushes and (right) with a crosslinked shell and tethered PnButA brushes in toluene at $80^{\circ} \mathrm{C}$ and in DMF at $110{ }^{\circ} \mathrm{C}$ for various times. Reprinted with permission from H. Dong et al., J. Am. Chem. Soc., 2008, 130, 12852-12853. Copyright 2008 American Chemical Society. ${ }^{22}$ linear PnButA brushes in the outer layer. The crosslinked shell protected the gold nanoparticles from dissociation at high temperature which linear polymer brushes cannot achieve (Fig. 16b). ${ }^{22}$ Not only functional ATRP initiators, but also RAFT agents were attached onto gold nanoparticles to surfaceinitiate polymerizations. Tenhu et al. attached a RAFT agent, CPDB, onto MUD stabilized gold nanocrystals (Table 5, entry 8). Then, NIPAM was polymerized from the CPDB anchored gold nanocrystals via the R-group approach. ${ }^{345}$

Polymeric layers not only provide gold nanoparticles with good dispersibility and stability, but can also provide the gold nanocomposites with stimulus properties by choosing adequate polymers. Several examples have been described by $\mathrm{Li}$ et al. for the fabrication of thermoresponsive polymer/gold nanoparticle hybrids by surface-initiated ATRP (Table 5, entry 1). A series of thermoresponsive PNIPAM with different feeds of MBAA was synthesized from $18 \mathrm{~nm}$ gold nanoparticles by surface-initiated ATRP in i-PrOH/water, $1 / 1 \mathrm{v} / \mathrm{v}$ (Fig. 17a). ${ }^{337}$ Slight crosslinking by MBAA occurred during the polymerization on the gold nanoparticle surface which resulted in stable core/shell gold/polymer nanohybrids. Compared with a shell composed of linear PNIPAM, the crosslinked copolymer shell took up more space as observed by TEM, showing that the incorporation of the crosslinker MBAA can influence the network of the outer shell (Fig. 17b). ${ }^{337}$ Meanwhile, dual thermoresponsive shells containing linear homo PNIPAM and NIPAM/OEGMMA copolymers were grafted from gold nanoparticle surfaces via a consecutive one-pot multistage surfaceinitiated ATRP in a mixture of i-PrOH/water, $1 / 1 \mathrm{v} / \mathrm{v}$ (Fig. 17c). ${ }^{23}$ The first inner block PNIPAM was polymerized directly giving an $M_{\mathrm{n}}$ of $16000 \mathrm{~g} \mathrm{~mol}^{-1}$. After that, the second monomer OEGMMA was added without purification resulting in NIPAM and OEGMMA copolymers as the second block with an $M_{\mathrm{n}}$ of $29000 \mathrm{~g} \mathrm{~mol}^{-1}$. DLS and surface plasmon resonance (SPR) characterization showed two distinct thermoresponsive transitions at 33 and $55{ }^{\circ} \mathrm{C}$, which correspond well with the conformation transitions of inner PNIPAM and outer POEGMMA containing copolymer, respectively. ${ }^{23}$ Fig. $17 \mathrm{~d}$ shows the schematic illustration of the dual thermoresponsive collapse phase transitions of the block copolymer/gold nanoparticles. ${ }^{23}$ Finally, thermoresponsive PNIPAM brushes were also successfully polymerized from gold nanoparticles in aqueous solution $^{338}$ or gold nanorods in DMF/water, v/v 1/1 (Table 5, entry 1). ${ }^{339}$

$\mathrm{pH}$-Responsive gold nanocomposites were fabricated using surface-initiated ATRP of 4VP from gold nanoparticles under ambient conditions (Table 5, entry 1$)^{340}$ and the pH-responsive properties were systematically investigated. ${ }^{323}$ At low $\mathrm{pH}(<3.1)$, the pyridine groups were protonated and therefore positively charged. Consequently, the grafted polymer chains were stretched by electrostatic repulsion forces rendering the polymer layer strongly swollen with a zeta potential higher than $30 \mathrm{mV}$. As the $\mathrm{pH}$ increased up to 4.0, the P4VP chains transferred into a shrunken state originating from the deprotonation of the pyridine groups. At that state, the polymer chains were wrapped tightly around the gold nanoparticles, leading to 
(a)

(b)

(c)

(d)
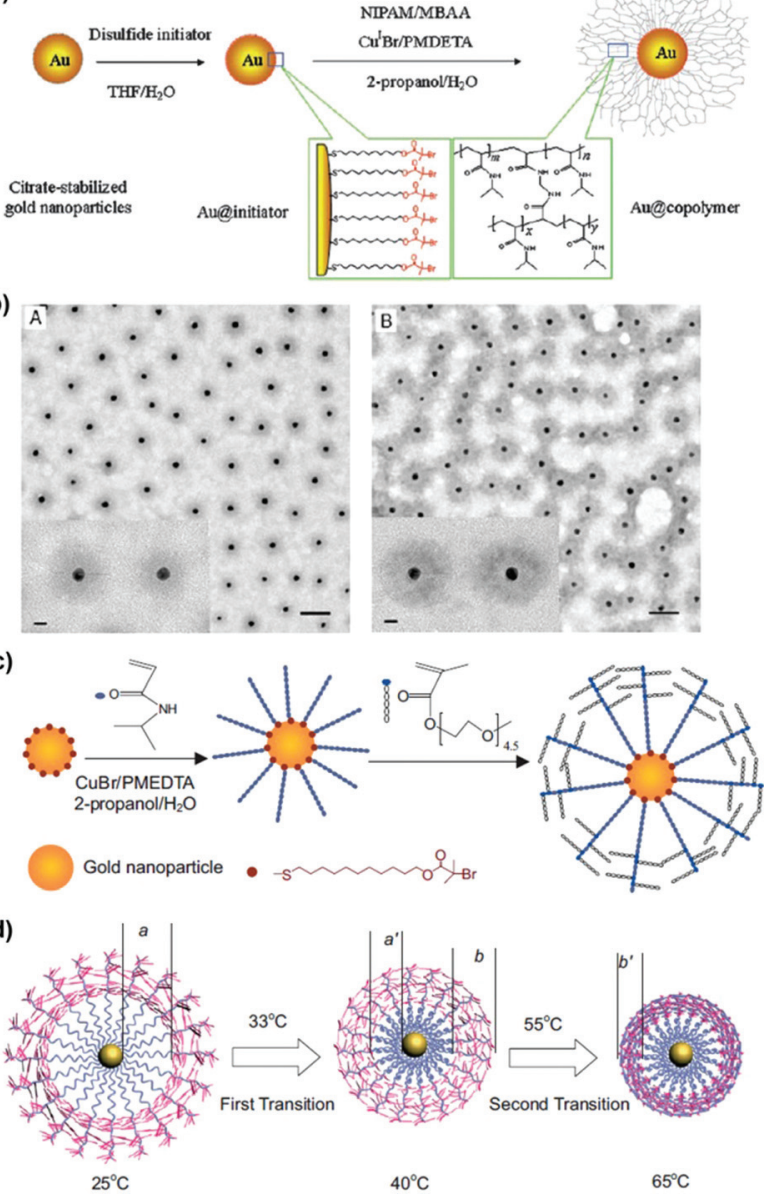

Fig. 17 (a) Scheme of the fabrication of PNIPAM from MBAA/gold nanoparticle hybrids by surface-initiated ATRP. (b) TEM images of copolymer/gold hybrids with (A) 0\% MBAA and (B) 1\% MBAA dispersed in water; scale bars: $100 \mathrm{~nm}$. Insets: images at a higher magnification, scale bars: $20 \mathrm{~nm}$. Reprinted with permission from D. Li et al., Chem. Eur. J., 2007, 13, 2224-2229. Copyright 2007 Wiley- $\mathrm{VCH}^{337}$ (c) Scheme of the fabrication of gold nanoparticles with dual thermoresponsive shells containing linear homo PNIPAM and NIPAM/OEGMMA copolymers via a consecutive one-pot multistage surface-initiated ATRP. (d) Schematic illustration of the thermoresponsive size changes of copolymer/gold nanoparticles. The thickness of the inner layer, a, at $25^{\circ} \mathrm{C}$ changes to a' at $40^{\circ} \mathrm{C}$ above the first transition point, and the thickness of the outer layer, $\mathrm{b}$, at $40^{\circ} \mathrm{C}$ changes to $\mathrm{b}^{\prime}$ at $65^{\circ} \mathrm{C}$ above the second transition point. Reprinted with permission from D. Li, et al., Adv. Funct. Mater., 2007, 17, 3134-3140, Copyright 2007 Wiley-VCH. ${ }^{23}$

a decrease in size and zeta potential. At $\mathrm{pH}$ higher than 5.5, the zeta potential drastically decreased to neutral. At this point, the colloidal particles aggregated to form large structures. The pH-responsiveness of the $\mathrm{P} 4 \mathrm{VP} /$ gold nanocomposites is illustrated schematically in Fig. 18. Corresponding to the two transitions, the SPR of the gold nanoparticle hybrids shows a two-stage red shift which is ascribed to the polymer collapse and particle agglomeration, respectively. ${ }^{323}$ Other pH-responsive monomers, e.g. DMAEMA, DEAEMA, and PEGMMA, have been used for surface-initiated ATRP by Duan

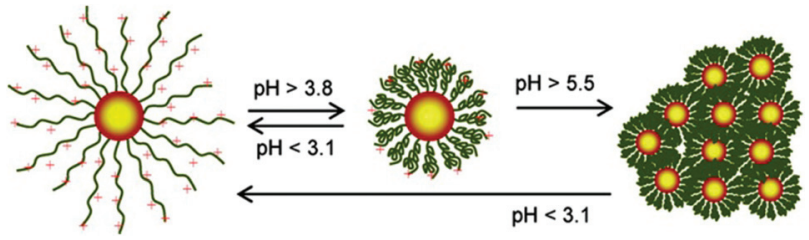

Fig. 18 Scheme of the pH-responsive morphology change of the $\mathrm{P} 4 \mathrm{VP} /$ gold nanocomposites. The polymer chains are branched, and the whole particles are monodispersed and nonaggregated at low $\mathrm{pH}(<3.1)$; the polymer chains collapse onto the gold cores, but the whole particles are also monodispersed in a middle $\mathrm{pH}$ range (3.8-4.4); the whole particles agglomerate at higher $\mathrm{pH}(>5.5)$. Reprinted with permission from D. Li et al., Macromolecules, 2008, 41, 7254-7256. Copyright 2008 American Chemical Society. ${ }^{323}$

and coworkers (Table 5, entry 5). ${ }^{341}$ A series of pH-responsive capsules ranging from 40 to $300 \mathrm{~nm}$ was fabricated by first selectively crosslinking the DMAEMA moiety with 1,2-bis(2iodoethoxy)ethane (BIE) in the polymer shell and subsequently etching the gold nanoparticle template with potassium cyanide (KCN). ${ }^{341}$

A protein is a natural macromolecule whose 20 different amino acid residues introduce many kinds of polar or nonpolar, anionic or cationic moieties. Based on different chemical compositions and conformations, proteins exhibit varying physical and chemical properties, e.g. solubility, different isoelectric points (pI), and changeable denaturation and gelation temperatures. The combination with gold nanoparticles renders the nanoparticles responsive to $\mathrm{pH}$, ionic strength, solvent and/or heavy metals. ${ }^{292}$ A novel kind of dual pH- and thermoresponsive gold nanocomposite based on protein/ polymer conjugate systems was synthesized via surfaceinitiated ATRP of OEGMMA and DEGMMA from protein coated gold nanoparticles by the group of Liz-Marzán (Table 5 , entry 6). ${ }^{24}$ First, gold nanoparticles with different sizes and ligands, i.e. $15 \mathrm{~nm}$ with stabilizing citrate and $60 \mathrm{~nm}$ gold nanoparticles with CTAB, were synthesized. BSA was strongly bound with its thiol/disulfide and amine groups to the gold nanoparticle surfaces via ligand exchange forming a robust coating. Afterwards, free amine groups, mainly from the lysine residues in BSA, were utilized to covalently link the ATRP initiator BiBB followed by surface-initiated ATRP of OEGMMA and DEGMMA yielding random copolymer brushes. TEM images reveal individual nanoparticles with an organic layer of 3-4 $\mathrm{nm}$ in the dry state (Fig. 19a). ${ }^{24}$ The polymer/protein coated gold nanocomposites exhibited a wide range of $\mathrm{pH}^{-}$ dependent thermoresponsiveness as visualized in Fig. 19b and c. ${ }^{24}$ At high pH, pH > pI (BSA), the nanoparticles were negatively charged. At temperatures $T<$ LCST, the polymer brush was hydrophilic and stretched (upper left in Fig. 19b), while at $T>$ LCST, the polymer brush was collapsed (lower left in Fig. 19b). For both cases, the nanohybrids did not aggregate due to the electrostatic stabilization stemming from the negatively charged protein layer. At $\mathrm{pH} 10$, the plasmon peaks in UV-vis-NIR spectra of copolymer/BSA/Au15 (i in Fig. 19c) and 
(a)

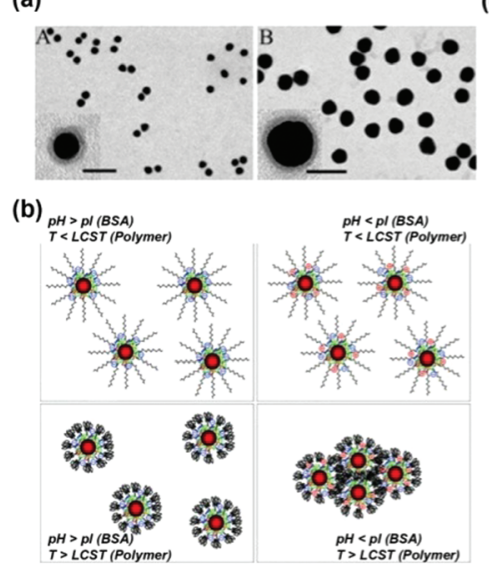

(c)
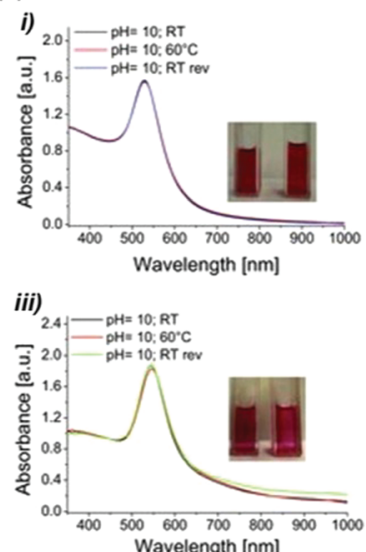
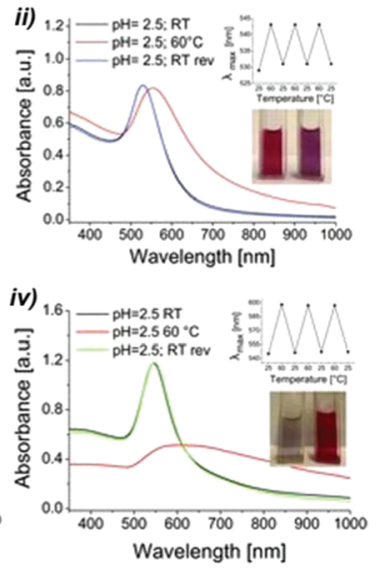

Fig. 19 (a) TEM images of BSA-coated gold nanoparticles grafted with P(DEGMMA-CO-OEGMMA) brushes, in which the ratio of DEGMMA to OEGMMA is $85: 15$. Au15@BSA@copolymer nanoparticles (left), the scale bar represents $100 \mathrm{~nm}$ for the image and $20 \mathrm{~nm}$ for the inset; Au60@BSA@ copolymer nanoparticles (right), the scale bar represents $200 \mathrm{~nm}$ for the image and $50 \mathrm{~nm}$ for the inset. Schematic illustration (b) and UV-vis-NIR spectra with photographs (c) of the $\mathrm{pH}$-dependent thermoresponsive behavior of the BSA-coated 15 or $60 \mathrm{~nm}$ gold nanoparticles grafted with P(DEGMMA-co-OEGMMA) brushes. Reprinted with permission from M. S. Strozyk et al., Adv. Funct. Mater., 2012, 22, 1436-1444. Copyright 2012 Wiley- $\mathrm{VCH}^{24}$

copolymer/BSA/Au60 (iii in Fig. 19c) are centered at $525 \mathrm{~nm}$ and $540 \mathrm{~nm}$, respectively, for temperatures below and above the LCST, indicating the presence of well separated nanoparticles in a wide temperature range. However, during the ATRP initiator attachment, the residual amine groups in BSA were consumed and only carboxylic groups remained. Therefore, at low $\mathrm{pH}, \mathrm{pH}<\mathrm{pI}$ (BSA), the nanoparticles carried nearly no net charge. At $T<$ LCST, the polymer brush was hydrophilic and stretched, conferring steric stability to the nanoparticles (upper right in Fig. 19b). In contrast, at $T>$ LCST, the polymer brush was collapsed and reversible aggregation of the nanoparticles occurred due to the lack of electrostatic repulsion and increased hydrophobic interactions (lower right in Fig. 19b). UV-vis-NIR spectra and photographs show the reversible thermoresponsive behavior of copolymer/BSA/Au15 (ii in Fig. 19c) and copolymer/BSA/Au60 (iv in Fig. 19c) between $T<$ LCST (RT) and $T>\operatorname{LCST}\left(60^{\circ} \mathrm{C}\right)$ at $\mathrm{pH}$ 2.5. Such aggregation can be visually observed through the color change due to plasmon coupling between gold nanoparticles. The process was completely reversible and can be repeated multiple times (graph insets ii and iv in Fig. 19c). These stimulus responsive nanocomposites are a new kind of smart responsive material which can be conjugated with functional biological proteins for drug delivery and diagnostic systems. In another report, a DNA supported ATRP initiator was synthesized and attached to gold nanoparticle surfaces (Table 5, entry 7). ${ }^{344}$ From this gold-ssDNA-Br macroinitiator, surface-initiated ATRP of HEMA or OEGMMA was performed. ${ }^{344}$ Compared to only DNA conjugated gold nanoparticles, the presence of thick polymer shells improved the stability and broadened the applications of DNA biosensing.
Using sequential grafting-to and grafting-from steps, amphiphilic mixed brushes were grafted on gold nanocrystal surfaces. The resultant hybrid structures have been widely studied experimentally and theoretically. ${ }^{316,319,335,336,343,346}$ For example, hydrophilic thiol-poly(ethylene glycol) (thiol-PEG) was first attached to gold nanoparticles or nanorods simultaneously with the initiator DTBE (Table 5, entry 5), followed by surface-initiated ATRP of MMA or DEAEMA (Fig. 20a). ${ }^{316}$ The pre-attached PEG chains stabilized the gold nanocrystals during further reaction steps. This integrated grafting-to and surface-initiated ATRP method allows varying combinations of polymers for fabricating different mixed brushes tethered on gold nanocrystals, e.g. PEG/PDEAEMA, PEG/PMMA or PEG/ $\mathrm{P}(\mathrm{MMA}-\mathrm{co}-4 \mathrm{VP}) .{ }^{316,319,343}$ Upon $\mathrm{pH}$, temperature or solvent induction, the fabricated nanocomposites can be assembled into stimulus responsive plasmonic superstructures, e.g. reversible 2-D arrays on interfaces (Fig. 20b and c) ${ }^{316}$ or plasmonic vesicular nanostructures (Fig. 20d and e). ${ }^{319}$ For nanoparticles coated with mixed PEG/P(MMA-co-4VP) brushes, vesicular assemblies with a hollow cavity were formed that were disrupted through the hydrophobic-to-hydrophilic transition of the $4 \mathrm{VP}$ blocks under acidic conditions. ${ }^{319,343}$ Thus, the plasmonic assemblies can serve as a drug carrier, allowing for efficient cargo loading and release. ${ }^{343}$ Moreover, the selfassembled plasmonic vesicles exhibited significantly different plasmonic properties and greatly enhanced SERS intensity in comparison with single gold nanoparticles, because of the strong interparticle plasmon coupling. The disassembly of these vesicles during the drug release generated independent optical feedback which can be easily traced by plasmonic imaging and SERS spectroscopy. ${ }^{343}$ 
(a)

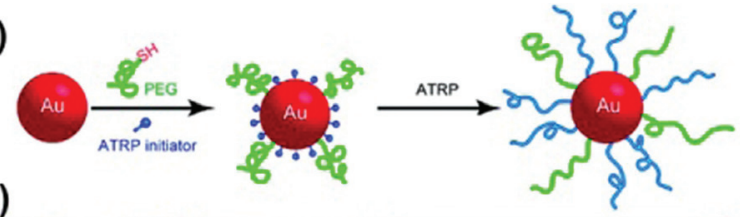

(b)
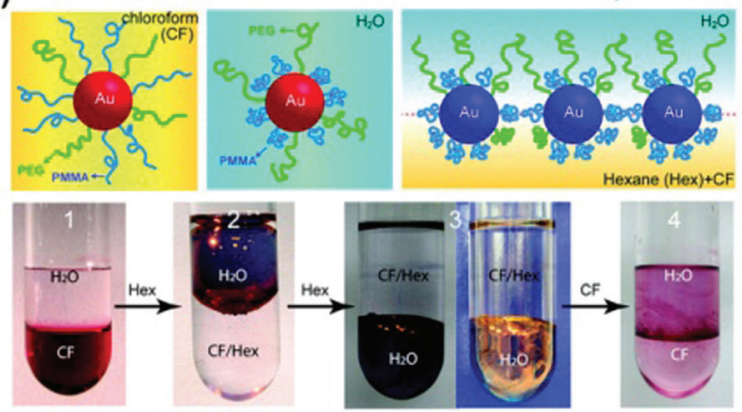

(c)
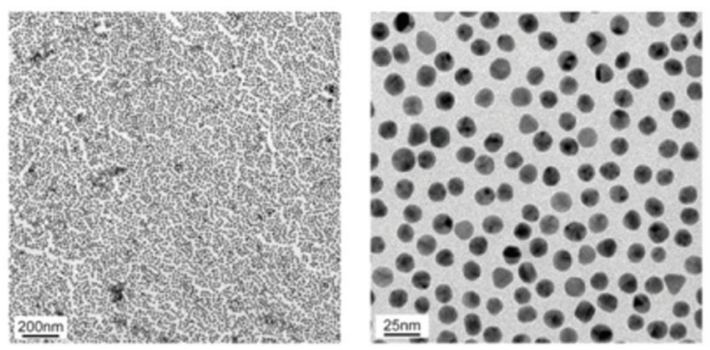

(d)
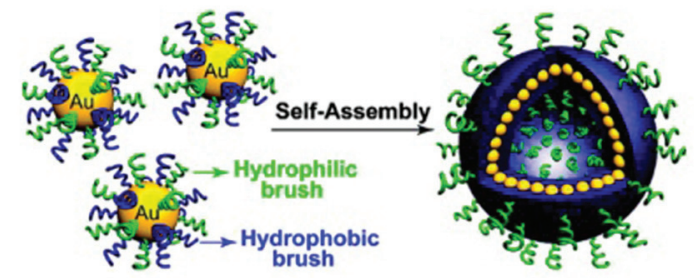

(e)

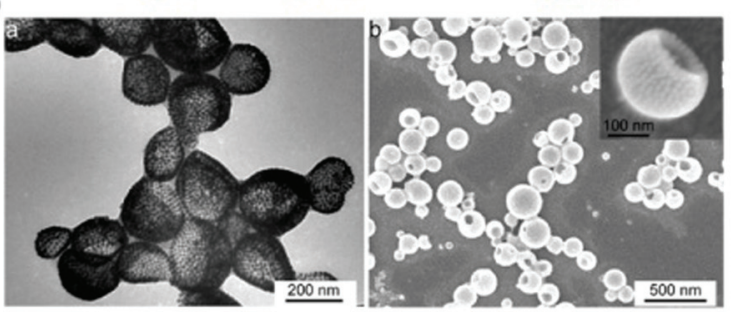

Fig. 20 (a) Scheme of the synthesis of amphiphilic gold nanocrystals by sequentially combined grafting-to (co-adsorption of PEG and DTBE) and grafting-from (surface-initiated ATRP) approaches. (b) Schematic illustration of the amphiphilic gold nanoparticles in chloroform, water as well as liquid/ liquid interfaces (upper part), and photographs of the assembling process by adding hexane into chloroform with volume fractions from $30 \%$ to $80 \%$ (lower part). The gold nanoparticles transfer to the interface forming a separated layer between the two phases. This layer shows characteristic golden-color reflectance and purple/blue transmittance due to the strong coupling of gold nanoparticles manifesting the self-assembled 2-D arrays at the interface. (c) TEM images of the gold nanoparticle assembly at the water/organic solvent interface at different magnifications. Reprinted with permission from L. Cheng et al., ACS Nano, 2010, 4, 6098-6104. Copyright 2010 American Chemical Society. ${ }^{316}$ (d) Schematic illustration of the selfassembly of amphiphilic nanocrystals with mixed polymer brushes into plasmonic vesicular structures. (e) TEM (left) and scanning electron microscopy (SEM) (right) images of the plasmonic vesicles assembled from $14 \mathrm{~nm}$ gold nanoparticles with mixed PEG/PMMA brushes. Reprinted with permission from J. Song et al., J. Am. Chem. Soc., 2011, 133, 10760-10763. Copyright 2011 American Chemical Society. ${ }^{319}$ Note: the monomers for ATRP are MMA, DEAEMA in ref. 316, and MMA, 4VP in ref. 319.

\section{Bionanoparticles}

Proteins can be regarded as bionanoparticles. They have unique properties originating from their applications in nature that other nanoparticles cannot provide. Proteins act as catalysts, transporters, nanochannels, recognition sites and much more. It is very desirable to make use of the properties of proteins by creating hybrid materials and hence their functionalization was studied in much detail. The applications of protein-polymer hybrid materials are drug/gene-delivery, biosensing, bio-imaging as well as creating materials for electronic devices and functional membranes. ${ }^{17,347-349}$ The established bioconjugation strategies can improve stability, solubility, biocompatibility and interfacial activity of a protein. ${ }^{17,350}$ The activity of proteins is often preserved to a high degree in hybrid materials. ${ }^{351}$ Up to now, many proteinpolymer conjugates were synthesized successfully whereby ATRP and RAFT polymerizations were used most of the time. The synthesis of the conjugates can be sometimes delicate as conditions are needed so that the protein stays stable in solution. The distinct three-dimensional structure of proteins resulting from the self-assembly of the amino acid chain into the tertiary structure can be influenced dramatically by heat, the $\mathrm{pH}$ value and certain chemicals. Aqueous buffer conditions are usually required to keep a protein stable in solution and the addition of organic co-solvents has to be tested in every single case. Regarding especially medical applications, the toxicity of copper catalysts from ARTP is a subject that needs considerable attention, hence the purification is crucial. ${ }^{352}$

The synthesis of conjugate structures consisting of proteins and polymers is restricted by the reactions that are applicable to modify amino acid residues. ${ }^{350,352,353}$ Two amino acids are especially used for modification. The amine group of lysine is modified by acylations and alkylations while the thiol group of cysteine is often alkylated or used to form disulfide bonds. ${ }^{350,354}$ Activated carboxylic acid derivatives like NHS esters are mostly used to target lysines. However, due to the high abundance of lysines in common proteins, control of the local modification is difficult to achieve. By modifying more than one lysine group, the unique property of proteins to form monodispersed particles is lost due to a varying degree of modification. The number of accessible cysteine groups in a protein is much less compared to lysine and some cysteine thiol groups are not available for modification as they are blocked in disulfide bonds. Cysteine residues can be selectively addressed by activated disulfide groups leading to disulfide bond formation with the cysteine thiol group. Michael additions and thiol-ene chemistry are used for alkylation of the thiol group. For the targeting of amino acid residues, it has to be considered that not all of them are accessible for modification on the surface of a protein as they can be located inside the protein structure. Lysine is mostly located on the surface of proteins while this is the case for only very few cysteine groups. ${ }^{354,355}$ In addition, also tyrosine, glutamine, tryptophan, histidine, aspartic acid, glutamic acid, arginine, 
phenylalanine plus the $\mathrm{N}$ - and C-terminus of the peptide can be principally used for modification. ${ }^{354}$ In general, the synthesis of site-specific and stoichiometric conjugates in high yield is challenging, ${ }^{356}$ and the investigation of suitable reaction conditions and strategies to further improve the bioconjugation is a main topic of current research. Going one step further, genetic modification of proteins was used to introduce initiator groups into the C-terminus of a protein or even incorporate unnatural amino acids into the primary structure bearing the initiator unit. ${ }^{357-360}$ In this way, the stoichiometry and site-specificity of the bioconjugation can be perfectly controlled. ${ }^{352,356,361}$

Although the stability and required reaction conditions differ much comparing proteins with classic inorganic nanoparticles, the strategies used for the synthesis of hybrid structures are nearly the same with grafting-to, grafting-from and grafting-through. Concerning the delicate stability of proteins, the advantage of grafting-to is that the protein is only involved in the last synthetic step and not during the polymerization. Although it is challenging to synthesize peptide-functional monomers, grafting-through leads to polymers containing several peptide or protein units. ${ }^{350,351,353}$ In contrast to inorganic nanoparticles, the differences of purification after performing grafting-to or grafting-from play a major role for protein-polymer conjugates. While after grafting-to, unreacted polymer and maybe even unmodified protein have to be removed, the purification of the hybrid material is easier for grafting-from as with unreacted monomer and sometimes catalyst, only small molecules have to be removed. For grafting-from, which is the main topic of this review, reaction conditions are needed for the polymerization from the so-called protein macroinitiator that do not affect the protein stability. CRP techniques are well-suited due to their high tolerance towards many functional groups and are almost exclusively used for the conjugate synthesis. ${ }^{361}$ The two techniques that have been particularly studied for use under biological conditions are ATRP and RAFT. ${ }^{361,362}$ However, the choice of wellconsidered reaction conditions is important to perform ATRP in aqueous buffer systems. ${ }^{363,364}$ RAFT has the advantage over ATRP that no transition metal catalyst is required. Several articles provide an extensive overview of the different approaches and examples, ${ }^{350-353,361,365-368}$ but within the scope of this review we can only present a few important and recent conjugation examples via grafting-from for some frequently used proteins.

To the best of our knowledge, grafting-from was first used in combination with proteins by Maynard et al. Biotin functionalized ATRP initiators were non-covalently attached to streptavidin utilizing the extremely high affinity of biotin to this protein. ${ }^{369}$ NIPAM and PEGMMA have been polymerized individually by ATRP from the protein macroinitiator in the presence of a sacrificial initiator. Similar conjugates were formed with BSA and lysozyme, respectively, with covalently attached initiator molecules at cystein residues and grafting of PNIPAM. ${ }^{370}$ Not much later, Sumerlin et al. presented grafting from BSA via the RAFT R-group approach. ${ }^{371} \mathrm{~A}$ maleimide- functionalized trithiocarbonate RAFT agent was linked to a free cysteine residue of BSA via its R-group. The successful subsequent RAFT polymerization of NIPAM in buffer at room temperature was proven by size-exclusion chromatography (SEC) and sodium dodecyl sulfate polyacrylamide gel electrophoresis (SDS-PAGE). The esterase activity of BSA could be thermally regulated due to the responsive nature of the attached polymer chain. ${ }^{371}$

As was shown for silica and gold nanoparticles before, further examples exist for proteins to create hybrid conjugates with responsive polymers. ${ }^{372}$ Recent examples show that the responsiveness of attached polymers can be used to tailor enzyme activity and stability through the triggered change of the polymer shell that is surrounding the protein. ${ }^{373-375}$ The enzyme chymotrypsin was modified at its lysine residues with an ATRP initiator and responsive polymers were grafted from the protein. Therefore, the thermoresponsive PNIPAM and poly([2-(methacryloyloxy)ethyl]dimethyl-(3-sulfopropyl)ammonium hydroxide) (PDMAPS $)^{374}$ as well as the temperature- and pH-responsive PDMAEMA ${ }^{375}$ were utilized. Even a block copolymer with different upper critical solution temperature (UCST) or LCST values, respectively, was linked to chymotrypsin. The polymer shell P(SBAM- $b$-NIPAM) was created by the same grafting-from approach and responds structurally to both low and high temperatures (Fig. 21). ${ }^{373}$

The last mentioned conjugate is one of the few examples to graft a block-copolymer from a protein by two consecutive polymerizations. Other examples are lysozyme and BSA which were modified by two successive RAFT polymerizations. ${ }^{376-378}$ RAFT CTAs were conjugated to the lysine residues of lysozyme or a cysteine residue of BSA, respectively, via their R-groups. After the first polymerization of NIPAM, the RAFT group was retained at the end of the grown polymer chains. Thus, the polymer chains could be extended by polymerization of DMAA in both cases to yield the thermoresponsive conjugates containing block copolymer chains.

Our group used ferritin for hybrid materials as components in polymer-based membranes. Due to their defined structure as well as their variability in size and shape, proteins can be

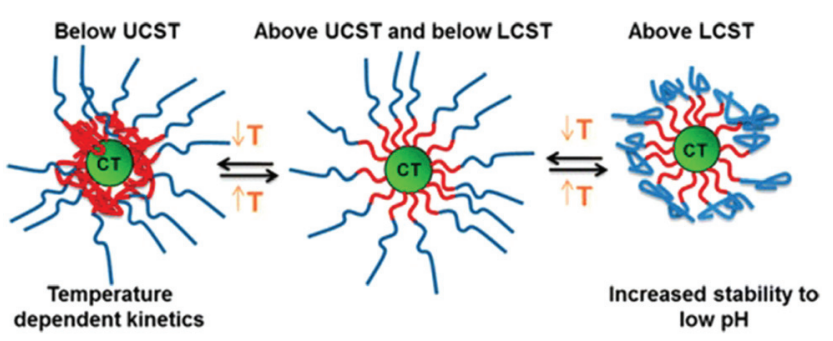

Fig. 21 Illustration of the responsiveness of the chymotrypsin-P(SBAM$b$-NIPAM) conjugates. Below the UCST of poly([2-(methacryloylamino)ethyl]dimethyl-(3-sulfopropyl)ammonium hydroxide) (PSBAM), the inner polymer block collapses in aqueous solution. Above the LCST of PNIPAM, the outer block of the conjugate collapses. Reprinted with permission from C. Cummings et al., Biomacromolecules, 2014, 15, 763-771. Copyright 2014 American Chemical Society. ${ }^{373}$ 


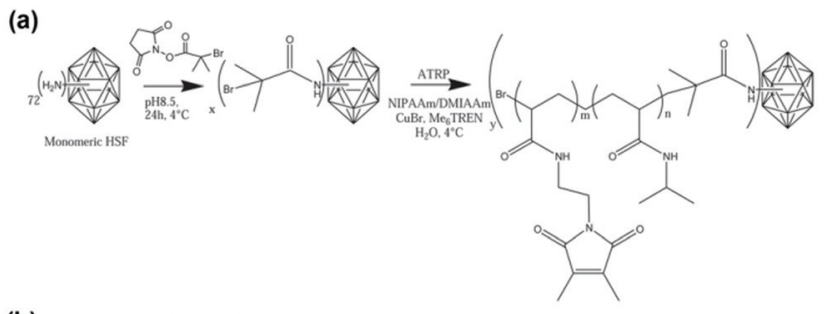

(b)

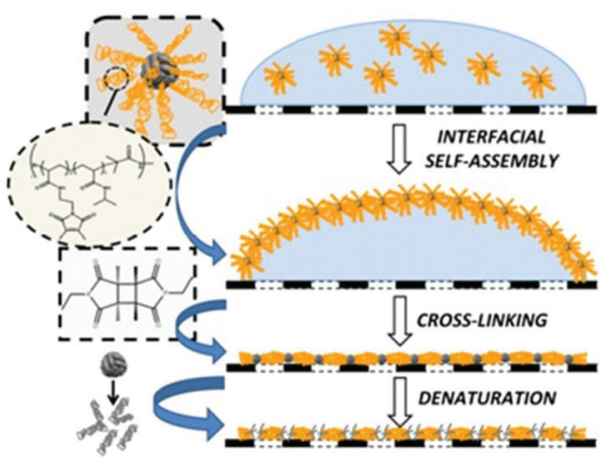

Fig. 22 (a) Synthesis of ferritin-P(NIPAM-CO-DMIAAm) conjugates. First, BMPA was linked to the lysine residues of horse spleen ferritin (HSF) to form the protein macroinitiator. In the following step, NIPAM and DMIAAm were randomly copolymerized by ATRP to graft polymer chains from ferritin that contain maleimide groups which can be crosslinked by [2 + 2]-photocyclization. Reprinted with permission from N. C. Mougin et al., Adv. Funct. Mater., 2011, 21, 2470-2476. Copyright 2011 Wiley$\mathrm{VCH}^{383}$ (b) After self-assembly of the conjugates at the air/water interface, the polymer chains were crosslinked. A membrane was formed through denaturation of the proteins in the polymer layer on top of a porous support. Reprinted with permission from P. van Rijn et al., Adv. Funct. Mater., 2014, 24, 6762-6770. Copyright 2014 Wiley-VCH. ${ }^{384}$

used as well-defined and uniform templates in membrane materials. ${ }^{379}$ The lysine residues of ferritin were easily modified with NHS-activated BMPA to subsequently initiate an ATRP reaction. NIPAM and photo crosslinkable DMIAAm were randomly copolymerized from the protein surface (Fig. 22a). The conjugates showed a much higher interfacial activity than the pure protein which enables the assembly at interfaces. ${ }^{380}$ Hybrid membranes could be constructed from Pickering emulsions at liquid/liquid as well as liquid/air interfaces by crosslinking the polymer chains. ${ }^{381-384}$ Ferritin acts as a sacrificial template for uniform pores in the polymer membrane that can be created through denaturing the protein (Fig. 22b). ${ }^{384}$ The permeation through the resulting membrane was controlled by temperature switching below and above the lower critical solution temperature of the polymer. A high mass transport was measured and a size-selectivity of particles below $20 \mathrm{~nm}$ was determined which is in very good agreement with the size of the used protein. ${ }^{384}$

The principle of forming protein-polymer conjugates was expanded to virus-like particles (VLP) by the groups of Finn and Douglas. ${ }^{385-388}$ Viruses consist of identical protein subunits that self-assemble into hollow capsids, usually encapsulating its own genetic material. ${ }^{385}$ This encapsulated RNA can be efficiently removed to obtain a sufficiently large cavity. ${ }^{385}$ Grafting-from polymerization has been done both on the outside and on the inside of viral capsids. Interestingly, the protein shell acts as a barrier so that the polymerization can be controlled to take place exclusively inside or outside of the capsids. The only requirement is to identify and exploit addressable amino acids for the modification that are exposed exclusively to the inside or the outside, as needed. To graft polymers on the outside of a viral capsid, ATRP initiators were linked to $\mathrm{N}_{3}$-modified amine residues of the VLP $\mathrm{Q} \beta$ by CuAAC, and consecutively OEGMA was polymerized by ATRP. ${ }^{388}$ The post-polymerization modification of polymer end groups and $\mathrm{N}_{3}$-functionalized monomers proved successful in functionalizing the particles with fluorescent dyes or Gd complexes. The terminal bromide could be substituted by azide and alkyne-functionalized dyes linked by CuAAC. Alternatively, the click reaction was done after polymerizing $\mathrm{N}_{3}$-functionalized OEGMA monomers to link further functionalities to the polymer side chains. To grow polymers inside the capsids, mutants with unnatural amino acids or specifically positioned cysteine groups were generated by genetic engineering. ATRP initiators were linked to the unnatural amino acid azidohomoalanine inside the $\mathrm{Q} \beta$ VLP by CuAAC and PDMAEMA chains grown by ATRP. ${ }^{385}$ In another attempt, cysteine residues of VLP derived from the bacteriophage P22 were functionalized with initiators by thiol-ene coupling. ${ }^{386,387}$ It was shown that the poly(2-aminoethyl methacrylate) (PAEMA) polymer chains grew only inside the cavity if the cysteine residues are oriented solely towards the interior. Compared to single proteins described in the previous paragraphs, the advantage of viruslike particles is to be able to modify both the inside and the outside of the capsid. This enables a precise manufacturing of the hybrid structures for applications. The growth of the cationic polymer PDMAEMA resulted in increased binding of the VLP polymer conjugates to cells. ${ }^{385}$ Small molecules of interest can be linked to amine groups of PAEMA leading to a very high labeling degree of a VLP. ${ }^{387}$ A copolymerization with functional $\mathrm{Ru}^{2+}$ complexes equipped the particles with a photoactive group being promising for photocatalysis. ${ }^{386}$ Besides fluorescent dyes, also $\mathrm{Gd}^{3+}$ complexes which can act as magnetic resonance imaging (MRI) contrast agents were bound to the polymer matrix inside the viral capsids. ${ }^{387}$ These first experiments can be extended to the development of improved delivery systems which have a payload inside the cavity and functional recognition motifs like targeting ligands outside the capsid. ${ }^{385}$

\section{Conclusion and perspectives}

The synthesis of nanoparticle/polymer hybrid materials via grafting-from techniques was pointed out to be an elegant and prosperous way to form such composites with unique properties. Surface-initiated CRP techniques, mainly ATRP and RAFT polymerization as well as NMP, are the methods of choice to successfully graft polymers from nanoparticle surfaces. The crucial step prior to surface-initiated CRP is the 
attachment of a functional initiator or RAFT agent onto the nanoparticle surface. Therefore, a wide range of approaches exist for silica nanoparticles, gold nanocrystals, and bionanoparticles. Surface-initiated CRP is flexible and dependent on many factors, e.g. the type of nanoparticles, and their surface properties, the monomers, as well as the mechanism. In-depth research on CRP techniques has facilitated the synthesis of many advanced polymer architectures on nanoparticle surfaces, ranging from block to random copolymers, hyperbranched to combed-coil architectures, and many different attached polymer chains to responsive polymers.

The attached polymer chains provide unique properties to the fabricated polymer/nanoparticle hybrids which the bare nanoparticles do not possess. The hybrid materials are much more stable to environmental factors and can resist flocculation. Due to the confinement on the nanoparticle surfaces, the polymers exhibit different phase behaviors compared to the relatively free polymer chains in bulk, solution, or thin films. Upon incorporating stimuli responsive polymers, the formed nanohybrids show thermo-, pH-, or light-responsive behavior, which is highly promising for next generation nanodevices and nanosensors. The applicability of nanoparticle/polymer hybrids for the very attractive field of drug transport and release has been demonstrated with a few examples. Furthermore, via toposelective modification techniques, Janus nanoparticles with different polymers grafted on the two faces were obtained. Even more interesting, grafted polymers can act as a scaffold to guide the self-assembly of e.g. gold nanocrystal hybrids into superstructures.

However, despite the flourishing development in the synthesis of nanoparticle/polymer core/shell composites, some challenges still exist, particularly regarding potential applications. The compatibility between different CRP techniques is one demanding issue trying to combine ATRP, RAFT, and NMP efficiently. In recent years, environmentally friendly and biologically active polymers have drawn extensive attention. However, their incorporation into nanoparticle/polymer hybrids is still problematic. As of now, many examples of the hybrid material formation demonstrate the feasibility only with model systems. Other than the small lab-scale development of first applicationrelated materials, not much has been achieved in the large-scale production. With proper collaboration among different disciplines and between academic research and industry, the possible applications of such materials are immense. The extensively generated knowledge about nanoparticle/polymer composites can be used to obtain applicable materials for solar cells, medical and energy applications. Concerning protein-polymer conjugates, the research focus will move from the modification of relatively simple proteins like BSA and ferritin to applicationrelated virus-like particles and membrane proteins.

\section{Acknowledgements}

L. W. thanks CSC (China Scholarship Council) for a PhD scholarship. U. G. and A. B. thank the Bundesministerium für
Bildung und Forschung (BMBF) for financial support in the framework of the BMBF-Forschertandem "Chiral Membranes".

\section{References}

1 M. Manca, A. Cannavale, L. De Marco, A. S. Aricò, R. Cingolani and G. Gigli, Langmuir, 2009, 25, 6357-6362.

2 F. Tiarks, K. Landfester and M. Antonietti, Langmuir, 2001, 17, 5775-5780.

3 P. Mesquida and A. Stemmer, Adv. Mater., 2001, 13, 13951398.

4 K. Sathiyaraj, M. Harshiny, B. Nazeema Banu, K. Rajendran and S. Kumaran, Superlattices Microstruct., 2011, 49, 581-590.

5 J. F. Chen, H. M. Ding, J. X. Wang and L. Shao, Biomaterials, 2004, 25, 723-727.

6 P. Rosso, L. Ye, K. Friedrich and S. Sprenger, J. Appl. Polym. Sci., 2006, 100, 1849-1855.

7 D. Xia, A. Biswas, D. Li and S. R. J. Brueck, Adv. Mater., 2004, 16, 1427-1432.

8 J. Bravo, L. Zhai, Z. Wu, R. E. Cohen and M. F. Rubner, Langmuir, 2007, 23, 7293-7298.

9 H. H. Yang, S. Q. Zhang, X. L. Chen, Z. X. Zhuang, J. G. Xu and X. R. Wang, Anal. Chem., 2004, 76, 1316-1321.

10 A. Burns, H. Ow and U. Wiesner, Chem. Soc. Rev., 2006, 35, 1028-1042.

11 M. C. Daniel and D. Astruc, Chem. Rev., 2004, 104, 293346.

12 K. Saha, S. S. Agasti, C. Kim, X. Li and V. M. Rotello, Chem. Rev., 2012, 112, 2739-2779.

13 L. Vigderman, B. P. Khanal and E. R. Zubarev, Adv. Mater., 2012, 24, 4811-4841.

14 D. Graham, Angew. Chem., Int. Ed., 2010, 49, 9325-9327.

15 L. Tong, T. Zhu and Z. Liu, Chem. Soc. Rev., 2011, 40, 1296-1304.

16 E. Katz and I. Willner, Angew. Chem., Int. Ed., 2004, 43, 6042-6108.

17 P. van Rijn and A. Böker, J. Mater. Chem., 2011, 21, 1673516747.

18 H. Fujiwara, S. Yanagida and P. V. Kamat, J. Phys. Chem. B, 1999, 103, 2589-2591.

19 V. Chegel, O. Rachkov, A. Lopatynskyi, S. Ishihara, I. Yanchuk, Y. Nemoto, J. P. Hill and K. Ariga, J. Phys. Chem. C, 2011, 116, 2683-2690.

20 W. Wang, Int. J. Pharm., 1999, 185, 129-188.

21 J. M. Harris and R. B. Chess, Nat. Rev. Drug Discovery, 2003, 2, 214-221.

22 H. Dong, M. Zhu, J. A. Yoon, H. Gao, R. Jin and K. Matyjaszewski, J. Am. Chem. Soc., 2008, 130, 1285212853.

23 D. Li, Y. Cui, K. Wang, Q. He, X. Yan and J. Li, Adv. Funct. Mater., 2007, 17, 3134-3140.

24 M. S. Strozyk, M. Chanana, I. Pastoriza-Santos, J. PérezJuste and L. M. Liz-Marzán, Adv. Funct. Mater., 2012, 22, 1436-1444. 
25 T. Saigal, H. Dong, K. Matyjaszewski and R. D. Tilton, Langmuir, 2010, 26, 15200-15209.

26 K. Y. Tan, J. E. Gautrot and W. T. S. Huck, Langmuir, 2011, 27, 1251-1259.

27 T. Wu, G. Zou, J. Hu and S. Liu, Chem. Mater., 2009, 21, 3788-3798.

28 S. S. Balamurugan, E. Soto-Cantu, R. Cueto and P. S. Russo, Macromolecules, 2009, 43, 62-70.

29 J. Chen, M. Liu, C. Chen, H. Gong and C. Gao, ACS Appl. Mater. Interfaces, 2011, 3, 3215-3223.

30 A. Lukach, K. Liu, H. Therien-Aubin and E. Kumacheva, J. Am. Chem. Soc., 2012, 134, 18853-18859.

31 L. Feng, L. He, Y. Ma and Y. Wang, Mater. Chem. Phys., 2009, 116, 158-163.

32 Y. Kotsuchibashi, M. Ebara, T. Aoyagi and R. Narain, Polym. Chem., 2012, 3, 2545-2550.

33 W. Zhou, J. H. Dong, K. Y. Qiu and Y. Wei, J. Polym. Sci., Part A: Polym. Chem., 1998, 36, 1607-1613.

34 C. C. Chang and W. C. Chen, Chem. Mater., 2002, 14, 4242-4248.

35 E. W. Edwards, M. Chanana and D. Wang, J. Phys. Chem. C, 2008, 112, 15207-15219.

36 G. Marcelo and M. Fernandez-Garcia, RSC Adv., 2014, 4, 11740-11749.

37 Z. Chen, Z. M. Cui, C. Y. Cao, W. D. He, L. Jiang and W. G. Song, Langmuir, 2012, 28, 13452-13458.

38 C. Fernández-López, C. Pérez-Balado, J. Pérez-Juste, I. Pastoriza-Santos, Á. R. de Lera and L. M. Liz-Marzán, Soft Matter, 2012, 8, 4165-4170.

39 M. Henze, D. Mädge, O. Prucker and J. Rühe, Macromolecules, 2014, 47, 2929-2937.

40 T. von Werne and T. E. Patten, J. Am. Chem. Soc., 1999, 121, 7409-7410.

41 D. Sunday, S. Curras-Medina and D. L. Green, Macromolecules, 2010, 43, 4871-4878.

42 J. Jin, J. Liu, X. Lian, P. Sun and H. Zhao, RSC Adv., 2013, 3, 7023-7029.

43 Y. Tsujii, M. Ejaz, K. Sato, A. Goto and T. Fukuda, Macromolecules, 2001, 34, 8872-8878.

44 K. Ohno, Y. Ma, Y. Huang, C. Mori, Y. Yahata, Y. Tsujii, T. Maschmeyer, J. Moraes and S. Perrier, Macromolecules, 2011, 44, 8944-8953.

45 R. Ranjan and W. J. Brittain, Macromol. Rapid Commun., 2008, 29, 1104-1110.

46 M. Husseman, E. E. Malmström, M. McNamara, M. Mate, D. Mecerreyes, D. G. Benoit, J. L. Hedrick, P. Mansky, E. Huang, T. P. Russell and C. J. Hawker, Macromolecules, 1999, 32, 1424-1431.

47 S. Abraham, A. So and L. D. Unsworth, Biomacromolecules, 2011, 12, 3567-3580.

48 O. Prucker and J. Rühe, Macromolecules, 1998, 31, 592601.

49 G. Carrot, D. Rutot-Houzé, A. Pottier, P. Degée, J. Hilborn and P. Dubois, Macromolecules, 2002, 35, 8400-8404.

50 Q. Zhou, S. Wang, X. Fan, R. Advincula and J. Mays, Langmuir, 2002, 18, 3324-3331.
51 N. Y. Kim, N. L. Jeon, I. S. Choi, S. Takami, Y. Harada, K. R. Finnie, G. S. Girolami, R. G. Nuzzo, G. M. Whitesides and P. E. Laibinis, Macromolecules, 2000, 33, 2793-2795.

52 J. Moraes, K. Ohno, T. Maschmeyer and S. Perrier, Chem. Commun., 2013, 49, 9077-9088.

53 A. D. Jenkins, R. G. Jones and G. Moad, Pure Appl. Chem., 2010, 82, 483-491.

54 W. A. Braunecker and K. Matyjaszewski, Prog. Polym. Sci., 2007, 32, 93-146.

55 K. Matyjaszewski, Macromolecules, 2012, 45, 4015-4039.

56 M. Kato, M. Kamigaito, M. Sawamoto and T. Higashimura, Macromolecules, 1995, 28, 1721-1723.

57 J. S. Wang and K. Matyjaszewski, Macromolecules, 1995, 28, 7901-7910.

58 J. S. Wang and K. Matyjaszewski, J. Am. Chem. Soc., 1995, 117, 5614-5615.

59 K. Matyjaszewski and J. H. Xia, Chem. Rev., 2001, 101, 2921-2990.

60 M. Kamigaito, T. Ando and M. Sawamoto, Chem. Rev., 2001, 101, 3689-3746.

61 M. Ouchi, T. Terashima and M. Sawamoto, Chem. Rev., 2009, 109, 4963-5050.

62 K. Matyjaszewski and N. V. Tsarevsky, Nat. Chem., 2009, 1, 276-288.

63 J. Chiefari, Y. K. Chong, F. Ercole, J. Krstina, J. Jeffery, T. P. T. Le, R. T. A. Mayadunne, G. F. Meijs, C. L. Moad, G. Moad, E. Rizzardo and S. H. Thang, Macromolecules, 1998, 31, 5559-5562.

64 G. Moad, E. Rizzardo and S. H. Thang, Acc. Chem. Res., 2008, 41, 1133-1142.

65 S. Perrier and P. Takolpuckdee, J. Polym. Sci., Part A: Polym. Chem., 2005, 43, 5347-5393.

66 G. Moad, E. Rizzardo and S. H. Thang, Aust. J. Chem., 2005, 58, 379-410.

67 G. Moad, E. Rizzardo and S. H. Thang, Polymer, 2008, 49, 1079-1131.

68 M. K. Georges, R. P. N. Veregin, P. M. Kazmaier and G. K. Hamer, Macromolecules, 1993, 26, 2987-2988.

69 C. J. Hawker, J. Am. Chem. Soc., 1994, 116, 1118511186.

70 C. J. Hawker, J. M. J. Frechet, R. B. Grubbs and J. Dao, J. Am. Chem. Soc., 1995, 117, 10763-10764.

71 D. Benoit, V. Chaplinski, R. Braslau and C. J. Hawker, J. Am. Chem. Soc., 1999, 121, 3904-3920.

72 C. J. Hawker, A. W. Bosman and E. Harth, Chem. Rev., 2001, 101, 3661-3688.

73 L. Tebben and A. Studer, Angew. Chem., Int. Ed., 2011, 50, 5034-5068.

74 J. Nicolas, Y. Guillaneuf, C. Lefay, D. Bertin, D. Gigmes and B. Charleux, Prog. Polym. Sci., 2013, 38, 63-235.

75 H. Fischer, Chem. Rev., 2001, 101, 3581-3610.

76 W. Tang and K. Matyjaszewski, Macromolecules, 2006, 39, 4953-4959.

77 W. Tang, N. V. Tsarevsky and K. Matyjaszewski, J. Am. Chem. Soc., 2006, 128, 1598-1604. 
78 W. Tang, Y. Kwak, W. Braunecker, N. V. Tsarevsky, M. L. Coote and K. Matyjaszewski, J. Am. Chem. Soc., 2008, 130, 10702-10713.

79 H. Tang, M. Radosz and Y. Shen, AIChE J., 2009, 55, 737746.

80 X. Liu, K. Sun, Z. Wu, J. Lu, B. Song, W. Tong, X. Shi and H. Chen, Langmuir, 2012, 28, 9451-9459.

81 A. S. Brar and S. Kaur, J. Polym. Sci., Part A: Polym. Chem., 2006, 44, 1745-1757.

82 V. Coessens, T. Pintauer and K. Matyjaszewski, Prog. Polym. Sci., 2001, 26, 337-377.

83 J. Dai, Z. Bao, L. Sun, S. U. Hong, G. L. Baker and M. L. Bruening, Langmuir, 2006, 22, 4274-4281.

84 S. P. Cullen, X. Liu, I. C. Mandel, F. J. Himpsel and P. Gopalan, Langmuir, 2008, 24, 913-920.

85 N. D. Treat, N. Ayres, S. G. Boyes and W. J. Brittain, Macromolecules, 2005, 39, 26-29.

86 J. Chiefari, R. T. A. Mayadunne, C. L. Moad, G. Moad, E. Rizzardo, A. Postma and S. H. Thang, Macromolecules, 2003, 36, 2273-2283.

87 Y. K. Chong, J. Krstina, T. P. T. Le, G. Moad, A. Postma, E. Rizzardo and S. H. Thang, Macromolecules, 2003, 36, 2256-2272.

88 D. J. Keddie, G. Moad, E. Rizzardo and S. H. Thang, Macromolecules, 2012, 45, 5321-5342.

89 G. Moad, E. Rizzardo and S. H. Thang, Aust. J. Chem., 2006, 59, 669-692.

90 G. Moad, E. Rizzardo and S. H. Thang, Aust. J. Chem., 2009, 62, 1402-1472.

91 G. Moad, E. Rizzardo and S. H. Thang, Aust. J. Chem., 2012, 65, 985-1076.

92 G. Moad, E. Rizzardo and S. H. Thang, Polym. Int., 2011, 60, 9-25.

93 H. Willcock and R. K. O'Reilly, Polym. Chem., 2010, 1, 149-157.

94 G. Carrot, S. Diamanti, M. Manuszak, B. Charleux and J. P. Vairon, J. Polym. Sci., Part A: Polym. Chem., 2001, 39, 4294-4301.

95 K. Ohno, T. Akashi, Y. Huang and Y. Tsujii, Macromolecules, 2010, 43, 8805-8812.

96 C. Li, J. Han, C. Y. Ryu and B. C. Benicewicz, Macromolecules, 2006, 39, 3175-3183.

97 L. Wang and B. C. Benicewicz, ACS Macro Lett., 2013, 2, 173-176.

98 J. Parvole, G. Laruelle, C. Guimon, J. Francois and L. Billon, Macromol. Rapid Commun., 2003, 24, 1074-1078.

99 J. Parvole, G. Laruelle, A. Khoukh and L. Billon, Macromol. Chem. Phys., 2005, 206, 372-382.

100 F. Jiang, W. H. Meyer and J. Zhang, Colloids Surf., A, 2013, 436, 302-308.

101 Y. Wang, Y. Xiao, X. Huang and M. Lang, J. Colloid Interface Sci., 2011, 360, 415-421.

102 P. Ye, H. Dong, M. Zhong and K. Matyjaszewski, Macromolecules, 2011, 44, 2253-2260.

103 K. Matyjaszewski, H. Dong, W. Jakubowski, J. Pietrasik and A. Kusumo, Langmuir, 2007, 23, 4528-4531.
104 B. Li, B. Yu, W. T. S. Huck, F. Zhou and W. Liu, Angew. Chem., Int. Ed., 2012, 51, 5092-5095.

105 A. C. C. Esteves, L. Bombalski, T. Trindade, K. Matyjaszewski and A. Barros-Timmons, Small, 2007, 3, 1230-1236.

106 F. Tang, L. Zhang, J. Zhu, Z. Cheng and X. Zhu, Ind. Eng. Chem. Res., 2009, 48, 6216-6223.

107 Q. Li, L. Zhang, Z. Zhang, N. Zhou, Z. Cheng and X. Zhu, J. Polym. Sci., Part A: Polym. Chem., 2010, 48, 20062015.

108 A. Haase, P. Hesse, L. Brommer, O. Jacobs, C. Abetz, U. A. Handge, A. Boschetti-de-Fierro and V. Abetz, Macromol. Mater. Eng., 2013, 298, 292-302.

109 B. T. Cheesman, J. D. Willott, G. B. Webber, S. Edmondson and E. J. Wanless, ACS Macro Lett., 2012, 1, 1161-1165.

110 S. Hansson, E. Östmark, A. Carlmark and E. Malmström, ACS Appl. Mater. Interfaces, 2009, 1, 2651-2659.

111 J. Liu, W. He, L. Zhang, Z. Zhang, J. Zhu, L. Yuan, H. Chen, Z. Cheng and X. Zhu, Langmuir, 2011, 27, 12684-12692.

112 T. J. Aitchison, M. Ginic-Markovic, M. Saunders, P. Fredericks, S. Valiyaveettil, J. G. Matisons and G. P. Simon, J. Polym. Sci., Part A: Polym. Chem., 2011, 49, 4283-4291.

113 C. Li and B. C. Benicewicz, Macromolecules, 2005, 38, 5929-5936.

114 J. Liu, L. Zhang, S. Shi, S. Chen, N. Zhou, Z. Zhang, Z. Cheng and X. Zhu, Langmuir, 2010, 26, 14806-14813.

115 Y. Zhao and S. Perrier, Macromolecules, 2006, 39, 86038608.

116 Y. Zhao and S. Perrier, Macromol. Symp., 2007, 248, 94-103.

117 Y. Zhao and S. Perrier, Macromolecules, 2007, 40, 9116-9124.

118 L. Barner, N. Zwaneveld, S. Perera, Y. Pham and T. P. Davis, J. Polym. Sci., Part A: Polym. Chem., 2002, 40, 4180-4192.

119 L. Barner, C. E. Li, X. Hao, M. H. Stenzel, C. Barner-Kowollik and T. P. Davis, J. Polym. Sci., Part A: Polym. Chem., 2004, 42, 5067-5076.

120 M. H. Stenzel and T. P. Davis, J. Polym. Sci., Part A: Polym. Chem., 2002, 40, 4498-4512.

121 J. F. Quinn, R. P. Chaplin and T. P. Davis, J. Polym. Sci., Part A: Polym. Chem., 2002, 40, 2956-2966.

122 M. H. Stenzel, L. Zhang and W. T. S. Huck, Macromol. Rapid Commun., 2006, 27, 1121-1126.

123 Q. Peng, D. M. Y. Lai, E. T. Kang and K. G. Neoh, Macromolecules, 2006, 39, 5577-5582.

124 W. Stöber, A. Fink and E. Bohn, J. Colloid Interface Sci., 1968, 26, 62-69.

125 F. J. Arriagada and K. Osseo-Asare, J. Colloid Interface Sci., 1995, 170, 8-17.

126 T. Yokoi, Y. Sakamoto, O. Terasaki, Y. Kubota, T. Okubo and T. Tatsumi, J. Am. Chem. Soc., 2006, 128, 1366413665.

127 T. M. Davis, M. A. Snyder, J. E. Krohn and M. Tsapatsis, Chem. Mater., 2006, 18, 5814-5816. 
128 T. Yokoi, J. Wakabayashi, Y. Otsuka, W. Fan, M. Iwama, R. Watanabe, K. Aramaki, A. Shimojima, T. Tatsumi and T. Okubo, Chem. Mater., 2009, 21, 3719-3729.

129 J. Wang, A. Sugawara-Narutaki, M. Fukao, T. Yokoi, A. Shimojima and T. Okubo, ACS Appl. Mater. Interfaces, 2011, 3, 1538-1544.

130 B. Radhakrishnan, R. Ranjan and W. J. Brittain, Soft Matter, 2006, 2, 386-396.

131 H. Zou, S. Wu and J. Shen, Chem. Rev., 2008, 108, 38933957.

132 B. Peng, D. Johannsmann and J. Rühe, Macromolecules, 1999, 32, 6759-6766.

133 K. R. Yoon, Y.-J. Koh and I. S. Choi, Macromol. Rapid Commun., 2003, 24, 207-210.

134 R. Advincula, Q. Zhou, M. Park, S. Wang, J. Mays, G. Sakellariou, S. Pispas and N. Hadjichristidis, Langmuir, 2002, 18, 8672-8684.

135 A. F. Mingotaud, S. Reculusa, C. Mingotaud, P. Keller, C. Sykes, E. Duguet and S. Ravaine, J. Mater. Chem., 2003, 13, 1920-1925.

136 M. A. Jordi and T. A. P. Seery, J. Am. Chem. Soc., 2005, 127, 4416-4422.

137 T. von Werne and T. E. Patten, J. Am. Chem. Soc., 2001, 123, 7497-7505.

138 B. Radhakrishnan, A. N. Constable and W. J. Brittain, Macromol. Rapid Commun., 2008, 29, 1828-1833.

139 K. Ueno, A. Inaba, M. Kondoh and M. Watanabe, Langmuir, 2008, 24, 5253-5259.

140 K. Ueno, A. Inaba, T. Ueki, M. Kondoh and M. Watanabe, Langmuir, 2010, 26, 18031-18038.

141 C. Perruchot, M. A. Khan, A. Kamitsi, S. P. Armes, T. von Werne and T. E. Patten, Langmuir, 2001, 17, 4479-4481.

142 X. Chen, D. P. Randall, C. Perruchot, J. F. Watts, T. E. Patten, T. von Werne and S. P. Armes, J. Colloid Interface Sci., 2003, 257, 56-64.

143 T. Zhou, B. Wang, B. Dong and C. Y. Li, Macromolecules, 2012, 45, 8780-8789.

144 K. Nagase, J. Kobayashi, A. Kikuchi, Y. Akiyama, H. Kanazawa and T. Okano, Langmuir, 2011, 27, 1083010839.

145 S. Banerjee, T. K. Paira, A. Kotal and T. K. Mandal, Adv. Funct. Mater., 2012, 22, 4751-4762.

146 D. S. Achilleos, T. A. Hatton and M. Vamvakaki, J. Am. Chem. Soc., 2012, 134, 5726-5729.

147 K. Ohno, T. Morinaga, K. Koh, Y. Tsujii and T. Fukuda, Macromolecules, 2005, 38, 2137-2142.

148 J. Pyun, S. Jia, T. Kowalewski, G. D. Patterson and K. Matyjaszewski, Macromolecules, 2003, 36, 50945104.

149 M. Kruk, B. Dufour, E. B. Celer, T. Kowalewski, M. Jaroniec and K. Matyjaszewski, Macromolecules, 2008, 41, 8584-8591.

150 J. M. Horton, Z. Bai, X. Jiang, D. Li, T. P. Lodge and B. Zhao, Langmuir, 2011, 27, 2019-2027.

151 N. Saleh, T. Sarbu, K. Sirk, G. V. Lowry, K. Matyjaszewski and R. D. Tilton, Langmuir, 2005, 21, 9873-9878.
152 P. Pasetto, H. Blas, F. Audouin, C. Boissière, C. Sanchez, M. Save and B. Charleux, Macromolecules, 2009, 42, 59835995.

153 D. Li, G. L. Jones, J. R. Dunlap, F. Hua and B. Zhao, Langmuir, 2006, 22, 3344-3351.

154 D. Li and B. Zhao, Langmuir, 2007, 23, 2208-2217.

155 J. M. Horton, C. Bao, Z. Bai, T. P. Lodge and B. Zhao, Langmuir, 2011, 27, 13324-13334.

156 Y. Wu, C. Zhang, X. Qu, Z. Liu and Z. Yang, Langmuir, 2010, 26, 9442-9448.

157 B. Liu, W. Wei, X. Qu and Z. Yang, Angew. Chem., Int. Ed., 2008, 47, 3973-3975.

158 H. Mori, D. C. Seng, M. Zhang and A. H. E. Müller, Langmuir, 2002, 18, 3682-3693.

159 M. Piech and N. S. Bell, Macromolecules, 2006, 39, 915922.

160 N. S. Bell and M. Piech, Langmuir, 2006, 22, 14201427.

161 A. El Harrak, G. Carrot, J. Oberdisse, C. Eychenne Baron and F. Boué, Macromolecules, 2004, 37, 6376-6384.

162 G. Louis Chakkalakal, M. Alexandre, C. Abetz, A. Boschetti-de-Fierro and V. Abetz, Macromol. Chem. Phys., 2012, 213, 513-528.

163 X. Chen and S. P. Armes, Adv. Mater., 2003, 15, 1558-1562. 164 C. D. Vo, A. Schmid, S. P. Armes, K. Sakai and S. Biggs, Langmuir, 2007, 23, 408-413.

165 J. T. Park, J. A. Seo, S. H. Ahn, J. H. Kim and S. W. Kang, J. Ind. Eng. Chem., 2010, 16, 517-522.

166 Y. Kotsuchibashi, Y. Wang, Y. J. Kim, M. Ebara, T. Aoyagi and R. Narain, ACS Appl. Mater. Interfaces, 2013, 5, 1000410010.

167 Y. Kotsuchibashi, A. Faghihnejad, H. Zeng and R. Narain, Polym. Chem., 2013, 4, 1038-1047.

168 J. T. Sun, C. Y. Hong and C. Y. Pan, J. Phys. Chem. C, 2010, 114, 12481-12486.

169 K. Zhang, J. Ma, B. Zhang, S. Zhao, Y. Li, Y. Xu, W. Yu and J. Wang, Mater. Lett., 2007, 61, 949-952.

170 T. Wu, Y. Zhang, X. Wang and S. Liu, Chem. Mater., 2008, 20, 101-109.

171 Z. J. Liu, Y. L. Liang, F. F. Geng, F. Lv, R. J. Dai, Y. K. Zhang and Y. L. Deng, Front. Mater. Sci., 2012, 6, 60-68.

172 H. Zhao, X. Kang and L. Liu, Macromolecules, 2005, 38, 10619-10622.

173 J. R. Wu, G. Q. Lai, H. J. Yu and Z. H. Luo, J. Appl. Polym. Sci., 2012, 124, 3821-3830.

174 Z. Lei and S. Bi, Mater. Lett., 2007, 61, 3531-3534.

175 Z. Dong, H. Wei, J. Mao, D. Wang, M. Yang, S. Bo and X. Ji, Polymer, 2012, 53, 2074-2084.

176 S. Berger, A. Synytska, L. Ionov, K. J. Eichhorn and M. Stamm, Macromolecules, 2008, 41, 9669-9676.

177 T. Cui, J. Zhang, J. Wang, F. Cui, W. Chen, F. Xu, Z. Wang, K. Zhang and B. Yang, Adv. Funct. Mater., 2005, 15, 481486.

178 M. Ejaz, S. Yamamoto, K. Ohno, Y. Tsujii and T. Fukuda, Macromolecules, 1998, 31, 5934-5936. 
179 M. Ejaz, K. Ohno, Y. Tsujii and T. Fukuda, Macromolecules, 2000, 33, 2870-2874.

180 Y. Lu, Y. J. Choi, H. S. Lim, D. Kwak, C. Shim, S. G. Lee and K. Cho, Langmuir, 2010, 26, 17749-17755.

181 L. Zhao, A. Li, R. Xiang, L. Shen and L. Shi, Langmuir, 2013, 29, 8936-8943.

182 J. H. Xia, X. Zhang and K. Matyjaszewski, Macromolecules, 1999, 32, 3531-3533.

183 N. V. Tsarevsky, W. A. Braunecker, S. J. Brooks and K. Matyjaszewski, Macromolecules, 2006, 39, 68176824.

184 H. G. Schild, M. Muthukumar and D. A. Tirrell, Macromolecules, 1991, 24, 948-952.

185 Y. H. Bae, T. Okano and S. W. Kim, J. Polym. Sci., Part B: Polym. Phys., 1990, 28, 923-936.

186 T. Kawaguchi, Y. Kojima, M. Osa and T. Yoshizaki, Polym. J., 2008, 40, 455-459.

187 G. Masci, L. Giacomelli and V. Crescenzi, Macromol. Rapid Commun., 2004, 25, 559-564.

188 Y. Xia, X. Yin, N. A. D. Burke and H. D. H. Stöver, Macromolecules, 2005, 38, 5937-5943.

189 Y. Xia, N. A. D. Burke and H. D. H. Stöver, Macromolecules, 2006, 39, 2275-2283.

190 P.-E. Millard, N. C. Mougin, A. Böker and A. H. E. Müller, in Controlled/Living Radical Polymerization: Progress in ATRP, American Chemical Society, 2009, vol. 1023, pp. 127-137.

191 M. Wagner, F. Brochard-Wyart, H. Hervet and P. G. de Gennes, Colloid Polym. Sci., 1993, 271, 621-628.

192 J. Shan, J. Chen, M. Nuopponen and H. Tenhu, Langmuir, 2004, 20, 4671-4676.

193 F. Liu and M. W. Urban, Prog. Polym. Sci., 2010, 35, 3-23.

194 R. Klajn, Chem. Soc. Rev., 2014, 43, 148-184.

195 J. Michaelis, in Single Particle Tracking and Single Molecule Energy Transfer, Wiley-VCH Verlag GmbH \& Co. KGaA, 2009, pp. 191-214.

196 S. J. Rowan, S. J. Cantrill, G. R. L. Cousins, J. K. M. Sanders and J. F. Stoddart, Angew. Chem., Int. Ed., 2002, 41, 898-952.

197 Y. Jin, C. Yu, R. J. Denman and W. Zhang, Chem. Soc. Rev., 2013, 42, 6634-6654.

198 Y. Jin, Q. Wang, P. Taynton and W. Zhang, Acc. Chem. Res., 2014, 47, 1575-1586.

199 L. Hong, S. Jiang and S. Granick, Langmuir, 2006, 22, 9495-9499.

200 J. Moraes, K. Ohno, G. Gody, T. Maschmeyer and S. Perrier, J. Org. Chem., 2013, 9, 1226-1234.

201 J. Moraes, K. Ohno, T. Maschmeyer and S. Perrier, Chem. Mater., 2013, 25, 3522-3527.

202 Z. Qu, F. Hu, K. Chen, Z. Duan, H. Gu and H. Xu, J. Colloid Interface Sci., 2013, 398, 82-87.

203 B. R. Park, Y. Nabae, M. Surapati, T. Hayakawa and M.a. Kakimoto, Polym. J., 2013, 45, 210-215.

204 R. Rotzoll and P. Vana, Aust. J. Chem., 2009, 62, 14731478.
205 Y. Li and B. C. Benicewicz, Macromolecules, 2008, 41, 7986-7992.

206 X. Huang, D. Appelhans, P. Formanek, F. Simon and B. Voit, Macromolecules, 2011, 44, 8351-8360.

207 B. M. Cash, L. Wang and B. C. Benicewicz, J. Polym. Sci., Part A: Polym. Chem., 2012, 50, 2533-2540.

208 A. Rungta, B. Natarajan, T. Neely, D. Dukes, L. S. Schadler and B. C. Benicewicz, Macromolecules, 2012, 45, 93039311.

209 X. Huang, D. Appelhans, P. Formanek, F. Simon and B. Voit, ACS Nano, 2012, 6, 9718-9726.

210 C. H. Liu and C. Y. Pan, Polymer, 2007, 48, 3679-3685.

211 D. Hua, J. Tang, J. Jiang, Z. Gu, L. Dai and X. Zhu, Mater. Chem. Phys., 2009, 114, 402-406.

212 C. Y. Hong, X. Li and C. Y. Pan, Eur. Polym. J., 2007, 43, 4114-4122.

213 C. Y. Hong, X. Li and C. Y. Pan, J. Phys. Chem. C, 2008, 112, 15320-15324.

214 C. Y. Hong, X. Li and C. Y. Pan, J. Mater. Chem., 2009, 19, 5155-5160.

215 Q. Li, L. Zhang, L. Bai, Z. Zhang, J. Zhu, N. Zhou, Z. Cheng and X. Zhu, Soft Matter, 2011, 7, 6958-6966.

216 C. H. Lu, W. H. Zhou, B. Han, H. H. Yang, X. Chen and X. R. Wang, Anal. Chem., 2007, 79, 5457-5461.

217 K. M. Yeh and Y. Chen, J. Polym. Sci., Part A: Polym. Chem., 2006, 44, 5362-5377.

218 G. D. Fu, L. Q. Xu, F. Yao, K. Zhang, X. F. Wang, M. F. Zhu and S. Z. Nie, ACS Appl. Mater. Interfaces, 2009, 1, 239243.

219 Y. Chen, G. Chen and M. H. Stenzel, Macromolecules, 2010, 43, 8109-8114.

220 H. Feng, Y. Zhao, M. Pelletier, Y. Dan and Y. Zhao, Polymer, 2009, 50, 3470-3477.

221 H. C. Kolb, M. G. Finn and K. B. Sharpless, Angew. Chem., Int. Ed., 2001, 40, 2004-2021.

222 R. A. Evans, Aust. J. Chem., 2007, 60, 384-395.

223 J. F. Lutz, Angew. Chem., Int. Ed., 2007, 46, 1018-1025.

224 G. K. Such, J. F. Quinn, A. Quinn, E. Tjipto and F. Caruso, J. Am. Chem. Soc., 2006, 128, 9318-9319.

225 G. Jian, Y. Liu, X. He, L. Chen and Y. Zhang, Nanoscale, 2012, 4, 6336-6342.

226 B. Helms, J. L. Mynar, C. J. Hawker and J. M. J. Fréchet, J. Am. Chem. Soc., 2004, 126, 15020-15021.

227 B. C. Englert, S. Bakbak and U. H. F. Bunz, Macromolecules, 2005, 38, 5868-5877.

228 Q. Wang, T. R. Chan, R. Hilgraf, V. V. Fokin, K. B. Sharpless and M. G. Finn, J. Am. Chem. Soc., 2003, 125, 3192-3193.

229 A. E. Speers, G. C. Adam and B. F. Cravatt, J. Am. Chem. Soc., 2003, 125, 4686-4687.

230 H. El-Hamshary, M. El-Garawany, F. N. Assubaie and M. Al-Eed, J. Appl. Polym. Sci., 2003, 89, 2522-2526.

231 B. L. Rivas, B. Quilodrán and E. Quiroz, J. Appl. Polym. Sci., 2004, 92, 2908-2916.

232 K. R. M. Vidts and F. E. Du Prez, Eur. Polym. J., 2006, 42, 43-50. 
233 S. Blomberg, S. Ostberg, E. Harth, A. W. Bosman, B. Van Horn and C. J. Hawker, J. Polym. Sci., Part A: Polym. Chem., 2002, 40, 1309-1320.

234 C. Bartholome, E. Beyou, E. Bourgeat-Lami, P. Chaumont and N. Zydowicz, Macromolecules, 2003, 36, 7946-7952.

235 E. Beyou, J. Humbert and P. Chaumont, e-Polymers, 2003, 3, 249.

236 C. Bartholome, E. Beyou, E. Bourgeat-Lami, P. Cassagnau, P. Chaumont, L. David and N. Zydowicz, Polymer, 2005, 46, 9965-9973.

237 C. Bartholome, E. Beyou, E. Bourgeat-Lami, P. Chaumont and N. Zydowicz, Polymer, 2005, 46, 8502-8510.

238 G. Laruelle, J. Parvole, J. Francois and L. Billon, Polymer, 2004, 45, 5013-5020.

239 R. Inoubli, S. Dagreou, M. H. Delville, A. Lapp, J. Peyrelasse and L. Billon, Soft Matter, 2007, 3, 10141024.

240 C. Deleuze, M. H. Delville, V. Pellerin, C. Derail and L. Billon, Macromolecules, 2009, 42, 5303-5309.

241 H. Blas, M. Save, C. Boissière, C. Sanchez and B. Charleux, Macromolecules, 2011, 44, 2577-2588.

242 C. Bartholome, E. Beyou, E. Bourgeat-Lami, P. Chaumont, F. Lefebvre and N. Zydowicz, Macromolecules, 2005, 38, 1099-1106.

243 B. Bailly, A. C. Donnenwirth, C. Bartholome, E. Beyou and E. Bourgeat-Lami, J. Nanomater., 2006, 2006, 1-10.

244 C. Chevigny, D. Gigmes, D. Bertin, J. Jestin and F. Boue, Soft Matter, 2009, 5, 3741-3753.

245 J. Parvole, L. Ahrens, H. Blas, J. Vinas, C. Boissière, C. Sanchez, M. Save and B. Charleux, J. Polym. Sci., Part A: Polym. Chem., 2010, 48, 173-185.

246 R. Inoubli, S. Dagréou, A. Khoukh, F. Roby, J. Peyrelasse and L. Billon, Polymer, 2005, 46, 2486-2496.

247 R. Andrzej, W. Micheline, B. Emmanuel, C. Philippe, B. Mikhael, B. Arnaud, T. Bérangère, C. David, M. Philippe, G. Benoit, S. Laurence and G. Daniel, Nanotechnology, 2010, 21, 145610.

248 S. Abraham and L. D. Unsworth, J. Polym. Sci., Part A: Polym. Chem., 2011, 49, 1051-1060.

249 B. Zhao and L. Zhu, Macromolecules, 2009, 42, 9369-9383.

250 A. Sidorenko, S. Minko, K. Schenk-Meuser, H. Duschner and M. Stamm, Langmuir, 1999, 15, 8349-8355.

251 S. Minko, D. Usov, E. Goreshnik and M. Stamm, Macromol. Rapid Commun., 2001, 22, 206-211.

252 M. Motornov, S. Minko, K.-J. Eichhorn, M. Nitschke, F. Simon and M. Stamm, Langmuir, 2003, 19, 8077-8085.

253 B. Zhao, Polymer, 2003, 44, 4079-4083.

254 D. Usov, V. Gruzdev, M. Nitschke, M. Stamm, O. Hoy, I. Luzinov, I. Tokarev and S. Minko, Macromolecules, 2007, 40, 8774-8783.

255 X. Jiang, B. Zhao, G. Zhong, N. Jin, J. M. Horton, L. Zhu, R. S. Hafner and T. P. Lodge, Macromolecules, 2010, 43, 8209-8217.

256 S. Tang, T. Y. Lo, J. M. Horton, C. Bao, P. Tang, F. Qiu, R. M. Ho, B. Zhao and L. Zhu, Macromolecules, 2013, 46, 6575-6584.
257 Y. Wang and W. J. Brittain, Macromol. Rapid Commun., 2007, 28, 811-815.

258 W. Li, C. Bao, R. A. E. Wright and B. Zhao, RSC Adv., 2014, 4, 18772-18781.

259 X. Huang, N. Hauptmann, D. Appelhans, P. Formanek, S. Frank, S. Kaskel, A. Temme and B. Voit, Small, 2012, 8, 3579-3583.

260 B. Zhao and T. He, Macromolecules, 2003, 36, 85998602.

261 D. Li, X. Sheng and B. Zhao, J. Am. Chem. Soc., 2005, 127, 6248-6256.

262 B. Zhao, R. T. Haasch and S. MacLaren, J. Am. Chem. Soc., 2004, 126, 6124-6134.

263 B. Zhao and L. Zhu, J. Am. Chem. Soc., 2006, 128, 45744575.

264 L. Zhu and B. Zhao, J. Phys. Chem. B, 2008, 112, 1152911536.

265 X. Jiang, G. Zhong, J. M. Horton, N. Jin, L. Zhu and B. Zhao, Macromolecules, 2010, 43, 5387-5395.

266 C. Bao, S. Tang, J. M. Horton, X. Jiang, P. Tang, F. Qiu, L. Zhu and B. Zhao, Macromolecules, 2012, 45, 8027-8036.

267 J. M. Horton, S. Tang, C. Bao, P. Tang, F. Qiu, L. Zhu and B. Zhao, ACS Macro Lett., 2012, 1, 1061-1065.

268 D. Mecerreyes, G. Moineau, P. Dubois, R. Jérôme, J. L. Hedrick, C. J. Hawker, E. E. Malmström and M. Trollsas, Angew. Chem., Int. Ed., 1998, 37, 1274-1276.

269 M. W. Weimer, O. A. Scherman and D. Y. Sogah, Macromolecules, 1998, 31, 8425-8428.

270 N. R. Jana, L. Gearheart and C. J. Murphy, Adv. Mater., 2001, 13, 1389-1393.

271 B. Nikoobakht and M. A. El-Sayed, Chem. Mater., 2003, 15, 1957-1962.

272 C. J. Orendorff and C. J. Murphy, J. Phys. Chem. B, 2006, 110, 3990-3994.

273 J. Kimling, M. Maier, B. Okenve, V. Kotaidis, H. Ballot and A. Plech, J. Phys. Chem. B, 2006, 110, 15700-15707.

274 J. Rodríguez-Fernández, J. Pérez-Juste, F. J. García de Abajo and L. M. Liz-Marzán, Langmuir, 2006, 22, 70077010 .

275 W. Haiss, N. T. K. Thanh, J. Aveyard and D. G. Fernig, Anal. Chem., 2007, 79, 4215-4221.

276 M. Grzelczak, J. Perez-Juste, P. Mulvaney and L. M. LizMarzan, Chem. Soc. Rev., 2008, 37, 1783-1791.

277 N. G. Bastús, J. Comenge and V. Puntes, Langmuir, 2011, 27, 11098-11105.

278 K. Park, L. F. Drummy, R. C. Wadams, H. Koerner, D. Nepal, L. Fabris and R. A. Vaia, Chem. Mater., 2013, 25, 555-563.

279 T. Bai, J. Sun, R. Che, L. Xu, C. Yin, Z. Guo and N. Gu, ACS Appl. Mater. Interfaces, 2014, 6, 3331-3340.

280 S. H. Liu and M. Y. Han, Adv. Funct. Mater., 2005, 15, 961967.

281 K. L. Wustholz, A. I. Henry, J. M. McMahon, R. G. Freeman, N. Valley, M. E. Piotti, M. J. Natan, G. C. Schatz and R. P. V. Duyne, J. Am. Chem. Soc., 2010, 132, 10903-10910. 
282 W. Xie, B. Walkenfort and S. Schlücker, J. Am. Chem. Soc., 2013, 135, 1657-1660.

283 Q. Cui, A. Yashchenok, L. Zhang, L. Li, A. Masic, G. Wienskol, H. Möhwald and M. Bargheer, ACS Appl. Mater. Interfaces, 2014, 6, 1999-2002.

284 L. Peng, M. You, C. Wu, D. Han, I. Öçsoy, T. Chen, Z. Chen and W. Tan, ACS Nano, 2014, 8, 2555-2561.

285 Y. Gu, W. Liu, R. Chen, L. Zhang and Z. Zhang, Electroanalysis, 2013, 25, 1209-1216.

286 C. Park, H. Youn, H. Kim, T. Noh, Y. H. Kook, E. T. Oh, H. J. Park and C. Kim, J. Mater. Chem., 2009, 19, 23102315.

287 Y. Shi, J. Goodisman and J. C. Dabrowiak, Inorg. Chem., 2013, 52, 9418-9426.

288 Y. Yao, M. Xue, Z. Zhang, M. Zhang, Y. Wang and F. Huang, Chem. Sci., 2013, 4, 3667-3672.

289 F. Xia, X. Zuo, R. Yang, Y. Xiao, D. Kang, A. Vallée-Bélisle, X. Gong, J. D. Yuen, B. B. Y. Hsu, A. J. Heeger and K. W. Plaxco, Proc. Natl. Acad. Sci. U. S. A., 2010, 107, 10837-10841.

290 S. Y. Park, A. K. R. Lytton-Jean, B. Lee, S. Weigand, G. C. Schatz and C. A. Mirkin, Nature, 2008, 451, 553556.

291 M. Hong, X. Zhou, Z. Lu and J. Zhu, Angew. Chem., Int. Ed., 2009, 48, 9503-9506.

292 M. Chanana, M. A. Correa-Duarte and L. M. Liz-Marzán, Small, 2011, 7, 2650-2660.

293 C. D. Keating, K. M. Kovaleski and M. J. Natan, J. Phys. Chem. B, 1998, 102, 9404-9413.

294 J. Wang, H. Xia, Y. Zhang, H. Lu, R. Kamat, A. V. Dobrynin, J. Cheng and Y. Lin, J. Am. Chem. Soc., 2013, 135, 11417-11420.

295 E. Boisselier, A. K. Diallo, L. Salmon, C. Ornelas, J. Ruiz and D. Astruc, J. Am. Chem. Soc., 2010, 132, 27292742.

296 D. Astruc, L. Liang, A. Rapakousiou and J. Ruiz, Acc. Chem. Res., 2011, 45, 630-640.

297 L. M. Bronstein and Z. B. Shifrina, Chem. Rev., 2011, 111, 5301-5344.

298 S. Mischler, S. Guerra and R. Deschenaux, Chem. Commun., 2012, 48, 2183-2185.

299 L. Cseh and G. H. Mehl, J. Am. Chem. Soc., 2006, 128, 13376-13377.

300 C. H. Yu, C. P. J. Schubert, C. Welch, B. J. Tang, M. G. Tamba and G. H. Mehl, J. Am. Chem. Soc., 2012, 134, 5076-5079.

301 M. Wojcik, W. Lewandowski, J. Matraszek, J. Mieczkowski, J. Borysiuk, D. Pociecha and E. Gorecka, Angew. Chem., Int. Ed., 2009, 48, 5167-5169.

302 B. Donnio, P. García-Vázquez, J. L. Gallani, D. Guillon and E. Terazzi, Adv. Mater., 2007, 19, 3534-3539.

303 X. Zeng, F. Liu, A. G. Fowler, G. Ungar, L. Cseh, G. H. Mehl and J. E. Macdonald, Adv. Mater., 2009, 21, 1746-1750.

304 Z. Sun, Z. Bao, C. Fang and J. Wang, Langmuir, 2012, 28, 9082-9092.
305 H. Wang, L. Chen, X. Shen, L. Zhu, J. He and H. Chen, Angew. Chem., Int. Ed., 2012, 51, 8021-8025.

306 K. Liu, Z. Nie, N. Zhao, W. Li, M. Rubinstein and E. Kumacheva, Science, 2010, 329, 197-200.

307 H. Robenek, in Colloidal gold: Principles, methods, and applications, Academic Press, Inc., Wiley Periodicals, Inc., New York, 1990.

308 H. Dautzenberg, in Polymeric stabilization of colloidal dispersions, Academic Press Inc., London/New York, 1983.

309 S. Nuß, H. Böttcher, H. Wurm and M. L. Hallensleben, Angew. Chem., Int. Ed., 2001, 40, 4016-4018.

310 K. Ohno, K.-m. Koh, Y. Tsujii and T. Fukuda, Macromolecules, 2002, 35, 8989-8993.

311 T. K. Mandal, M. S. Fleming and D. R. Walt, Nano Lett., 2002, 2, 3-7.

312 R. Contreras-Cáceres, A. Sánchez-Iglesias, M. Karg, I. Pastoriza-Santos, J. Pérez-Juste, J. Pacifico, T. Hellweg, A. Fernández-Barbero and L. M. Liz-Marzán, Adv. Mater., 2008, 20, 1666-1670.

313 R. Contreras-Cáceres, J. Pacifico, I. Pastoriza-Santos, J. Pérez-Juste, A. Fernández-Barbero and L. M. Liz-Marzán, Adv. Funct. Mater., 2009, 19, 3070-3076.

314 S. Luo, J. Xu, Y. Zhang, S. Liu and C. Wu, J. Phys. Chem. B, 2005, 109, 22159-22166.

315 W. Yang, J. R. Ella-Menye, S. Liu, T. Bai, D. Wang, Q. Yu, Y. Li and S. Jiang, Langmuir, 2014, 30, 25222529.

316 L. Cheng, A. Liu, S. Peng and H. Duan, ACS Nano, 2010, 4, 6098-6104.

317 K. Ohno, K. Koh, Y. Tsujii and T. Fukuda, Angew. Chem., Int. Ed., 2003, 42, 2751-2754.

318 K. Liu, A. Lukach, K. Sugikawa, S. Chung, J. Vickery, H. Therien-Aubin, B. Yang, M. Rubinstein and E. Kumacheva, Angew. Chem., Int. Ed., 2014, 53, 26482653.

319 J. Song, L. Cheng, A. Liu, J. Yin, M. Kuang and H. Duan, J. Am. Chem. Soc., 2011, 133, 10760-10763.

320 J. He, Y. Liu, T. Babu, Z. Wei and Z. Nie, J. Am. Chem. Soc., 2012, 134, 11342-11345.

321 J. Hu, T. Wu, G. Zhang and S. Liu, J. Am. Chem. Soc., 2012, 134, 7624-7627.

322 M. Tagliazucchi, M. G. Blaber, G. C. Schatz, E. A. Weiss and I. Szleifer, ACS Nano, 2012, 6, 8397-8406.

323 D. Li, Q. He, Y. Yang, H. Möhwald and J. Li, Macromolecules, 2008, 41, 7254-7256.

324 M. Q. Zhu, L. Q. Wang, G. J. Exarhos and A. D. Q. Li, J. Am. Chem. Soc., 2004, 126, 2656-2657.

325 C. Boyer, M. R. Whittaker, M. Luzon and T. P. Davis, Macromolecules, 2009, 42, 6917-6926.

326 T. Zhang, Z. Zheng, X. Ding and Y. Peng, Macromol. Rapid Commun., 2008, 29, 1716-1720.

327 E. R. Zubarev, J. Xu, A. Sayyad and J. D. Gibson, J. Am. Chem. Soc., 2006, 128, 4958-4959.

328 Z. L. Wang, J. T. Xu, B. Y. Du and Z. Q. Fan, J. Colloid Interface Sci., 2011, 360, 350-354. 
329 C. Yuan, W. Luo, L. Zhong, H. Deng, J. Liu, Y. Xu and L. Dai, Angew. Chem., Int. Ed., 2011, 50, 3515-3519.

330 S. Carregal-Romero, N. J. Buurma, J. Pérez-Juste, L. M. Liz-Marzán and P. Hervés, Chem. Mater., 2010, 22, 3051-3059.

331 R. A. Álvarez-Puebla, R. Contreras-Cáceres, I. PastorizaSantos, J. Pérez-Juste and L. M. Liz-Marzán, Angew. Chem., Int. Ed., 2009, 48, 138-143.

332 K. J. Watson, J. Zhu, S. T. Nguyen and C. A. Mirkin, J. Am. Chem. Soc., 1999, 121, 462-463.

333 S. Koenig and V. Chechik, Langmuir, 2006, 22, 5168-5173.

334 R. Jordan, N. West, A. Ulman, Y.-M. Chou and O. Nuyken, Macromolecules, 2001, 34, 1606-1611.

335 B. Wang, B. Li, B. Zhao and C. Y. Li, J. Am. Chem. Soc., 2008, 130, 11594-11595.

336 B. Wang, B. Li, B. Dong, B. Zhao and C. Y. Li, Macromolecules, 2010, 43, 9234-9238.

337 D. Li, Q. He, Y. Cui, K. Wang, X. Zhang and J. Li, Chem. Eur. J., 2007, 13, 2224-2229.

338 D. J. Kim, S. M. Kang, B. Kong, W. J. Kim, H. J. Paik, H. Choi and I. S. Choi, Macromol. Chem. Phys., 2005, 206, 1941-1946.

339 Q. Wei, J. Ji and J. Shen, Macromol. Rapid Commun., 2008, 29, 645-650.

340 D. Li, Q. He, Y. Cui and J. Li, Chem. Mater., 2007, 19, 412417.

341 H. Duan, M. Kuang, G. Zhang, D. Wang, D. G. Kurth and H. Möhwald, Langmuir, 2005, 21, 11495-11499.

342 A. Kotal, T. K. Mandal and D. R. Walt, J. Polym. Sci., Part A: Polym. Chem., 2005, 43, 3631-3642.

343 J. Song, J. Zhou and H. Duan, J. Am. Chem. Soc., 2012, 134, 13458-13469.

344 X. Lou, C. Wang and L. He, Biomacromolecules, 2007, 8, 1385-1390.

345 J. Raula, J. Shan, M. Nuopponen, A. Niskanen, H. Jiang, E. I. Kauppinen and H. Tenhu, Langmuir, 2003, 19, 34993504.

346 J. Dong and J. Zhou, Macromol. Theory Simul., 2013, 22, 174-186.

347 A. W. Du and M. H. Stenzel, Biomacromolecules, 2014, 15, 1097-1114.

348 D. E. Borchmann, T. P. Carberry and M. Weck, Macromol. Rapid Commun., 2014, 35, 27-43.

349 C. G. Palivan, O. Fischer-Onaca, M. Delcea, F. Itel and W. Meier, Chem. Soc. Rev., 2012, 41, 2800-2823.

350 L. A. Canalle, D. W. P. M. Lowik and J. C. M. van Hest, Chem. Soc. Rev., 2010, 39, 329-353.

351 B. Le Droumaguet and J. Nicolas, Polym. Chem., 2010, 1, 563-598.

352 R. M. Broyer, G. N. Grover and H. D. Maynard, Chem. Commun., 2011, 47, 2212-2226.

353 M. A. Gauthier and H. A. Klok, Chem. Commun., 2008, 2591-2611.

354 B. Jung and P. Theato, in Bio-synthetic Polymer Conjugates, ed. H. Schlaad, Springer, Berlin, Heidelberg, 2013, vol. 253 , ch. 169 , pp. 37-70.
355 S. Moelbert, E. Emberly and C. Tang, Protein Sci., 2004, 13, 752-762.

356 Y. Qi and A. Chilkoti, Polym. Chem., 2014, 5, 266-276.

357 S. E. Averick, C. G. Bazewicz, B. F. Woodman, A. Simakova, R. A. Mehl and K. Matyjaszewski, Eur. Polym. J., 2013, 49, 2919-2924.

358 W. Gao, W. Liu, T. Christensen, M. R. Zalutsky and A. Chilkoti, Proc. Natl. Acad. Sci. U. S. A., 2010, 107, 1643216437.

359 J. C. Peeler, B. F. Woodman, S. Averick, S. J. MiyakeStoner, A. L. Stokes, K. R. Hess, K. Matyjaszewski and R. A. Mehl, J. Am. Chem. Soc., 2010, 132, 13575-13577.

360 R. M. Broyer, G. M. Quaker and H. D. Maynard, J. Am. Chem. Soc., 2008, 130, 1041-1047.

361 J. D. Wallat, K. A. Rose and J. K. Pokorski, Polym. Chem., 2014, 5, 1545-1558.

362 B. S. Sumerlin, ACS Macro Lett., 2012, 1, 141-145.

363 S. Averick, A. Simakova, S. Park, D. Konkolewicz, A. J. D. Magenau, R. A. Mehl and K. Matyjaszewski, ACS Macro Lett., 2012, 1, 6-10.

364 A. Simakova, S. E. Averick, D. Konkolewicz and K. Matyjaszewski, Macromolecules, 2012, 45, 63716379.

365 R. P. Johnson, J. V. John and I. Kim, Eur. Polym. J., 2013, 49, 2925-2948.

366 H. A. Klok, Macromolecules, 2009, 42, 7990-8000.

367 J. Nicolas, G. Mantovani and D. M. Haddleton, Macromol. Rapid Commun., 2007, 28, 1083-1111.

368 A. C. Obermeyer and B. D. Olsen, ACS Macro Lett., 2015, 4, 101-110.

369 D. Bontempo and H. D. Maynard, J. Am. Chem. Soc., 2005, 127, 6508-6509.

370 K. L. Heredia, D. Bontempo, T. Ly, J. T. Byers, S. Halstenberg and H. D. Maynard, J. Am. Chem. Soc., 2005, 127, 16955-16960.

371 P. De, M. Li, S. R. Gondi and B. S. Sumerlin, J. Am. Chem. Soc., 2008, 130, 11288-11289.

372 I. Cobo, M. Li, B. S. Sumerlin and S. Perrier, Nat. Mater., 2015, 14, 143-159.

373 C. Cummings, H. Murata, R. Koepsel and A. J. Russell, Biomacromolecules, 2014, 15, 763-771.

374 C. Cummings, H. Murata, R. Koepsel and A. J. Russell, Biomaterials, 2013, 34, 7437-7443.

375 H. Murata, C. S. Cummings, R. R. Koepsel and A. J. Russell, Biomacromolecules, 2013, 14, 1919-1926.

376 H. Li, M. Li, X. Yu, A. P. Bapat and B. S. Sumerlin, Polym. Chem., 2011, 2, 1531-1535.

377 M. Li, H. Li, P. De and B. S. Sumerlin, Macromol. Rapid Commun., 2011, 32, 354-359.

378 G. Yasayan, A. O. Saeed, F. Fernandez-Trillo, S. Allen, M. C. Davies, A. Jangher, A. Paul, K. J. Thurecht, S. M. King, R. Schweins, P. C. Griffiths, J. P. Magnusson and C. Alexander, Polym. Chem., 2011, 2, 1567-1578.

379 P. van Rijn, M. Tutus, C. Kathrein, L. Zhu, M. Wessling, U. Schwaneberg and A. Böker, Chem. Soc. Rev., 2013, 42, 6578-6592. 
380 P. van Rijn, H. Park, K. Özlem Nazli, N. C. Mougin and A. Böker, Langmuir, 2013, 29, 276-284.

381 P. van Rijn, N. C. Mougin and A. Böker, Polymer, 2012, 53, 6045-6052.

382 P. van Rijn, N. C. Mougin, D. Franke, H. Park and A. Böker, Chem. Commun., 2011, 47, 8376-8378.

383 N. C. Mougin, P. van Rijn, H. Park, A. H. E. Müller and A. Böker, Adv. Funct. Mater., 2011, 21, 2470-2476.

384 P. van Rijn, M. Tutus, C. Kathrein, N. C. Mougin, H. Park, C. Hein, M. P. Schürings and A. Böker, Adv. Funct. Mater., 2014, 24, 6762-6770.
385 M. L. Hovlid, J. L. Lau, K. Breitenkamp, C. J. Higginson, B. Laufer, M. Manchester and M. G. Finn, ACS Nano, 2014, 8, 8003-8014.

386 J. Lucon, E. Edwards, S. Qazi, M. Uchida and T. Douglas, Eur. Polym. J., 2013, 49, 2976-2985.

387 J. Lucon, S. Qazi, M. Uchida, G. J. Bedwell, B. LaFrance, P. E. Prevelige and T. Douglas, Nat. Chem., 2012, 4, 781788.

388 J. K. Pokorski, K. Breitenkamp, L. O. Liepold, S. Qazi and M. G. Finn, J. Am. Chem. Soc., 2011, 133, 92429245 . 